\title{
Adolescents in Saudi Arabia
}

Citation for published version (APA):

AlBuhairan, F. S. (2022). Adolescents in Saudi Arabia: Their status of health. [Doctoral Thesis, Maastricht University]. Maastricht University. https://doi.org/10.26481/dis.20220112fa

Document status and date:

Published: 01/01/2022

DOI:

10.26481/dis.20220112fa

Document Version:

Publisher's PDF, also known as Version of record

\section{Please check the document version of this publication:}

- A submitted manuscript is the version of the article upon submission and before peer-review. There can be important differences between the submitted version and the official published version of record.

People interested in the research are advised to contact the author for the final version of the publication, or visit the DOI to the publisher's website.

- The final author version and the galley proof are versions of the publication after peer review.

- The final published version features the final layout of the paper including the volume, issue and page numbers.

Link to publication

\footnotetext{
General rights rights.

- You may freely distribute the URL identifying the publication in the public portal. please follow below link for the End User Agreement:

www.umlib.nl/taverne-license

Take down policy

If you believe that this document breaches copyright please contact us at:

repository@maastrichtuniversity.nl

providing details and we will investigate your claim.
}

Copyright and moral rights for the publications made accessible in the public portal are retained by the authors and/or other copyright owners and it is a condition of accessing publications that users recognise and abide by the legal requirements associated with these

- Users may download and print one copy of any publication from the public portal for the purpose of private study or research.

- You may not further distribute the material or use it for any profit-making activity or commercial gain

If the publication is distributed under the terms of Article $25 \mathrm{fa}$ of the Dutch Copyright Act, indicated by the "Taverne" license above, 


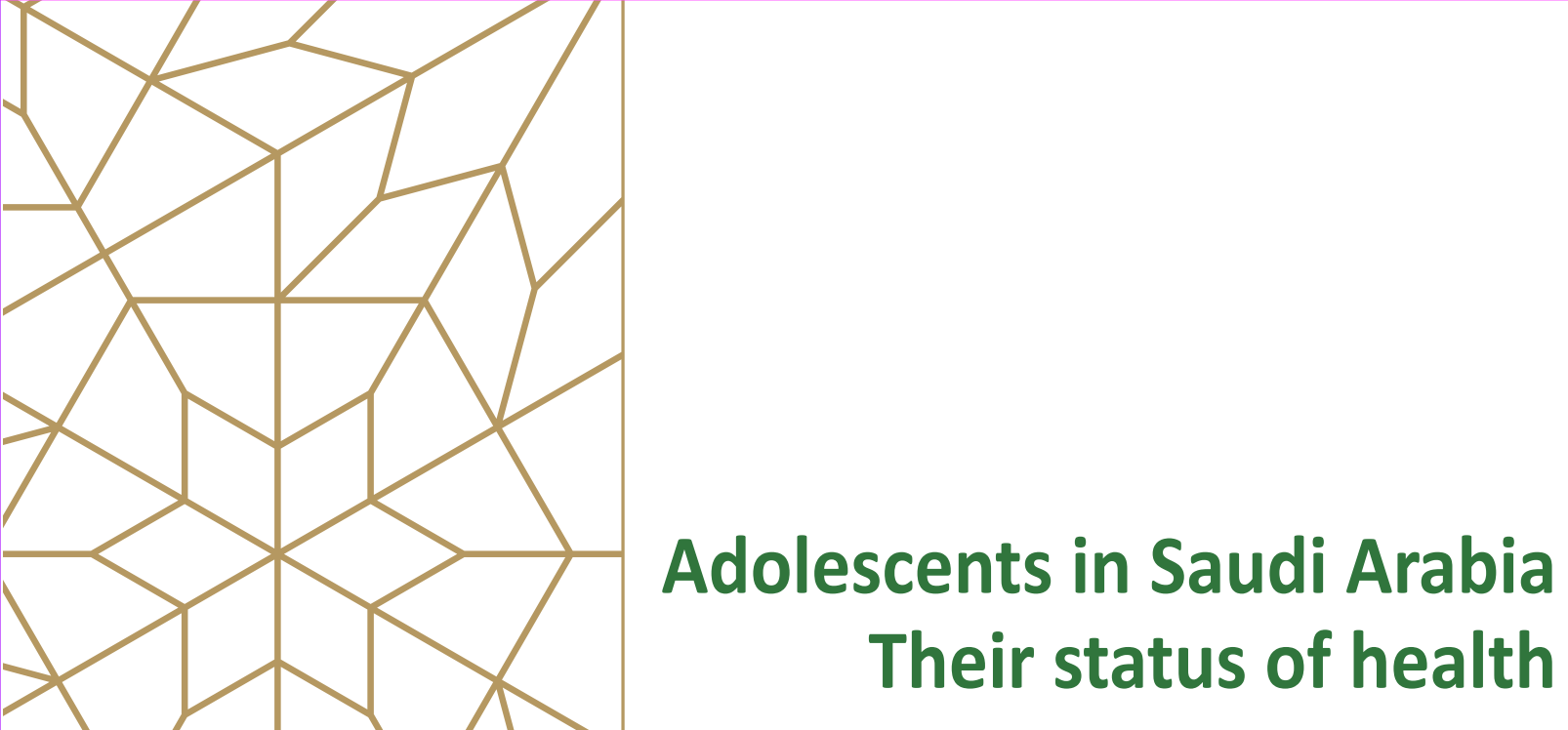

Fadia S. AlBuhairan 


\section{Adolescents in Saudi Arabia Their status of health}

Fadia S. AlBuhairan 
Copyright $@ 2022$ by Fadia S. AlBuhairan

All rights reserved.

No part of this publication may be reproduced or transmitted in any form or by any means, electronic or mechanical, including photocopying, recording, or any information storage and retrieval without prior permission from the author, or, when appropriate, the publishers of the papers.

Cover design, Layout, and Printing by: ProefschriftMaken || www.proefschriftmaken.nl

ISBN: 978-94-6423-602-6 


\section{Adolescents in Saudi Arabia Their status of health}

\section{Dissertation}

to obtain the degree of Doctor at Maastricht University, on the authority of the Rector Magnificus, Prof. Dr. Rianne M. Letschert in accordance with the decision of the Board of Deans, to be defended in public on Wednesday, 12 th of January 2022, at 16:00 hours

by

\section{Fadia S. AlBuhairan}




\section{Promotor}

Prof. dr. N. de Vries

\section{Co-promotor}

Prof. Mohieldin Magzoub (United Arab Emirates University, United Arab Emirates)

\section{Assessment Committee}

Prof. dr. S. Kremers (Chair)

Prof. dr. R. Afifi (University of lowa, USA)

Prof. dr. R.W. Blum (Johns Hopkins University, USA)

Prof. dr. F. Feron

Dr. A. Vreugdenhil

The study presented in this thesis was conducted under the auspices of CAPHRI Care and Public Health Research Institute, Department of Health Promotion, Maastricht University. CAPHRI participates in the Netherlands School of Public Health and Care Research CaRe.

The field work and research were conducted in the Kingdom of Saudi Arabia. It was supported and funded by the King Abdullah International Medical Research Center, Grant RC08-092. 
To my children Zaina, Omar, and Tameem and to all children and adolescents. I do this for you... 


\section{Contents}

$\begin{array}{lll}\text { Chapter } 1 \quad \text { Introduction } & 9\end{array}$

Chapter 2 Methodology 15

$\begin{array}{lll}2.1 & \text { Study design } & 17\end{array}$

$\begin{array}{lll}2.2 & \text { Study setting } & 17\end{array}$

2.3 Determination of sample size 19

$2.4 \quad$ Selection of study population 20

$2.5 \quad$ Refusal of school to participate in study and substitution of schools 21

2.6 Training of fieldwork teams and their roles 21

$\begin{array}{lll}2.7 & \text { Data collection } & 23\end{array}$

$\begin{array}{ll}2.8 & 29\end{array}$

$\begin{array}{lll}2.9 & \text { Statistical methods } & 29\end{array}$

$\begin{array}{lll}2.10 \quad \text { Ethics and regulatory approval } & 29\end{array}$

Chapter 3 Time for an adolescent health surveillance system in Saudi Arabia: Findings from 'Jeeluna' 33

Chapter $4 \quad$ Underweight, body image and weight loss measures among adolescents in Saudi Arabia 53

Chapter $5 \quad$ Predictors of adolescents' mental health problems in Saudi Arabia 75

Chapter 6 The relationship of bullying and physical violence to mental health and academic $\begin{array}{ll}\text { performance } & 93\end{array}$

Chapter 7 Relationship of media exposure to substance use among adolescents in Saudi Arabia 107

Chapter 8 Sleep deprivation: prevalence and associated factors among adolescents in Saudi Arabia 131

$\begin{array}{lll}\text { Chapter } 9 \text { Discussion } & 151\end{array}$

Summary 161

$\begin{array}{ll}\text { Impact paragraph } & 167\end{array}$

$\begin{array}{ll}\text { About the author } & 173\end{array}$ 
Chapter 1

Introduction 
Chapter 1 
Adolescence may be considered to be one of the most important phases of life. Though it is often thought to be associated with problematic and risky behaviors, adolescence in fact comes with much opportunity. It is a time of significant growth, not just the obvious physical growth but also much cognitive, social, and emotional growth. It is the time for identity development and a transition to independence and autonomy which all contribute to characteristics supporting young people in becoming active and contributing members of civil society. Protective factors exist, and it is during this time that focus and investing on protective factors is necessary.

Adolescents are individuals aged 10-19 years. Currently, there are 1.2 billion adolescents globally, constituting $16 \%$ of the world's population (1), making it the largest number of adolescents in history. The Middle East North Africa (MENA) regions has an overall adolescent population of $17 \%$ (2). Saudi Arabia is the largest country in the Arabian Peninsula with a population of 34 million. Fourteen percent of the population are adolescents aged $10-19$ years $(3,4)$. Similar to many other Arab countries, Saudi Arabia has been experiencing a youth bulge. With success in achieving reduced infant mortality, yet continuing to have relatively high fertility rates, the young population of Saudi Arabia has grown and reflects the current demographic structure of the population, which has a larger young population in relation to the elderly population. The resulting demographic dividend that spurs from the population's age structure has economic growth potential, including a low dependency ratio. In fact, the dependency ratio is predicted to be the lowest during the next 20-30 years (5). This is in contrast to many developed countries of the world, where they have relatively older populations and experience a bigger burden of health issues related to aging. The current demographic structure of Saudi Arabia, along with the rest of the MENA region, presents as an opportunity for these nations. In fact, over the past decade, there has been increasing global attention to the importance of investing in adolescents and the triple dividend that such investment results in: impact on the adolescent him/herself, future adult life, and intergenerational benefits (6).

In Saudi Arabia, effective public health measures, such as childhood immunizations, and healthcare delivery have been largely successful in decreasing the burden of communicable disease and infant mortality respectively. The current burden of disease is greatly due to non-communicable disease (NCD) (7) and so the healthcare agenda, including the health research agenda, has focused on NCDs among adults. The risk factors for these NCDs have been largely neglected; the key modifiable risk factors, i.e., tobacco use, excessive alcohol use, unhealthy diet, and insufficient physical activity, begin much earlier in life during adolescence and hence the focus should in fact be on the adolescent period and prevention of 
these risk factors and promotion of protective factors. It is only through this life-course lens to life and health, that one will truly be able to address population health.

Until recent years, adolescents have been 'inexistant' in the health care domain in Saudi Arabia, with no existing national data reflecting the health needs or status of this large proportion of the population. Existing data has been aggregated with the $<15$ or $\geq 15$-year-old population, addressing child or adult health issues, making it inconceivable to attempt to understand the health issues of the adolescent population per se. Healthcare delivery also addressed child care or adult care, with the age cut-off being 12 years (until recently when it was increased to 14 years). From a societal point of view, an individual at the time of puberty, was considered to be an adult, meaning that an individual moved from being a child straight into being an adult (8). This may be due in part to the social and cultural interpretation of the term 'adolescent'. The Arabic equivalent of adolescent is 'murahiq', which historically has had negative connotations associated with it, i.e., immature and reflecting someone who lacks responsibility, accountability, etc.

With every gap, there comes an opportunity. Though local evidence was lacking and unavailable to support decision making and address specific challenges I was facing as I came to establish the first adolescent health service in the country in 2007 , I fortunately identified this lack of evidence to be a potential opportunity to fill. I wanted to answer the question "What is the status of health of the adolescents of Saudi Arabia?" I also realized that in order for me to be able to answer this question, I would need to address the holistic nature of health, i.e., physical, mental, and social wellbeing. With that, my journey began as I conceived the idea of Jeeluna.

Jeeluna is the national study addressing the health status of adolescent in Saudi Arabia. Jeeluna is an Arabic word which means "Our generation". This name was selected through a participatory approach of young people in the community. It is meant to be a vehicle for their voices and their needs. The next chapter provides detailed information on how the study was conducted with over 12,500 adolescent participants throughout the country. Each of the subsequent several chapters present a specific adolescent health issue, knowing that these multiple issues must be collectively addressed in order to be able to comprehensively address adolescent health. 


\section{References}

1. Adolescents

Overview.

UNICEF.

Available

at:

https://data.unicef.org/topic/adolescents/overview/\#: :text=Adolescents\%20\%E2\%80\%93\%20defin ed\%20by\%20the\%20United, the\%20Rights\%20of\%20the\%20Child. [Accessed on 17 May 2021]

2. Adolescent health dashboard. UNICEF. Available at: https://data.unicef.org/resources/adolescenthealth-dashboard-regional-profiles/ [Accessed on 17 May 2021]

3. General Authority for Statistics Kingdom of Saudi Arabia. Available at: https://www.stats.gov.sa/en [Accessed on 17 May 2021]

4. Population Pyramid. Available at: https://www.populationpyramid.net/saudi-arabia/2020/ [Accessed on 17 May 2021]

5. Saudi Arabia. MENA Generation 2030 Country Fact Sheet. UNICEF. Available at: https://www.unicef.org/mena/media/4236/file/Saudi\%20Arabia\%20Fact\%20Sheet\%20\%20MENA\%20Generation\%202030.pdf [Accessed on 17 May 2021]

6. Patton, G.C., Sawyer, S.M., Santelli, J.S., et al. Our future: a Lancet commission on adolescent health and wellbeing. Lancet. 2016;387(10036):2423-2478. doi:10.1016/S0140-6736(16)00579-1

7. Memish, Z. A., Jaber, S., Mokdad, A. H., AlMazroa, M. A., Murray, C. J., Al Rabeeah, A. A., \& Saudi Burden of Disease Collaborators (2014). Burden of disease, injuries, and risk factors in the Kingdom of Saudi Arabia, 1990-2010. Preventing chronic disease, 11, E169. doi:10.5888/pcd11.140176

8. AlBuhairan, F. \& Olsson, T. Advancing adolescent health and health services in Saudi Arabia: Exploring healthcare providers' training, interest and perceptions of the healthcare needs of young people. Adv Med Educ Pract 2014;5: 281-287. DOI http://dx.doi.org/10.2147/AMEP.S66272 


\section{Chapter 2 \\ Methodology}

This chapter has been published with the following citation:

AlBuhairan, F. (2016) Methodology In Jeeluna Study: National assessment of the health needs of adolescents in Saudi Arabia. King Abdullah International Medical Research Center. Riyadh, Saudi Arabia. ISBN: 978-603-90316-1-1 
Chapter 2 


\subsection{Study design}

The present study is a cross-sectional, school-based, national, epidemiological observational study. It was conducted during 2011-2012 in the KSA among adolescents in intermediate and secondary schools.

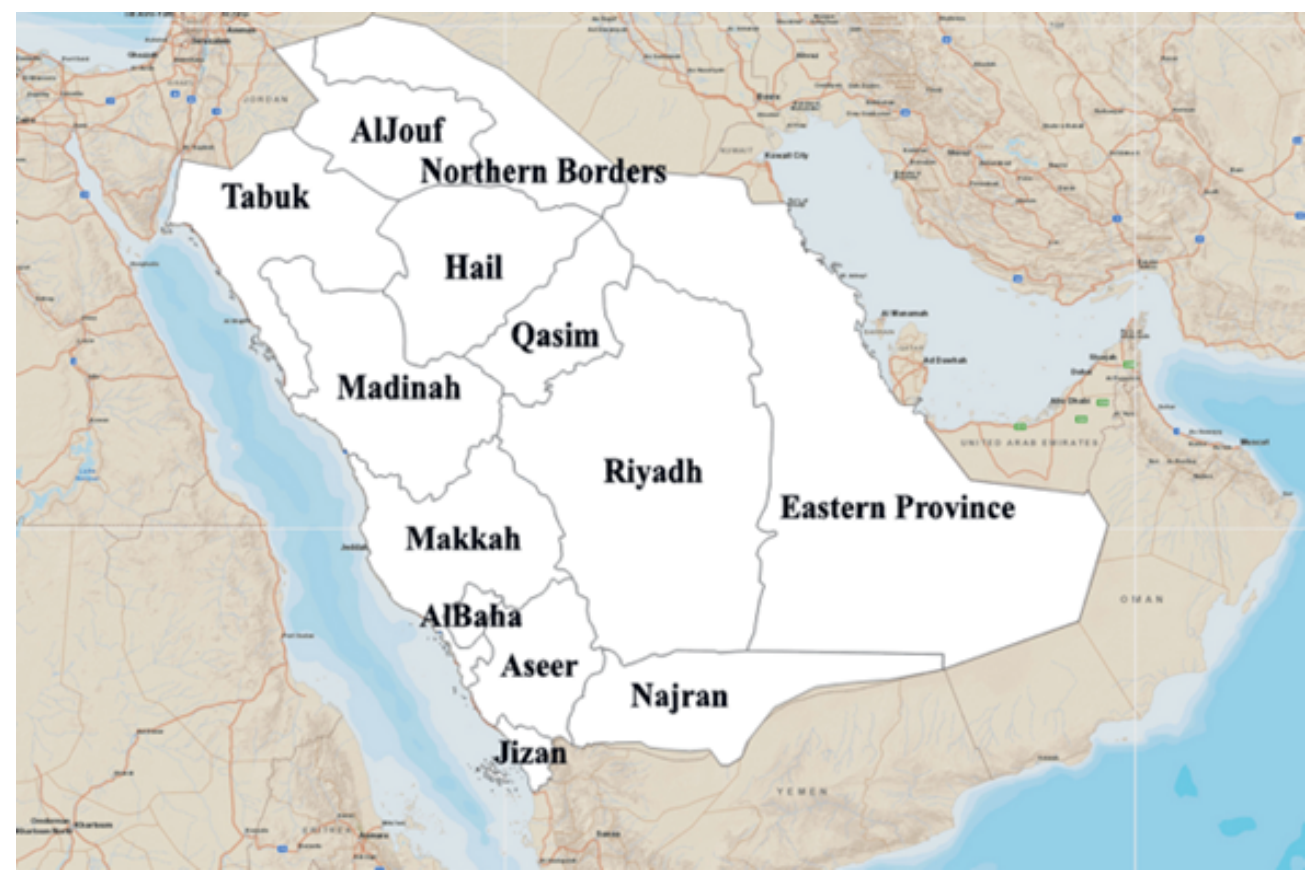

Figure 1. Map of the Kingdom of Saudi Arabia showing the 13 regions of the country

\subsection{Study setting}

This study was conducted at the 13 administrative regions of the Kingdom of Saudi Arabia: Riyadh, Qasim, Makkah, Madinah, Eastern Province, Tabuk, AlJouf, Hail, Northern Borders, AlBaha, Aseer, Jizan, and Najran (Figure 1).

The KSA is divided into 13 administrative regions. Each region has its own municipality and services. Education is uniformly under the directorate/governance of the Ministry of Education (MOE). Variations in some local cultural values/norms may exist. 


\section{Education System in Saudi Arabia}

Preprimary (kindergarten), primary, intermediate, and secondary school education are under the jurisdiction of the MOE (1). Primary school starts at grade 1, age of 6 , and lasts 6 years. It is not a prerequisite to attend kindergarten prior to enrolling in primary school. Intermediate school lasts 3 years, and secondary school lasts 3 years and is the final stage of general education. Specialized secondary schools also exist and provide technical and vocational education and training programs for three years in the fields of industry, commerce and agriculture (2). Special education is provided for students with special needs. There are also primary, intermediate, and secondary schools that provide education for adults who did not receive or complete their education, and these generally function during the afternoons/evenings. Children or adolescents, who drop out of mainstream education, sometimes enroll in these afternoon/evening schools. All schools starting at primary school are gender segregated. Classic Arabic language is used in education and is understood by all despite the differences in regional dialects. Primary education is mandatory for all children, and this was enforced in 2004 (1).

\section{Expenditure on Education and Literacy Rates}

According to the UNESCO Institute for Statistics (UIS), public spending on education was $5.6 \%$ of Gross Domestic Product (GDP) and 19.3\% of total government expenditure in 2008 (3).

In 2011, the overall literacy rate among youth aged $15-24$ years was $98 \%$ with $99 \%$ of male youth and $97 \%$ of female youth being literate (3).

\section{Regional and Provincial Education Bodies}

The MOE's Headquarters in the capital city, Riyadh, manages all of the strategic planning for the development of education in the country. It delegates the operational and administrative responsibilities to the regional and provincial educational bodies (1). There are a total of 13 regional education bodies and 29 provincial education bodies. 


\section{Private education}

Private education is important in supporting public education and is supervised by the MOE. The MOE, in return, provides support including annual financial aid. In 2007, $6.4 \%$ and $13.4 \%$ of intermediate and secondary school students respectively were enrolled in private schools (4).

\subsection{Determination of sample size}

The study sample was selected based on a stratified, cluster, random sampling procedure, with sampling occurring from all 13 regions in the country. Within each region, several school districts exist, with a total of 42 districts in the country. Sampling occurred at a district level, ensuring that both rural as well as urban/suburban areas were covered.

The sample was proportionate to the number of male and female students, as well as the number of intermediate versus secondary school students in each of the regions.

The sample size per district was proportionate to the student population per district. Some districts had relatively small student populations, so these districts were grouped with neighboring district(s) to form a cluster district from which random selection took place. For such cluster districts, the sample size was proportionate to the collective student population of those combined districts (Table 1).

A list of all intermediate and secondary schools in the country enlisted with the MOE (5) served as a source from which schools were randomly selected. We used a stratified, cluster, random sampling procedure. Based on student population per region, district, gender, and school level, proportionate sampling for each district was made to identify the sample size per district. Through stratification, a good representation of both genders and the number of intermediate versus secondary school students in each of the regions was ensured. Classes within selected schools were randomly selected. Sampling was clustered by inviting all students from a selected class to participate.

The number of schools to participate was calculated on the assumption that an average of 50 students would participate from each school. A sample size of 11,361 was determined to estimate the population proportions of different characteristics with a prevalence of $30 \%$ with a $1 \%$ margin of error and a $99 \%$ confidence, taking the multi-level nature of having pupils within schools, within type, within regions, and 
within gender into account. The sample size was additionally increased by $5 \%$ in order to account for contingencies such as non-response, resulting in a total sample size of 12,000 participants.

\subsection{Selection of study population}

All daytime male and female, intermediate and secondary, public and private schools registered with the MOE in Saudi Arabia were eligible to participate. Any student in the randomly chosen classroom of a selected school was eligible to participate. Evening schools and/or schools that serve special needs students were excluded.

\subsection{Refusal of school to participate in study and substitution of schools}

In the event that a school refused to participate in the study, a substituting school was randomly selected from the pool of schools that were from the same district/cluster of districts. A substituting school served the same gender and school level (intermediate or secondary) as the refusing school. In the capital city of Riyadh, where there are a large number of private schools, the school sector - public or private - was also maintained in substituting schools.

\subsection{Training of fieldwork teams and their roles}

Local fieldwork teams were recruited in each of the 13 regions. Due to cultural reasons, each region had at least 1 male team and 1 female team who were responsible for the data collection at male and female schools respectively. Depending on the magnitude of the region and the geographical distances between randomly selected schools, varying numbers of teams were recruited per region, with a total amounting to 52 teams around the country. Each of the teams underwent standardized and structured training prior to the commencement of the study.

Due to the large number of team members throughout the country, training was done locally in each region. Training was also gender specific, with a male trainer providing the training session for the male regional team and a female trainer providing the same for the female regional team. A total of 34 training workshops were carried out (workshop was attended by more than one same-gender team if geographically not too distant). In order to accommodate for the large number of training sessions, either 
Table 1. Student sampling per region

\begin{tabular}{|c|c|c|c|c|c|c|c|c|}
\hline & \multirow[t]{2}{*}{ Region } & \multirow[t]{2}{*}{ School district } & \multicolumn{2}{|c|}{ Number of male students } & \multicolumn{2}{|c|}{ Number of female students } & \multirow[t]{2}{*}{ Total } & \multirow[t]{2}{*}{$\%$} \\
\hline & & & $\begin{array}{c}\text { Intermediate school } \\
\text { level }\end{array}$ & $\begin{array}{c}\text { Secondary } \\
\text { school level }\end{array}$ & $\begin{array}{c}\text { Intermediate } \\
\text { school level }\end{array}$ & $\begin{array}{c}\text { Secondary } \\
\text { school level }\end{array}$ & & \\
\hline \multirow[t]{6}{*}{1} & \multirow[t]{6}{*}{ Riyadh } & Riyadh & 613 & 517 & 575 & 513 & 2,218 & \\
\hline & & $\begin{array}{l}\text { Aflaj/HotabaniTameem/Wadi } \\
\text { Dawaser }\end{array}$ & 37 & 32 & 27 & 25 & 121 & \\
\hline & & Kharj & 50 & 42 & 45 & 41 & 178 & \\
\hline & & Algowaiiyah/Dawadmi/Afif & 59 & 54 & 49 & 49 & 211 & \\
\hline & & Zulfi/Shaqra/Alghat/Majmaah & 34 & 30 & 28 & 28 & 120 & \\
\hline & & Total & 793 & 674 & 725 & 656 & 2,848 & 23.7 \\
\hline \multirow[t]{4}{*}{2} & \multirow[t]{4}{*}{ Qasim } & Qasim & 121 & 111 & 92 & 85 & 409 & \\
\hline & & Onaiza/Bikairiyah & 22 & 18 & 26 & 26 & 92 & \\
\hline & & Alrass/Almithnib & 24 & 20 & 28 & 26 & 98 & \\
\hline & & Total & 167 & 148 & 146 & 138 & 599 & 5.0 \\
\hline \multirow[t]{5}{*}{3} & \multirow[t]{5}{*}{ Makkah } & Makkah & 200 & 152 & 187 & 159 & 698 & \\
\hline & & Jeddah & 370 & 319 & 347 & 308 & 1,344 & \\
\hline & & Taif & 165 & 148 & 144 & 129 & 586 & \\
\hline & & Qunfidah/Allaith & 61 & 59 & 52 & 48 & 220 & \\
\hline & & Total & 795 & 678 & 730 & 645 & 2,848 & 23.7 \\
\hline \multirow[t]{3}{*}{4} & \multirow[t]{3}{*}{ Madinah } & Madinah/ Al Mahd & 205 & 183 & 181 & 162 & 731 & \\
\hline & & Alola/Yanbu & 49 & 44 & 43 & 40 & 176 & \\
\hline & & Total & 254 & 227 & 224 & 202 & 907 & 7.6 \\
\hline \multirow[t]{4}{*}{5} & \multirow{4}{*}{$\begin{array}{l}\text { Eastern } \\
\text { Province }\end{array}$} & Sharqiah & 287 & 250 & 262 & 244 & 1,043 & \\
\hline & & Ahsaa & 144 & 121 & 139 & 131 & 535 & \\
\hline & & Hafr Al Baten & 60 & 54 & 53 & 46 & 213 & \\
\hline & & Total & 491 & 424 & 455 & 421 & 1,791 & 14.9 \\
\hline \multirow[t]{2}{*}{6} & \multirow[t]{2}{*}{ Tabuk } & Tabuk & 110 & 89 & 100 & 80 & 379 & \\
\hline & & Total & 110 & 89 & 100 & 80 & 379 & 3.2 \\
\hline \multirow[t]{3}{*}{7} & \multirow[t]{3}{*}{ AlJouf } & AlJouf & 41 & 36 & 39 & 34 & 150 & \\
\hline & & Qurayyat & 23 & 21 & 22 & 18 & 84 & \\
\hline & & Total & 63 & 57 & 61 & 53 & 234 & 1.9 \\
\hline \multirow[t]{2}{*}{8} & Hail & Hail & 88 & 77 & 71 & 64 & 300 & \\
\hline & & Total & 88 & 77 & 71 & 64 & 300 & 2.5 \\
\hline 9 & Northern & Northern Borders & 44 & 41 & 40 & 37 & 162 & \\
\hline & Borders & Total & 44 & 41 & 40 & 37 & 162 & 1.4 \\
\hline 10 & AlBaha & AlBaha & 34 & 33 & 29 & 30 & 126 & \\
\hline & & Almikhwah & 18 & 19 & 16 & 15 & 68 & \\
\hline & & Total & 51 & 52 & 45 & 45 & 193 & 1.6 \\
\hline 11 & Aseer & Aseer/SiraatAbaidah & 139 & 126 & 135 & 114 & 2,305 & \\
\hline & & Bishah & 53 & 48 & 44 & 42 & 187 & \\
\hline & & RijalAlma'a/Mahayel/Nimaas & 71 & 71 & 53 & 48 & 243 & \\
\hline & & Total & 264 & 246 & 232 & 205 & 947 & 7.9 \\
\hline 12 & Jizan & Jizan & 102 & 86 & 138 & 109 & 435 & \\
\hline & & Sibya & 73 & 61 & 0 & 0 & 134 & \\
\hline & & Total & 175 & 147 & 138 & 109 & 569 & 4.7 \\
\hline 13 & Najran & Najran & 72 & 56 & 55 & 44 & 227 & \\
\hline & & Total & 72 & 56 & 55 & 44 & 227 & 1.9 \\
\hline & & & 3,367 & 2,916 & 3,021 & 2,696 & & \\
\hline Ove & ttal & & & & & & & \\
\hline
\end{tabular}

the principle investigator or another trainer, who received 'train-the-trainer' workshop ahead of time, travelled to the respective region and carried out the full day training workshop. All regional fieldwork team members were expected to attend the training workshop. There they received structured and standardized training with hands-on practice. They also received the necessary handouts and additional material to facilitate successful data collection. 
Each region had 1-2 regional coordinators who were responsible for liaising with the research team in Riyadh city. The regional coordinator was nominated from the School Health Department at the Ministry of Education. Each coordinator was provided with a list of the randomly selected schools in his/her respective region. $\mathrm{He} /$ she was then responsible to coordinate with the local schools to arrange a time to visit the school, introduce the study to the school and students, and to distribute the information letters and consent forms.

The fieldwork teams consisted of at least four individuals: two data collectors and two phlebotomists/nurses. The data collectors were responsible for collecting the consent forms, ensuring that only students with consent participated, taking the anthropometric measurements, and distributing/collecting the questionnaires upon completion. They were also there to address any questions participating students may have had about the self-administered questionnaire. The phlebotomists/nurses were responsible for labeling the test tubes; drawing blood samples from those students who consented to blood extraction and centrifuging the blood sample for chemistry (refer to data collection- blood sampling and laboratory investigations, Section 2.7.10).

All material and equipment necessary for data collection were prepared, packaged, and sent by the research team in Riyadh via courier to each of the respective regional teams. In order to subsequently be able to match various data from one participant and also to avoid errors in serial numbering of questionnaires and blood samples, computer printed barcodes, each with a unique serial number for each participant, were prepared and utilized in the data collection material.

Further measures were taken to avoid mix up between participants' questionnaire/anthropometric data and lab blood samples. The serial numbers were created so that they had a code embedded within them (Table 2). This was utilized as a quality check during data validation. No identifying material was provided that linked the student number with his/her name in order to ensure anonymity. 
Table 2. Interpretation of 7-digit serial code

\begin{tabular}{|lc|}
\hline \multicolumn{1}{|c|}{ Variable } & Number of digits \\
\hline Province (01= Riyadh) & 2 \\
Gender (1= Male, 2= Female) & 1 \\
School identification number & 2 \\
Student number (1-50) & 2 \\
\hline Total & 7 \\
\hline
\end{tabular}

\subsection{Data collection}

Data collection involved 3 steps and was conducted in the following sequence:

1) Blood sampling for laboratory investigations,

2) Anthropometric measurements,

3) Responding to a self-administered questionnaire.

The local research coordinator visited participating schools at least one week prior to the scheduled data collection. An introduction to the study, an explanation of what would be required, and the various steps included were explained to the students. They were each given an introductory letter and consent form to take home to their parents/guardians. A student and his/her parent/guardian were both required to provide written consent/assent for student's participation in the study.

\subsubsection{Blood sampling and laboratory investigations}

Blood sampling was the first step in data collection, as participants had fasted for 12 hours. Breakfast was provided to students immediately after blood sampling was carried out in order to avoid any inconvenience. Two test tubes were used for blood collection for each individual:

1) Tubes containing EDTA were used to assay the complete blood count (CBC) analysis, and

2) Serum gel-separator tubes were used to collect blood for chemistry and hormone analysis. 
Blood samples were transported via courier to the main clinical laboratory of King Abdulaziz Medical City in Riyadh within 24 hours from the time of collection and analysis/testing was carried out there.

\section{1) $C B C$ analysis for assessing anemia}

The first tubes for $C B C$ parameters such as hematocrit (HCT), hemoglobin (HB), red blood cells (RBC), white blood cells (WBC) and platelets (PLT) were analyzed immediately, without any further pretreatment by cell counter hematology analyzer (Abbott, USA), upon receipt in the laboratory. Other hematological parameters such as mean corpuscular hemoglobin ( $\mathrm{MCH})$, mean corpuscular hemoglobin concentration $(\mathrm{MCHC})$, mean corpuscular volume (MCV), mean platelet volume (MPV), and red cell distribution width (RDW) were calculated based on the previous measured parameters.

The 2001 World Health Organization (WHO) cut-off levels for hemoglobin were adopted (6), and accordingly anemia was defined as:

- $\quad<12 \mathrm{~g} / \mathrm{dl}$ for females $\geq 12$ years

- $\quad<12 \mathrm{~g} / \mathrm{dl}$ for males $12-14$ years and $<13.0 \mathrm{~g} / \mathrm{dl}$ for males $\geq 15$ years

2) Chemistry tests for assessing Vitamin $D$ status, diabetes and cardiovascular risks

The second blood samples for chemistry tests were centrifuged for 10-15 minutes at 3,000 RPM, separated, stored in deep freezers at $-70^{\circ} \mathrm{C}$ for future analysis. Chemistry tests were performed for albumin, alkaline phosphatase, calcium, phosphorus, glutamyltranspeptidase, cholesterol, triglycerides, high-density lipoprotein, low-density lipoprotein and glucose using the automated chemistry analyzer Architect 16000 (Abbott, USA).

Other hormones such as total 25-hydroxy vitamin D3, C-peptide and insulin levels were performed in serum samples using immunoassay analyzer Architect 2000 (Abbott, USA). Adjusted calcium was calculated whenever albumin level was affected using the following formula: Calcium + (40-Albumin) $\times 0.02(\mathrm{mmol} / \mathrm{L})$.

The cut-off levels for total 25-hydroxy vitamin D3 as recommended by the Institute of Medicine were adopted (7):

- Adequate vitamin $D$ status: $\geq 50 \mathrm{nmol} / \mathrm{L}$,

- Deficient: $<50 \mathrm{nmol} / \mathrm{L}$. 


\subsubsection{Anthropometric measurements}

Several anthropometric measurements were done, including height, weight, waist circumference, neck circumference and blood pressure.

Students were lightly dressed and without shoes. Height was measured to the nearest $0.5 \mathrm{~cm}$ using a wall mounted height chart and weight was measured to the nearest $0.1 \mathrm{~kg}$ using an electronic scale (OmronSC100 digital scale, USA). The scale was calibrated prior to use at each site. Each student was asked to report his/her weight prior to measurement and this was documented as well.

The waist circumference was measured at the midpoint between the costal margin and iliac crest at the end of expiration using a non-elastic flexible tape measure and was recorded to the nearest millimeter $(\mathrm{mm})(8)$.

Neck circumference was also measured using non-elastic flexible tape measured to the nearest $1 \mathrm{~mm}$ at a point just below the larynx (thyroid cartilage) and perpendicular to the long axis of the neck (9).

Blood pressure (BP) was measured by a digital BP monitor (Omron M2, Netherlands) on the right arm twice a few minutes apart and recorded as an average using appropriate cuff size.

Clinical evidence of acanthosis nigricans at the nape of the neck was also looked for and documented.

Upon entering data into database, the body mass index (BMI) was automatically calculated using the equation: weight $(\mathrm{kg}) /[\text { height }(\mathrm{m})]^{2}$ and plotted on the Center for Disease Control's (CDC) BMI charts (10) to determine the BMI status of each student. The BMI of each student was interpreted to be underweight, healthy weight, overweight, or obese if $<5$ th percentile, between the 5 th to $<85$ th percentile, between 85 th to $<95$ th percentile, or equal to or greater than the 95th percentile respectively (11).

\subsubsection{Questionnaire}

A review of the literature was done to search for available questionnaires that address priority health risk behaviors among adolescents. The Youth Risk Behavior Survey (YRBS) (12) and the Global School-based Student Health Survey (GSHS) (13) were both found to be inspiring and covered many of the issues aimed to cover in our study, such as unhealthy dietary behaviors, 
inadequate physical activity, behaviors that contribute to unintentional injuries and violence, tobacco use, and alcohol and drug use (12). Items that were found to be relevant to our study's objectives were adopted for use and underwent cultural adaptation when relevant. Items that were found to be irrelevant or culturally insensitive were not included (e.g sexual behaviors that contribute to unintended pregnancy and sexually transmitted diseases).

Furthermore, in order to achieve all objectives of our study, the domains covered in the psychosocial history taking that are widely used in adolescent clinical care also served as a guide. These domains are represented by the acronym $\operatorname{HEEADSSS}(14,15)$ and refer to Home, Education, Eating, Activities, Drugs, Safety, Suicide, and Sexuality. Domains not covered in the YRBS or GSHS but present in HEEADSSS were also included and questions addressing those issues were developed. Such domains included home and education. Additionally, questions addressing access to health care/services and health knowledge were also added.

Suicide was not directly addressed because of ethical considerations such as inability to acutely address the issue if a student were to report active suicidal ideations. Instead, mood and access to necessary support services were addressed. Sexuality, which is an important aspect of adolescent health, was also not addressed due to cultural sensitivities and the inappropriateness of addressing such a topic with local adolescents. (Table 3) shows the differences in domains covered by the YRBS, GSHS, and Jeeluna. 
Table 3. Domains covered by YRBS, GSHS and Jeeluna

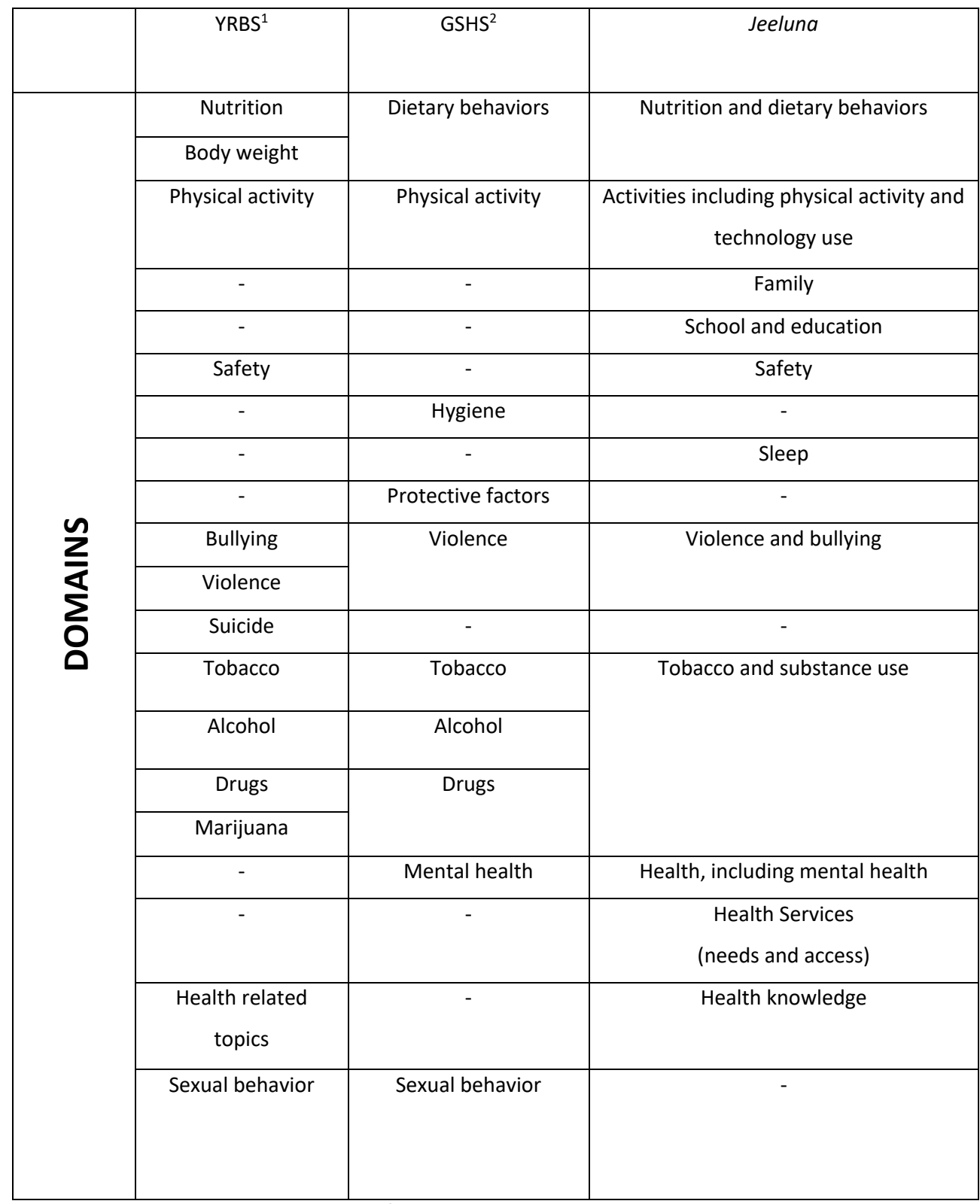

${ }^{1}$ YRBS: Youth Risk Behavior Surveillance; ${ }^{2}$ GSHS: Global School-based Student Health Survey 
The questionnaire drafts went through several rounds of expert review and refinement. Thereafter, this was tested on a pilot sample of adolescents. Questions or statements that were found difficult, unclear, or ambiguous to the adolescents to comprehend were further refined and/or modified. Examples in order to clarify some questions were added, e.g., examples of main meals, snacks, vegetables, energy drinks, etc. in order to provide more concrete information; some terms required more emphasis (e.g. 'weekday' versus 'weekend' in questions 50-51, 'self' in question 88); and option to choose more than one response if needed was added to a few questions (questions $48,75,102$ and 103). No questionnaire items were found to be inappropriate or distressing to the pilot sample of students and hence, none of the questions were completely eliminated and no additional questions were added. The final edited version of the questionnaire was utilized in the study.

The final questionnaire included eleven domains with 103 questions:

1) Family: 9 questions

2) Education/schooling: 5 questions

3) Nutrition/dietary behaviors: 15 questions

4) Activities, including physical activity and technology use (sedentary activity): 12 questions

5) Safety: 8 questions

6) Sleep: 4 questions

7) Violence and bullying: 7 questions

8) Tobacco and substance use: 22 questions

9) Health: 4 questions

10) Health services: 7 questions

11) Health knowledge: 10 questions

Participants self-responded to the questionnaire, which took approximately 35-45 minutes to complete. Any questions students had concerning the questionnaire were directed to and addressed by the data collector visiting the school. 


\subsection{Data management}

Collected data were entered into two different databases, namely, the anthropometric measures and the questionnaire data in one web-based database, and the laboratory data into the Laboratory Information Systems (LIS) database utilized at King Abdulaziz Medical City in Riyadh. Data from both databases were thereafter extracted and merged based on the unique student serial number. Data were checked for inconsistencies and extreme values as a first step of data cleaning. Moreover, missing data were checked and attempts to retrieve it were done by going back to the original data collection forms. Cross checking of different variables was also done to identify any data errors. Data management was carried out by checking the frequency distribution of each variable, and modifications (such as lumping groups together) was carried out when needed.

\subsection{Statistical methods}

We created weights based on the probability of selection of students within each school. Schools were selected using probability proportional to size. The sample was stratified by gender and grades (intermediate and secondary). We used Statistical Analysis Software (SAS, version 9; SAS Institute, Cary, North Carolina, USA) SURVEYFREQ procedure to analyze the data and adjust for the complex sampling design. Descriptive statistics was carried out by calculating means and standard deviations for continuous variables, and frequency and percentages for categorical variables. Prevalence rates of different characteristics along with their $95 \%$ confidence intervals $(\mathrm{Cl})$ were also calculated. Inferential statistics, mainly comparing results of different groups was carried out using Student's t-test for continuous data and Chi-square tests for categorical ones. A p-value of $<0.05$ was considered to indicate statistical significance. Graphical representations, including geographical mapping using geographic information system (GIS), for different variables were carried out as appropriate.

\subsection{Ethics and regulatory approval}

\subsubsection{Ethics approval}

This study was performed in agreement with the International Ethical Guidelines for

Epidemiological Studies (Geneva, World Health Organization, 2008) (16).

The institutional review board (IRB) and ethics committee at King Abdullah International Medical Research Center (KAIMRC) rigorously reviewed and approved the study protocol and the consent 
forms prior to the commencement of the study. Thereafter, consent to carry out the study was obtained from the Ministry of Education.

At each of the randomly selected schools, consent was obtained from the school's principal. Finally, parental consent as well as student assent were obtained. Students were ensured that participation in the study was completely voluntary and would not affect their school grades in any way. All students were ensured that their information and responses would remain confidential and anonymous.

In the event that critically abnormal results were found on laboratory investigations, a tracking method was initiated in order to alert the student/family of the need to visit his/her local physician.

\subsubsection{Regulatory approval}

The study was performed in compliance with applicable local regulations, Good Epidemiological Practice (GEP) guidelines, KAIMRC Policies, including the archiving of essential documents, and the Ministry of Education.

The study gained full regulatory approval and the research study protocol was issued with the following number: RC08-092. 


\section{References}

1. Saudi Arabia- World Data on Education (7th ed.). UNESCO IBE 2010/11, available from: http://www.ibe.unesco.org/fileadmin/user upload/Publications/WDE/2010/pdfversions/Saudi Arabia.pdfhttp://www.ibe.unesco.org/fileadmin/user upload/Publications/WDE/20 10/pdf-versions/Saudi Arabia.pdf (accessed February 12, 2014).

2. Ministry of Education 2011.2 Available http://www2.moe.gov.sa/english/Pages/about education.htm (accessed February 12, 2014).

3. UIS Statistics in Brief, UNESCO Institute for Statistics 2011. Available from: http://stats.uis.unesco.org/unesco/TableViewer/document.aspx?Reportld=121\&IF Language=eng\& BR Country=6820 (accessed February 12, 2014).

4. Saudi Arabia-World Data on Education (6th ed.). UNESCO IBE 2006/2007. Available from: http://www.ibe.unesco.org/Countries/WDE/2006/index.htmll (accessed February 12, 2014).

5. Ministry of Education, Kingdom of Saudi Arabia. Summary statistics on General Education in KSA, Academic year 2004/2005.

6. WHO/UNICEF/ICCIDD. Iron Deficiency Anaemia Assessment, Prevention, and Control. A guide for programme manager. Geneva, Switzerland: WHO, 2001. Available from: http://whqlibdoc.who.int/hq/2001/WHO NHD 01.3.pdf (accessed February 12, 2014).

7. Institute of Medicine (US) Committee to Review Dietary Reference Intakes for Vitamin D and Calcium; Ross AC, Taylor CL, Yaktine AL, et al., editors. Dietary Reference Intakes for Calcium and Vitamin D. Washington (DC): National Academies Press (US); 2011. Available from: http://www.ncbi.nlm.nih.gov/books/NBK56070/ (accessed February 12, 2014).

8. McCarthy HD, Ellis SM, Cole TJ. Central overweight and obesity in British youth aged 11-16 years: cross sectional surveys of waist circumference. BMJ. 2003; 326(7390): 624.

9. Aswathappa J, Garg S, Kutty K, Shankar V. Neck Circumference as an Anthropometric Measure of Obesity in Diabetics. N Am J Med Sci. 2013; 5(1): 28-31.

10. Centers for Disease Control and Prevention. BMI charts Developed by the National Center for Health Statistics in collaboration with the National Center for Chronic Disease Prevention and Health Promotion, 2000. Available online at: http://www.cdc.gov/growthcharts (accessed February 12, 2014).

11. To weigh and measure [height, weight, body mass index]. Guidance and recommendations for schools 2008. Department of Health and Family Services, Division of Public Health. Wisconsin Nutrition and 
Physical Activity Program. Available online at: http://www.dhs.wisconsin.gov/publications/P4/p40152.pdf (accessed February 12, 2014).

12. Centers for Disease Control and Prevention. Adolescent and School Health. YRBSS in Brief. Centers for Disease Control and Prevention, 2012. Available online at: http://www.cdc.gov/healthyyouth/yrbs/brief.htm (accessed February 12, 2014).

13. Chronic diseases and health promotion. Global School-based Student Health Survey. World Health Organization, 2012. Available online at: http://www.who.int/chp/gshs/en/ (accessed February 12, 2014).

14. Goldenring JM, Cohen E. Getting into adolescent heads. Contemporary Pediatrics 1998; 5(7): 75.

15. Goldenring JM, Rosen DS. Getting into Adolescent Heads: An essential update. Contemporary Pediatrics 2004; 21: 64-90.

16. Council for International Organizations of Medical Sciences (CIOMS) in collaboration with the World Health Organization (WHO). Ethical Guidelines for epidemiological Studies. Geneva, Switzerland: CIOMS, February 2008. Available online at: http://www.ufrgs.br/bioetica/cioms2008.pdf (accessed February 12, 2014). 


\section{Chapter 3 \\ Time for an Adolescent Health Surveillance System in Saudi Arabia: Findings from 'Jeeluna'}

This chapter has been published with the following citation:

AlBuhairan, F., Tamim, H., Al Dubayee, M., AlDhukair, S., Al Shehri, S., Tamimi, W., El Bcheraoui, C., Magzoub, M., de Vries, N., Al Alwan, I. Time for an Adolescent Health Surveillance System in Saudi Arabia: Findings from "Jeeluna". J Adol Health 2015; 57(3):263-269. doi:

10.1016/j.jadohealth.2015.06.009 


\begin{abstract}
Purpose: With the increasing burden of non-communicable disease, adolescence is viewed as an opportune time to prevent the onset of certain behaviors and promote healthy states. Though adolescents comprise a considerable portion of Saudi Arabia's population, they have received insufficient attention and indicators of their health status, as a first step in a prevention cycle are unavailable. This study was carried out with the aim of identifying the health risk behaviors and health status of adolescents in Saudi Arabia.
\end{abstract}

Methods: This cross-sectional, school-based study was carried out in all 13 regions of Saudi Arabia. Through multistage, cluster, random sampling, intermediate, and secondary school students were invited to participate. Data were collected by means of a self-administered questionnaire addressing health risk behaviors and health status including mental health and chronic illness, clinical anthropometric measurements, and laboratory investigations.

Results: A total of 12,575 adolescents participated. Various health risk behaviors, including dietary and sedentary behaviors, lack of safety measures, tobacco use, bullying, and violence were highly prevalent. Twenty-seven percent of adolescents self-reported having a chronic health condition, $14.3 \%$ reported having symptoms suggestive of depression, and 30\% were overweight/obese; $95.6 \%$ were vitamin D deficient; and $11 \%$ of adolescents were anemic.

Conclusion: Behaviors and conditions known to persist into adulthood and result in morbidity and premature mortality are prevalent among adolescents in Saudi Arabia. Preventive measures and local health policies are urgently needed and can impact adolescents as well as future adults. Establishing adolescent health surveillance is necessary to monitor trends and impacts of such measures.

Keywords: adolescent; risky behaviors; chronic illness; health status; surveillance; Saudi Arabia

\title{
Implications and Contribution
}

Though adolescents constitute a significant portion of Saudi Arabia's population, little is known about their health status. This nationally representative study has identified the high prevalence of health risk behaviors and salient health conditions which, for the first time, will serve as adolescent health indicators and support policy and program development. 


\section{Introduction}

Improvement has been seen in public health in recent decades with decreasing infant mortality rates and advances in prevention and treatment of communicable disease [1-4]. During the same period, however, the burden of non-communicable disease (NCD) has been increasing [3-4], with $63 \%$ of global deaths in 2008 being caused by NCD [5]. Attention has therefore turned to how nations can advance efforts that impact the onset of risky behaviors associated with NCD [6]. This has led to a focus on adolescence and to the opportunities to promote health and prevent onset of risk behaviors that are known to persist into adulthood and result in less positive adult outcomes and premature death [6].

Adolescence, a time of opportunity, has gained increasing global attention $[2,7,8]$. It is the transitional period from childhood to adulthood corresponding to 10-19 years of age, roughly corresponding to the age of onset of puberty and onset of adult identity, respectively [9]. Many physical, cognitive, emotional, and social developmental changes occur during this period [10], and experimentation and risk behaviors may begin. Due to the prevalence of many health risk behaviors as well as specific health problems, specific clinical guidelines and recommendations have been published to guide healthcare providers in screening practices and approach to adolescents [11,12]. Leading global organizations and scientific journals have dedicated special reports [2] or special series [7] to adolescence.

Eighty-eight percent of the world's 1.2 billion adolescents live in developing countries with a considerable number living in the Arab World [2]. Despite the youth bulge witnessed in this region, national datasets on adolescents are lacking and there is a shortage of adolescent health services and programs [13].

The Kingdom of Saudi Arabia (KSA) is the largest country in the Arabian Peninsula, with a population exceeding 27 million and with almost $20 \%$ of its population being adolescents aged $10-19$ years [14].

There is a paucity of literature addressing the health needs and health risks of adolescents in KSA, with none representative of national needs. National indicators addressing the health status of adolescents which are necessary for guiding policy and decision makers in establishing the required services, programs, and future national strategic plans are therefore unavailable. Concrete and workable recommendations on improving school health and on directing resources towards priority health risk behaviors in the adolescent age group are also necessary. A surveillance system, such as that available in some countries [15] and which allows for identification of trends, does not exist. The national population health study we present here, 'Jeeluna' (Arabic for 'Our Generation'), was therefore conceived with the 
aim of identifying the health needs and status of adolescents in KSA. The purpose of this paper is to identify the health risk behaviors and health conditions of adolescents in KSA.

\section{Methods}

\section{Setting}

This school-based, national cross-sectional study was conducted in all 13 regions of KSA. Variations in some local cultural values/norms may exist in different geographical areas/regions.

\section{Education system in Saudi Arabia}

Pre-primary, primary, intermediate, and secondary school education are under the jurisdiction of the Ministry of Education (MOE) [16]. Schools are gender segregated. Classic Arabic language is used in education and is understood by all despite the differences in regional dialects. In 2011, the overall literacy rate among youth aged 15-24 years was $98 \%$ [17]. Private education is important in addition to public education and is supervised by the MOE. In $2007,6.4 \%$ and $13.4 \%$ of intermediate and secondary school students respectively were enrolled in private schools [18].

\section{Participants' sampling and sample size}

The number of schools to participate was calculated on the assumption that an average of 50 students would participate from each school. A sample size of 11,361 was determined to estimate the population proportions of different characteristics with a prevalence of $30 \%$, a $1 \%$ margin of error and a $99 \%$ confidence, taking the multi-level nature of having pupils within schools, within type, within regions, and within gender into account. The sample size was additionally increased by $5 \%$ to account for contingencies such as non-response, resulting in a total sample size of 12,000 participants.

We used a stratified, cluster, random sampling procedure. Within each of the regions, school districts exist, totaling to 45 districts. Based on student population per region, district, gender, and school level, proportionate sampling for each district was made to identify the sample size per district. School districts with small student populations were grouped with neighboring district(s) to form a cluster from which random selection took place. For such cluster districts, the sample size was proportionate to the collective 
student population of the combined districts. A total of 10 cluster districts were formed ( 6 clusters made of 2 districts; 3 clusters made of 3 districts; and 1 cluster made of 4 districts). Along with the twenty individual districts, the final number of districts from which the sampling took place was therefore 30 districts.

A list of intermediate and secondary schools enlisted with the MOE served as a source from which schools were drawn using computer-based randomized sampling. Through stratification, a good representation of both genders and the number of intermediate versus secondary school students in each of the regions was ensured.

Classes within selected schools were randomly selected. Sampling was clustered by inviting all students from a selected class to participate. An information letter was sent to students and parents, and their consent, as well as student assent, were obtained.

School Inclusion/exclusion criteria. Any male/female, intermediate/secondary, public/private school in a Saudi Arabian city/town that functions during the day was eligible. Evening schools and schools that only serve special needs students were excluded.

\section{Data collection}

Data collecting teams (field teams) were identified for each region/district. Each team was led by a regional/district coordinator who was nominated by the MOE. Teams consisted of two data collectors and two phlebotomists or nurses. All received standardized training prior to the fieldwork [19]. Data collection involved 3 steps: (1) administration of self-administered questionnaire; (2) anthropometric measurements; and (3) blood sampling for laboratory investigations.

Administration of self-administered questionnaire. A review of the literature was done to search for available questionnaires that address priority health risk behaviors among adolescents. The Youth Risk Behavior Survey (YRBS) [15] and the Global School-based Student Health Survey (GSHS) [20] cover many of these. Items relevant to our study's objectives were adopted and underwent cultural adaptation when relevant. Items that were found to be culturally inappropriate were not included (e.g., sexual behaviors 
and sexually transmitted diseases). To address psychosocial domains as done in adolescent clinical care [21], questions regarding home and education were added, as were questions pertaining to health status. The final questionnaire included 11 domains [19]: family; education/schooling; nutrition/dietary behaviors; activities, including physical activity and technology use (sedentary activity); safety; sleep; violence and bullying; tobacco and substance use; health; health services; and health knowledge. Students were ensured that their responses would remain anonymous and confidential.

Anthropometric measurements. Height was measured to the nearest $0.5 \mathrm{~cm}$ and weight to the nearest 0.1 $\mathrm{kg}$ using an electronic scale (Omron SC100 digital scale). The calculated body mass index (BMI) was plotted on the Center for Disease Control and Prevention (CDC) BMI charts [22]. BMI's were interpreted, based on the norm for age and sex, to be underweight, healthy weight, overweight, or obese if $<5^{\text {th }}, 5^{\text {th }}-<85^{\text {th }}, 85^{\text {th }}$ $-<95^{\text {th }}$, or $\geq 95^{\text {th }}$ percentiles respectively.

Laboratory investigations. Blood samples were analyzed for hemoglobin (HB) by cell counter hematology analyzer (Abbott, IL, USA). Total 25-hydroxy vitamin D3 was measured in serum samples using immunoassay analyzer Architect 2000 (Abbott, IL, USA).

\section{Data analysis}

Data were weighted to account for the probability of selection of students within each school, and the probability of selection of schools, stratified by gender and grade (intermediate and secondary), within each district. We used Statistical Analysis Software (SAS) SURVEYFREQ procedure to analyze the data and adjust for the complex sampling design. Means and standard deviations for continuous variables and frequencies and percentages for categorical variables were calculated. Gender differences were detected by Chi square tests.

\section{Ethical considerations}

The ethics committee at King Abdullah International Medical Research Center reviewed and approved this study prior to commencement, as did the MOE. Permission from the selected schools' principals, active written parental consent, and student assent were all necessary. The written background information that 
was provided to students and parents clearly stated some of the ('sensitive') issues that would be addressed. Students were given the option to opt out of blood sampling.

\section{Results}

\section{School and student's response rates}

A total of 282 schools were invited to participate; 21 schools refused (92.5\% school response rate). Schools mainly refused because of conflicting times with other activities. The 'gatekeeper' to one school district was not responsive, and several failed attempts were made to schedule training and site visits there with no clear reason as to why. Based on the sampling strategy, four schools were supposed to participate from that district. Schools refusing participation, except for the four schools in the last district described (i.e., 17 schools), were replaced by another school based on random selection according to the original criteria for selection. A total of 278 schools participated in the final sample. As for the district that did not participate, neighboring districts within the same region did participate, and therefore participation from all regions occurred.

A total of 12,575 students participated. Based on the number of invitations distributed, $32.7 \%$ of invitees participated. Many field teams only recruited the minimum requirement of 50 students/school despite receiving a larger number of positive consents, and this has contributed to the above student response rate. The final participant sample, however, was consistent with the original population proportion-sampling frame. Furthermore, weighting of the data was carried out in order to ensure national representation of the sample.

Participants' demographics

Fifty-one percent were boys and the mean age of participants was $15.8 \pm 3.4$ years. Fifty-one percent of students were in secondary school and $87.3 \%$ were of Saudi Arabian origin. Table 1 shows the socio-demographics of participants. 
Table 1

Health risk behaviors among adolescents in Saudi Arabia and gender difference

\begin{tabular}{|c|c|c|c|c|c|c|c|c|c|}
\hline \multirow[t]{3}{*}{ Health risk behaviors } & \multicolumn{3}{|l|}{ Prevalence } & \multicolumn{6}{|l|}{ Prevalence by gender } \\
\hline & \multirow[t]{2}{*}{$\mathrm{n}=12,575(\%)$} & \multicolumn{2}{|l|}{$95 \% \mathrm{Cl}$} & \multirow[t]{2}{*}{ Male $n=6,444(\%)$} & \multicolumn{2}{|l|}{$95 \% \mathrm{CI}$} & \multirow[t]{2}{*}{ Female $n=6,131(\%)$} & \multicolumn{2}{|l|}{$95 \% \mathrm{CI}$} \\
\hline & & Lower & Upper & & Lower & Upper & & Lower & Upper \\
\hline \multicolumn{10}{|l|}{ Dietary behaviors (daily) } \\
\hline Breakfast intake (sometimes/daily) ${ }^{a}$ & 54.8 & 50.8 & 58.7 & 62.3 & 60.7 & 64.0 & 46.3 & 44.6 & 48.0 \\
\hline Fruit intake ( $\geq 1$ servings) & 38.1 & 34.0 & 42.1 & 43.6 & 41.5 & 45.7 & 31.8 & 29.7 & 33.9 \\
\hline Vegetable intake ( $\geq 1$ servings) & 54.3 & 50.7 & 58.0 & 55.7 & 53.8 & 57.7 & 52.8 & 50.8 & 54.8 \\
\hline Carbonated beverage consumption ( $\geq 2$ drinks) & 37.5 & 34.0 & 41.1 & 43.9 & 41.9 & 45.9 & 30.4 & 28.3 & 32.5 \\
\hline Energy drinks consumption ( $\geq 1$ drinks) & 21.8 & 19.7 & 23.9 & 25.5 & 23.8 & 27.2 & 17.7 & 16.1 & 19.3 \\
\hline \multicolumn{10}{|l|}{ Activity } \\
\hline Physical exercise (daily) & 13.7 & 10.4 & 16.9 & 19.0 & 17.4 & 20.6 & 7.7 & 6.9 & 8.5 \\
\hline Television viewing ( $\geq 2$ hours/day) & 42.4 & 41.0 & 43.9 & 40.4 & 38.8 & 42.1 & 44.7 & 42.8 & 46.6 \\
\hline Video game playing (yes) & 55.6 & 47.7 & 63.4 & 68.0 & 66.4 & 69.6 & 41.6 & 39.3 & 43.9 \\
\hline Internet use ( $\geq 2$ hours/day) & 30.1 & 26.8 & 33.4 & 26.0 & 24.3 & 27.8 & 34.6 & 32.5 & 36.8 \\
\hline Cellular phone ( $>1$ hour/day) & 14.8 & 13.2 & 16.3 & 13.2 & 12.0 & 14.4 & 16.6 & 14.8 & 18.3 \\
\hline \multicolumn{10}{|l|}{ Traffic safety } \\
\hline Seat belt using (sometimes/always) & 13.8 & 11.4 & 16.3 & 17.0 & 15.3 & 18.7 & 10.2 & 9.0 & 11.4 \\
\hline Car taking without permission (yes) & 17.9 & 11.7 & 24.2 & 28.6 & 26.8 & 30.4 & 5.9 & 5.1 & 6.7 \\
\hline \multicolumn{10}{|l|}{ Bullying and violence } \\
\hline Exposure to bullying ${ }^{a}$ & 25.0 & 23.0 & 27.0 & 27.1 & 25.1 & 29.0 & 22.7 & 21.3 & 24.2 \\
\hline Exposure to violence at school ${ }^{\mathrm{b}}$ & 20.8 & 15.8 & 25.7 & 28.9 & 26.3 & 31.5 & 11.7 & 10.4 & 12.9 \\
\hline Exposure to violence in community & 19.7 & 17.6 & 21.8 & 22.9 & 21.3 & 24.5 & 16.1 & 14.6 & 17.6 \\
\hline \multicolumn{10}{|l|}{ Tobacco and substance (ever use) } \\
\hline Cigarette smoking & 16.2 & 12.5 & 19.9 & 22.1 & 20.0 & 24.2 & 9.6 & 8.2 & 10.9 \\
\hline Sheesha smoking & 10.5 & 8.4 & 12.5 & 13.5 & 11.8 & 15.3 & 7.1 & 5.7 & 8.4 \\
\hline Solvents sniffing & 16.2 & 12.7 & 19.6 & 11.5 & 10.3 & 12.6 & 21.4 & 19.7 & 23.0 \\
\hline Prescription medication use for nonmedical purpose & 7.2 & 5.7 & 8.7 & 6.0 & 5.3 & 6.8 & 8.5 & 7.4 & 9.6 \\
\hline Alcohol consumption & 1.4 & 1.1 & 1.8 & 2.1 & 1.7 & 2.5 & .7 & .5 & 1.0 \\
\hline Stimulants use & 1.5 & 1.1 & 1.9 & 1.6 & 1.3 & 1.9 & 1.4 & 1.0 & 1.8 \\
\hline Marijuana use & 1.0 & .6 & 1.5 & 1.6 & 1.2 & 2.0 & .4 & .2 & .6 \\
\hline
\end{tabular}

$\mathrm{Cl}=$ confidence interval.

a During the past 30 days.

b During the past 12 months.

\section{Health risk behaviors and health status}

\section{Health risk behaviors}

Table 2 shows the prevalence of some of the important health risk behaviors and how they compare between the genders. 
Table 2

\begin{tabular}{|c|c|c|c|c|c|c|c|c|c|}
\hline & \multicolumn{3}{|l|}{ Prevalence } & \multicolumn{6}{|l|}{ Prevalence by gender } \\
\hline & \multirow[t]{2}{*}{$\mathrm{n}=12,575(\%)$} & \multicolumn{2}{|l|}{$95 \% \mathrm{Cl}$} & \multirow[t]{2}{*}{ Male $n=6,444(\%)$} & \multicolumn{2}{|l|}{$95 \% \mathrm{Cl}$} & \multirow[t]{2}{*}{ Female $\mathrm{n}=6,131(\%)$} & \multicolumn{2}{|l|}{$95 \% \mathrm{Cl}$} \\
\hline & & Lower & Upper & & Lower & Upper & & Lower & Upper \\
\hline \multicolumn{10}{|l|}{$\begin{array}{l}\text { Self-reported health status } \\
\text { Chronic illness }\end{array}$} \\
\hline Bronchial asthma & 8.4 & 7.1 & 9.8 & 10.8 & 9.6 & 11.9 & 5.8 & 5.1 & 6.5 \\
\hline Allergies (not asthma) & 4,9 & 3.5 & 6.2 & 4.2 & 3.5 & 4.9 & 5.6 & 4.7 & 6.5 \\
\hline Hematological disorder & 3.7 & 2.9 & 46 & 3.1 & 25 & 3.7 & 4.5 & 3.7 & 5.2 \\
\hline Skin disorders & 3.6 & 2.6 & 46 & 3.1 & 26 & 3.6 & 4.2 & 3.4 & 5.0 \\
\hline Musculoskeletal & 1.5 & 1.0 & 1.9 & 1.5 & 1.0 & 2.0 & 1.4 & 1.0 & 1.8 \\
\hline Genitourinary & 1.2 & .7 & 1.6 & 9 & .6 & 1.2 & 1.4 & 9 & 1.8 \\
\hline Diabetes & .7 & 5 & 1.0 & 9 & .7 & 1.2 & .6 & 3 & .8 \\
\hline Others & 4.6 & 3.8 & 5.4 & 5.0 & 40 & 6.0 & 4.2 & 3.3 & 5.0 \\
\hline \multicolumn{10}{|l|}{ Mental health } \\
\hline Sadness/depression & 14.3 & 11.0 & 17.6 & 10.1 & 9.3 & 11.0 & 19.0 & 17.6 & 20.4 \\
\hline Anxiety & 6.7 & 5.2 & 83 & 4.6 & 3,9 & 5.3 & 9.1 & 8.0 & 10.2 \\
\hline \multicolumn{10}{|c|}{ Measured indicators of health status } \\
\hline \multicolumn{10}{|l|}{$\mathrm{BMI}^{2}$} \\
\hline Underweight & 15.2 & 13.7 & 16.7 & 17.2 & 15.3 & 19.0 & 13.0 & 11.8 & 14.2 \\
\hline Healthy weight & 54.8 & 51.2 & 58.4 & 48.8 & 47.2 & 50.3 & 61.5 & 60.0 & 63.1 \\
\hline Overweight & 14.1 & 13.4 & 14.9 & 13.9 & 128 & 15.0 & 14.5 & 13.4 & 15.5 \\
\hline Obese & 15.9 & 12.6 & 19.1 & 20.2 & 187 & 21.7 & 11.0 & 9.8 & 12.3 \\
\hline
\end{tabular}

BMI = body mass index $; \mathrm{C}=$ confidence interval.

2 BMI: underweight $<5$ centile; healthy weight 5 to $<85$ centile; overweight $\geq 85$ to $<95$ centile; and obese $\geq 95$ centile based on Center for Disease Control and Prevention charts (2000).

Dietary Behaviors. Only $54.8 \%$ were found to consume breakfast daily or most of the time. Thirty-eight percent and $54.3 \%$ of adolescents had at least one serving of fruit or vegetables per day respectively. Thirty-eight percent and $21.8 \%$ reported drinking at least two carbonated beverages or one energy drink daily, respectively.

Activities. Almost half (45\%) of all adolescents did not engage in any physical exercise and only $13.7 \%$ had exercised daily for at least 30 minutes during the seven days preceding participation in the study. Females reported complete absence of exercise much more than males $(59.3 \%$ vs. $31.7 \%, p<0.0001)$.

As for sedentary activities, $42.4 \%$ of adolescents reported spending at least two hours per day watching television. Considerable amounts of time were spent performing other sedentary activities.

Behaviors affecting traffic safety. Only $13.8 \%$ reported seat belt use sometimes or always when passengers in a vehicle, while $35 \%$ had ever been in a car accident. Eighteen percent drove their parent's car without permission.

Sleep. More than half (59\%) had less than eight hours of sleep on weeknights. This was reported less on weekends, with $42.9 \%$ sleeping for similar duration. 
Bullying and violence. Twenty-five percent reported exposure to bullying at school during the 30 days preceding the study. As for physical violence, $20.8 \%$ and $19.7 \%$ were involved in such at school or in the community respectively, during the preceding 12 months.

Tobacco and substance use. Sixteen percent and $10.5 \%$ had ever smoked cigarettes or sheesha (waterpipe), respectively. Sixteen percent reported solvent sniffing in the preceding month with females reporting this more than males $(21.4 \%$ vs. $11.5 \%, p<0.0001)$. Frequencies of misusing prescription medications and other substances were lower.

\section{Health status}

Table 3 shows the health status among adolescents in KSA per gender.

Self-reported chronic health conditions. Overall prevalence of self-reported chronic illness was $27.3 \%$, with a total of $5.9 \%$ having at least one comorbidity. Bronchial asthma was the most common condition reported as the most common condition with prevalence of $8.4 \%$. This was followed by other allergic conditions and hematological disorders.

Self-reported mental health symptoms. Fourteen percent reported having depressive symptoms most of the time/always, and $6.7 \%$ had symptoms suggestive of anxiety most of the time/always during the past 12 months. Symptoms of an underlying mental health problem were significantly more prevalent among females $(p<.0001)$.

Measured indicators of health status. (1) Weight. Only $54.8 \%$ of adolescents had healthy weights. Thirty percent were overweight or obese, and $15.2 \%$ were underweight. (2) Vitamin D. The majority (95.6\%) of adolescents were vitamin D deficient ( $<50 \mathrm{nmol} / \mathrm{L}$ ). (3) Hemoglobin. Eleven percent of adolescents were anemic. 


\section{Discussion}

This study has shed light on the status of health risk behaviors and health status among adolescents in KSA. Our results show that many of these behaviors that put adolescents at risk for serious health problems exist and indeed such problems are saliently present (chronic illness, weight problems).

Adolescents in KSA generally reported poor dietary behaviors. Some are comparable to what has been reported regionally [23-26] or globally [27], though others, such as low fruit and vegetable intake and high soft drink consumption, were found to be even worse among our population. This is much lower than the daily recommended serving intake, yet despite this low threshold, our adolescents continue to have minimal fruit and vegetable intake. Energy drink consumption internationally has been found to be variable with $5-28 \%$ of adolescents reporting consumption $[28,29]$.

Lack of physical activity was found to be far more prevalent than desirable, and time spent with sedentary activities is similar to regional findings. This may be attributed to the limited engagement in outdoor activities, due to cultural practices and hot weather conditions. Lack of recreational facilities and inadequate education on the importance of physical activity may also be contributing to this difference. The strikingly less physical activity and more sedentary lifestyle among females may be attributed to less outdoor exposure because of cultural factors and lack of physical education (PE) in girl's schools. Furthermore, where available, PE is sometimes provided only once weekly and is often viewed as a supplementary class that students sometimes choose not to engage in.

Our findings related to traffic safety are alarming. They are worse than that reported in the United States (US) [27]. This may explain why disability associated with road traffic accidents has been found to increase in the region [3]. Local legislation mandates seat belt use for drivers and front seat passengers, yet is not enforced. Education on this matter and law enforcement by the government are essential. Males were significantly more likely than females to drive a parent's car without permission, and this can be explained by the fact that females are not allowed to drive in the country.

Exposure to bullying or violence, which are health risks in childhood and adulthood [30], were prevalent to extents found elsewhere [23-25,27]. Unfortunately, both conditions have received insufficient attention locally and further steps to address and prevent these behaviors are necessary.

Exploratory behaviors, which may persist into long-term addictions and consequent health problems, often begin in adolescence. The overall self-reported prevalence of having ever used tobacco or other 
substances was much lower among our population as compared to adolescents in other parts of the world. Alcohol is legally banned in KSA. As such, accessibility is limited, and its consumption is associated with religious and cultural stigma. Sheesha (waterpipe) smoking is a practice seen particularly in the Middle East and India. Unfortunately, it has been gaining popularity among youth globally, especially with youth immigrants from Middle Eastern countries [31]. On the other hand, we found a higher prevalence of solvent sniffing. As the accessibility to such substances is easier, adolescents might tend to resort to these choices. The higher prevalence seen among females may be explained by limited unsupervised outdoor access and hence the potential convenience of accessing solvents. Saudi Arabian society is conservative and addressing these behaviors, which are considered to be taboo, is a challenge within itself. The reported prevalence of these behaviors may therefore be an underestimate.

There is lack of population-based studies addressing adolescent chronic disease in the region. Our findings showed that bronchial asthma was the most prevalent chronic disease. These findings are similar to that reported in the US [32], yet lower than reports from the United Arab Emirates (UAE) [33]. Though diabetes was the least reported condition among our students, it has a higher prevalence than that reported among US adolescents (0.5\%) [34]. Furthermore, with the high rates of overweight and obesity that we found, monitoring for diabetes in at-risk individuals, as well as educating adolescents about possible symptoms is important. The prevalent symptoms suggestive of depression and anxiety are not surprising and gender differences are known to exist. Nonetheless, appropriate attention to these conditions is warranted.

As for measured indicators of health status, only half of our adolescents had a healthy weight. These findings are consistent with reports from the UAE and US [23,27], yet differ from that in Jordan who have $3.9 \%$ prevalence of overweight [26], and Kuwait where half of the students are overweight and $22.6 \%$ are obese [25]. These differences are observed in spite of comparable physical activity and dietary behaviors. The only exception to these behaviors was consumption of carbonated beverages that was found to be lower and higher in Jordan and Kuwait, respectively, in comparison to our findings. Further studies focusing on the impact and contribution of carbonated beverages on weight gain as well as addressing other aspects of diet and nutrition are necessary. The high prevalence of overweight and obese adolescents tracks into adulthood, where $36.5 \%$ and $21.9 \%$ of adults in Saudi Arabia suffer from obesity or diabetes respectively [35].

Vitamin D deficiency has been a source of concern globally. It has been found to be most prevalent in South Asia and the Middle East [36]. Our findings have shown higher prevalence of vitamin D deficiency 
than that reported in neighboring countries [37]. Further analysis to identify the determinants of vitamin D levels is necessary, as are studies to explore optimal levels for our local adolescent population.

According to the World Health Organization (WHO), our measured prevalence of anemia is considered to be within the mild category of public health significance [38]. Our findings though are higher than reports from the UAE [39].

Declining student response rates have been witnessed over the years [40]. The potential for non-response bias cannot be denied. We further analyzed to determine whether the characteristics of schools and participants differed between high-response rate and low-response rate-schools. We found no difference in characteristics and key adolescent risk behaviors and health conditions $(p>.05)$. Furthermore, weighting was carried out so as to ensure representativeness of the data. The minimum recruitment of students despite larger numbers giving consent, as described above in students' response rate subsection, has contributed to the low response rate. We speculate two additional points may have contributed to our response rates: 1) students and/or parents may have been reluctant to participate in a study addressing some sensitive issues. Saudi Arabian society is a conservative one, and several of the issues addressed are considered to be taboo; and 2) being the first national population-based study on adolescents, students and/or families may have not realized the importance or relevance of such research. Whether non-respondents are more or less involved in risky behaviors or have varying chronic health conditions is unknown. Similarly, adolescents who were absent on the day of the survey, who have dropped out of school, or who have certain disabilities may have had different needs and behaviors. Further strategies to enhance response rates in the future are necessary.

Jeeluna is the first large scale adolescent population study conducted in Saudi Arabia and one of the largest studies in the region. To our knowledge, it is the first population-based study that addresses, along with health risk behaviors, the health statues of adolescents and the prevalence of chronic conditions. The burden of adolescents' suffering is largely preventable and further delay in addressing the existing gaps between regional demographics and the current youth bulge and the paucity of services and programs dedicated to serve our adolescents will only result in national, economic, and social crisis.

We are optimistic that this rich information on the adolescents of KSA will be the drive for informing government policy and for establishing the necessary programs and services to address the needs of adolescents and support their health promotion. Our results support the importance of establishing a surveillance system with the data from this first round of Jeeluna serving as the baseline. This will allow a true public health approach in which we will be able to address local trends and compare adolescent 
Chapter 3

indicators across nations and regions. In order to build a public health regulatory cycle, repeated monitoring of health determinants and health status is needed that feed into and evaluate results of interventions to improve adolescent health which seem badly needed. 


\section{List of Abbreviations}

NCD: Non-communicable disease

KSA: Kingdom of Saudi Arabia

BMI: body mass index

MOE: Ministry of Education

YRBS: Youth Risk Behavior Survey

GSHS: Global School-based Health Survey

HB: Hemoglobin

SAS: Statistical Analysis Software

$\mathrm{Cl} \quad$ Confidence Intervals

US: $\quad$ United States

UAE: United Arab Emirates

WHO: World Health Organization 


\section{References}

[1] Fahimi FR, Kent MM. Challenges and Opportunities- The population of the Middle East and North Africa. PRB 2007;62:1-20.

[2] United Nations Children Fund. The State of the World's Children: Adolescence an Age of Opportunity. Available at: http://www.unicef.org/sowc2011/pdfs/SOWC-2011-Main-Report EN 02092011.pdf Accessed 10 November 2013.

[3] Mokdad AH, Jaber S, Abdel Aziz MI, et al. The state of health in the Arab World, 1990-2010: an analysis of the burden of disease, injuries and risk factors. Lancet 2014;383:309-320.

[4] Abdul Rahim HF, Sibai A, Khader Y, et al. Non-communicable diseases in the Arab world. Lancet 2014;383:356-367.

[5] World Health Organization. Global status report on noncommunicable diseases 2010. Available at: http://whqlibdoc.who.int/publications/2011/9789240686458 eng.pdf. Accessed 15 September 2013.

[6] Catalano RF, Fagan AA, Gavin LE, et al. Worldwide application of prevention science in adolescent health. Lancet 2012;379:1653-64.

[7] Sawyer SM, Afifi RA, Bearinger LH, et al. Adolescence: A foundation for future health. Lancet 2012:379:1630-40.

[8] World Health Organization. Developing a report "Health for the world's adolescents". Available at: http://www.who.int/maternal child adolescent/topics/adolescence/adolescent health2014/en/index. $\underline{\text { html. Accessed January } 2014 .}$

[9] Sacks D. Canadian Paediatric Society Position Statement: Age limits and adolescents. Paediatr Child Health 2003;8:577. 
[10] Albuhairan F, Areemit R, Harrison A, et al. Adolescent psychosocial development and evaluation: global perspectives. In: Özdemir Ö eds. Complementary Pediatrics, 2012:ISBN 978-953-51-0155-0. Available at: http://www.intechopen.com/books/complementary-pediatrics/adolescent-psychosocialdevelopment-and-evaluation-global-perspectives.

[12] Bright Futures Guidelines for Health Supervision of Infants, Children, and Adolescents. Available at: http://brightfutures.aap.org/pdfs/Guidelines PDF/18-Adolescence.pdf. Accessed 10 May 2013.

[12] Elster AB, Kuznets NJ. AMA Guidelines for Adolescent Preventive Services (GAPS): Recommendations and Rationale. JAMA 1994;272:980-981.

[13] AlBuhairan FS, Olsson T. Advancing adolescent health and health services in Saudi Arabia: Exploring healthcare providers' needs, attitudes and knowledge. [In Press].

[14] US Census Bureau. International Programs. International Data Base 2014. Available at: http://www.census.gov/population/international/data/idb/region.php? $\mathrm{N}=\% 20$ Results $\% 20 \& T=10 \& A=$ se parate \&RT $=0 \& Y=2014 \& R=-1 \& C=S A$ Accessed 11 April 2014.

[15] Centers for Disease Control and Prevention. YRBSS in Brief. Available at: http://www.cdc.gov/healthyyouth/yrbs/brief.htm. Accessed 15 September 2013.

[16] Ministry of Education 2011. http://www2.moe.gov.sa/english/Pages/about education.htm

[17] UNESCO Institute for Statistics. UIS Statistics in Brief. Available at: http://stats.uis.unesco.org/unesco/TableViewer/document.aspx?Reportld=121\&IF_Language=eng\&BR Country=6820.

[18] UNESCO International Bureau of Education 2006/2007. Saudi Arabia-World Data on Education $6^{\text {th }}$ edition. Available at: 
http://www.ibe.unesco.org/fileadmin/user upload/archive/Countries/WDE/2006/ARAB STATES/Saudi Arabia/Saudi Arabia.pdf. Accessed 5 May 2013.

[19] AlBuhairan FS, Al Dubayee M, Tamim H, et al. National Assessment of the Health Needs of Adolescents in Saudi Arabia: Screening for health risk behaviors and chronic illness. Jeeluna Study Protocol 2014. Available at:

[20] World Health Organization. Global school-based student health survey. Available at: http://www.who.int/chp/gshs/en/. Accessed 15 September 2013.

[21] Goldenring JM, Rosen DS. Getting into Adolescent Heads: An essential update. Contemp Pediatr 2004;21:64-90.

[22] Center for Chronic Disease Prevention. Growth chart. Available at: http://www.cdc.gov/growthcharts. Accessed 2 May 2012.

[23] Fikry M, Al-Matroushi MA. Global School-based Student Health Survey (GSHS)- United Arab Emirates. World Health Organization, Centers for Disease Control and Prevention. Available at: http://www.who.int/chp/gshs/2005 United Arab Emirates GSHS Country Report.pdf.

[24] Al-Muzahmi S, Hilmy SA. Oman Global School-based Student Health Survey. World Health Organization, Centers for Disease Control and Prevention. Available at: http://www.who.int/chp/gshs/Oman GSHS Country Report.pdf.

[25] Al Baho A, Badr HE. Global School-based Student Health Survey- Kuwait. World Health Organization, Centers for Disease Control and Prevention. Available at: http://www.who.int/chp/gshs/GSHS Kuwait report 2011.pdf. 
[26] Al Qaseer BM, Batarseh S, Asa'ad A. Global School-based Student Health Survey- Jordan. World Health Organization, Centers for Disease Control and Prevention. Available at: http://www.who.int/chp/gshs/GSHS Country Report Jordan 2007.pdf.

[27] Eaton DK, Kann L, Kinchen S, et al. Youth risk behavior surveillance - United States. Morbidity and Mortality Weekly Report Surveillance, MMWR 2012;61:1-162.

[28] Center for Disease Control and Prevention. Beverage Consumption Among High School Students --United States, 2010. Morbidity and Mortality Weekly Report Surveillance, MMWR 2011;60:778-780.

[29] Zucconi S, Volpato C, Adinolfi F, et al. Gathering consumption data on specific consumer groups of energy drinks. Supporting Publications 2013:EN-394. Available at: http://www.efsa.europa.eu/en/search/doc/394e.pdf.

[30] Wolke D, Copeland WE, Angold A, et al. Impact of Bullying in Childhood on Adult Health, Wealth, Crime, and Social Outcomes. Psych Sci 2013. doi:10.1177/0956797613481608

[31] Knishkowy B, Amitai Y. Water-Pipe (Narghile) Smoking: An Emerging Health Risk Behavior. Pediatrics 2005;116;113-119. doi: 10.1542/peds.2004-2173.

[32] Bloom B, Cohen RA, Freeman G. Summary health statistics for U.S. children: National Health Interview Survey 2011. National Center for Health Statistics. Vital Health Stat 2012;10:254.

[33] Alsowaidi S, Abdulle A, Bernsen R. Prevalence and risk factors of asthma among adolescents and their parents in Al-Ain (United Arab Emirates). Respiration 2010;79:105-11.

[34] Duncan GE. Prevalence of diabetes and impaired fasting glucose levels among US adolescents: National Health and Nutrition Examination Survey, 1999-2002. Arch Pediatr Adolesc Med 2006;160:5238. 
[35] World Health Organization. Saudi Arabia: Health Profile. Available at: http://www.who.int/gho/countries/sau.pdf?ua=1. Accessed May 2013

[36] Mithal A, Wahl DA, Bonjour JP, et al. Global vitamin D status and determinants of hypovitaminosis D. Osteoporos Int 2009; 20:1807-20. doi: 10.1007/s00198-009-0954-6.

[37] Muhairi SJ, Mehairi AE, Khouri AA, et al. Vitamin D deficiency among healthy adolescents in Al Ain, United Arab Emirates. BMC Public Health 2013;13:33. doi:10.1186/1471-2458-13-33.

[38] Benoist B, McLean E, Cogswell M, et al., eds. Worldwide prevalence of anaemia 1993-2005:WHO Global Database on Anaemia Geneva. In: World Health Organization, Centers for Disease Control and Prevention, 2008. Available at: http://whqlibdoc.who.int/publications/2008/9789241596657 eng.pdf.

[39] Haddad B. Prevalence of high blood pressure, heart disease, thalassemia, sickle-cell anemia, and iron deficiency anemia among the UAE adolescent population. J Environ Public Health 2013;2013:680631. doi: $10.1155 / 2013 / 680631$.

[40] Sturgis P, Smith P, Hughes G. A Study of Suitable Methods for Raising Response Rates in School Surveys. BMRB International Limited 2006:ISBN1844786862. Available at: http://webarchive.nationalarchives.gov.uk/20130401151715/https://www.education.gov.uk/publicatio ns/eOrderingDownload/RR721.pdf 


\section{Chapter 4 \\ Underweight, body image and weight loss measures among adolescents in Saudi Arabia}

This chapter has been published with the following citation:

Hijji, T., Saleheen, H., AlBuhairan, F. Underweight, body image, and weight loss measures among adolescents in Saudi Arabia: is it a fad or is there more going on? International Journal of Pediatrics and Adolescent Medicine 2020 https://doi.org/10.1016/i.ijpam.2020.01.002 


\section{Abstract}

Background and Objective: Adolescence is considered to be a pivotal point in which optimum nutrition and eating habits are developed. Although tackling the obesity epidemic has been much discussed, addressing the issue of underweight and body image is often neglected. This study was carried out to get a better understanding of underweight status among adolescents in Saudi Arabia and exploring selfperceptions of body image and weight loss measures among underweight adolescents.

Methods: Data from Jeeluna ${ }^{\circledR}$, a national cross-sectional school-based survey were utilized. Jeeluna ${ }^{\circledR}$ assessed the health status and health-risk behaviors of adolescents in school through data obtained by a self-administered questionnaire, anthropologic measurements, and laboratory investigations.

Results: A total of 12,463 adolescents participated. Eighteen percent of adolescent males and $12.4 \%$ of females were found to be underweight, representing $14.9 \%$ of adolescents collectively. Forty-five percent of underweight participants were happy with their weight. Underweight females between the age group of 10 and 14 years were the most likely to believe that they still need to lose weight (16.0\%) followed by females aged 15-19 years (9.7\%). Underweight females aged 10-14 years were also the group most likely to engage in purging (1.6\%). Stepwise logistic regression found that the strongest association with being underweight was with having a lower household income (OR 2.0, $\mathrm{Cl}$ 1.5e2.7) and having more than 5 siblings (OR 1.8, $\mathrm{Cl}$ 1.5e2.3).

Conclusion: Underweight status is prevalent among adolescents in Saudi Arabia and deserves more attention as a public health issue. Distorted body image and disordered eating behaviors exist, necessitating further investigation of underlying causes.

Keywords: Adolescent, Underweight, Body image, Low BMI, Health status, Kingdom of Saudi Arabia 


\section{Introduction}

Adolescence, the age of 10 to 19 years, is a time of critical development in an individual's cognitive, emotional and social characteristics, as well as their physical growth and development. The study of this important age group has gained global attention as it represents a critical intervention point, as we now know through the life course lens to health, that in order to decrease disease burden in adulthood, we need to promote healthy lifestyle and prevent risky behaviors in adolescence. ${ }^{1,2,3}$

Around 1.2 billion of the world's total population are considered to be in adolescent age group, $88 \%$ of which are in developing countries including the Arab world. ${ }^{4}$ As for the Kingdom of Saudi Arabia (KSA), around $14.5 \%$ of the 33 million total population are comprised of this age group. ${ }^{5}$ Yet focused attention and literature dedicated to the health needs of adolescents in the region which is essential in guiding policy has only been generated in the past several years. ${ }^{6}$

One area of study is the nutritional profile of adolescents, which is essential to inform decision making due to dietary behavior playing a crucial role in development and is a prerequisite for decreasing disease burden in adulthood. While obesity in adolescents is on the rise and certainly receives much attention, this condition now co-exists with underweight. The consequence of this paradox is often referred to as "the double burden of malnutrition" and presents a challenge to public health. ${ }^{7}$ Being underweight has been associated with a variety of conditions including musculoskeletal, respiratory, intestinal, adverse pregnancy outcomes and psychiatric disorders. ${ }^{8,9}$ as well as stunting, pubertal delay, and a weakened immune system. ${ }^{10}$

Global health reports have shown that although obesity rates are on the rise, rates of moderate or severe underweight are higher than rates of obesity among children and adolescents - as defined by World Health Organization (WHO) guidelines. This burden is increasingly concentrated in Africa and South Asia. Globally, the prevalence of moderate to severe underweight was $8.4 \%$ and $12.4 \%$ among boys and girls respectively in $2016 .{ }^{11}$

While available studies on adolescent nutritional profile in KSA have largely focused on obesity which is seen as an epidemic, there are very limited studies examining the other extreme of body mass index (BMI) in adolescents. One available study in done in Riyadh seems to suggest that underweight prevalence is alarmingly high compared to other similar countries in the region. ${ }^{12}$ However, their sample size was limited and only included females $12-15$ years. The only nationally representative study addressing this in 
the KSA is the Jeeluna ${ }^{\circledR}$ study in which we reported the prevalence of underweight (BMI below the $5^{\text {th }}$ centile for age and gender) to be $15.2 \%$ among a sample of over 12,500 adolescents. ${ }^{6}$

With our current study, we aim to build on previously reported results by using the Jeeluna data to get a better understanding of underweight among adolescents in the KSA. We explore self-perceptions of body image and weight loss measures among underweight adolescents and identify gender differences.

\section{Methods:}

Data for this study was taken from the Jeeluna ${ }^{\circledR}$ study, which is a school-based, national, cross-sectional study conducted in 282 schools across all 13 regions of KSA in the academic year of 2011-2012. The study used a student population proportionate, stratified, multi-stage, clustered sampling method to select a representative sample of adolescents. Data collection teams in all regions received standardized training for data collection. Data collection involved a self-administered questionnaire, anthropometric measurements, and blood samples for laboratory investigations.

The self-administered questionnaire was guided by pre-existing internationally recognized surveys with psychometric properties aimed to address health risk behaviors among adolescents. Details of the study methods have been previously published. ${ }^{6}$ Trained staff measured the height to the nearest $0.5 \mathrm{~cm}$ using a wall mounted height chart and weight to the nearest $0.1 \mathrm{~kg}$ using a digital scale while students were lightly dressed and without shoes. BMls were interpreted based percentiles of the norm for age and sex, to be underweight if $<5^{\text {th }}$, healthy weight if between $5^{\text {th }}$ and $<85^{\text {th }}$, overweight if between $85^{\text {th }}$ and $<95$ th, or obese if $95^{\text {th }}$ or more, in accordance to the Center for Disease Control (CDC) growth charts. ${ }^{13}$ Data was weighted to ensure that it is nationally representative. Domains relevant to this study include (1) family; (2) educational level; (3) nutrition and dietary behaviors; (4) activities, including physical activity, and (5) health status. These relevant variables were extracted from the data set and analyzed.

Dietary behavior was assessed by participants answering the following questions in the self-administered questionnaire: "during the past 7 days, why did you skip meals?", "are you currently on a diet for weight loss?" and "what have you done in order to lose weight?" Those who answered the last question as "I took weight-loss medications" or "I vomited after eating" were considered to be purging and coded as such in the analysis. Body image was assessed by the question "what do you think of your body" in which participants could answer: "I am happy with the way my body looks", "I think I need to lose some weight", "I think I need to gain some weight". 
Additionally, other variables of interest in the questionnaire were: age, gender, area of residence (urban or rural), nationality, school grade, how often they engaged in exercise, and whether they have been diagnosed with a chronic or mental illness. In order to get an idea about socioeconomic status (SES), the following two questions were asked: "What is your family's total monthly income?" and "How many full siblings do you have?"

Data analysis was performed using SPSS version 25.0 (SPSS Inc., 2017). Descriptive analysis was conducted as the first step of analysis. Participants were described in terms of their socio-demographic characteristics. The association between dietary behaviors and weight of the participants was evaluated using chi-square test. Odds ratio and $95 \%$ confidence intervals were calculated for each of the potential explanatory variables in relation to the outcome (underweight). A significance level of less than 0.05 was used for all statistical tests.

Ethical approval for the study was obtained from the Institutional Review Board (IRB) at King Abdullah International Medical Research Center (KAIMRC), and the Ministry of Education. Consent forms were obtained from parents and students, prior to participation in the study.

\section{Results}

A total of 12,463 adolescents participated. Fifty-one percent were males. Participant's ages ranged between 10 and 19 years, with a mean of 15.8 years $( \pm 1.8)$. The large majority of the students were of Saudi nationality (82.8\%) and lived in urban cities (97.9\%). Eighteen percent of males and $12.4 \%$ of females were found to be underweight according to CDC definition, representing $14.9 \%$ of adolescents collectively. Of the participants (52.6\%) had more than 5 siblings, and (34.9\%) had between 3 and 5 .

Disparities can be noted among adolescents in different regions within the KSA as shown in (Table 1). With Madinah having the highest frequency of underweight males (28.3\%) and Najran having the highest frequency among females (29.0\%), the Northern Borders region having the lowest for males $(1.0 \%)$ and Aljouf having the lowest for females (3.1\%) p-value $<0.05$ 
Table 1: Prevalence of underweight by region

\begin{tabular}{lllll}
\hline \multirow{2}{*}{ Region } & Male & Female & \\
\cline { 2 - 5 } & $\begin{array}{l}\text { Total } \\
\text { (N) }\end{array}$ & $\begin{array}{l}\text { Underweight } \\
\mathbf{N}(\%)\end{array}$ & $\begin{array}{l}\text { Total } \\
\mathbf{( N )}\end{array}$ & $\begin{array}{l}\text { Underweight } \\
\mathbf{N}(\%)\end{array}$ \\
\hline Riyadh & 1218 & $219(18.0)$ & 1377 & $172(12.5)$ \\
Qasim & 380 & $44(11.6)$ & 344 & $36(10.5)$ \\
Makkah & 1598 & $261(16.3)$ & 1185 & $172(14.5)$ \\
Madinah & 509 & $144(28.3)$ & 426 & $58(13.6)$ \\
Eastern province & 878 & $117(13.3)$ & 959 & $75(7.8)$ \\
Tabuk & 133 & $12(9.0)$ & 200 & $9(4.5)$ \\
Aljouf & 164 & $34(20.7)$ & 194 & $6(3.1)$ \\
Hail & 200 & $24(12.0)$ & 154 & $13(8.4)$ \\
Northen borders & 98 & $1(1.0)$ & 114 & $10(8.8)$ \\
Albaha & 117 & $28(23.9)$ & 191 & $23(12.0)$ \\
Aseer & 409 & $102(24.9)$ & 360 & $72(20.0)$ \\
Jizan & 377 & $106(28.1)$ & 223 & $47(21.1)$ \\
Najran & 191 & $42(22.0)$ & 107 & $31(29.0)$ \\
All & 6272 & $1134(18.1)$ & 5834 & $724(12.4)$ \\
\hline
\end{tabular}

Figure 1 depicts the prevalence of underweight by age for both males and females. A similar trend is observed among both genders where prevalence peaks at the age of 12 for males and 13 for females then declines and stabilizes for the rest of adolescence. However, males start off at the age of 10 and 11 with much lower rates compared to females then rapidly increases to the peak. This peak may be explained by the growth spurt occurring at puberty which may coincide with the time of the peak. 
Figure 1: Prevalence of underweight by age

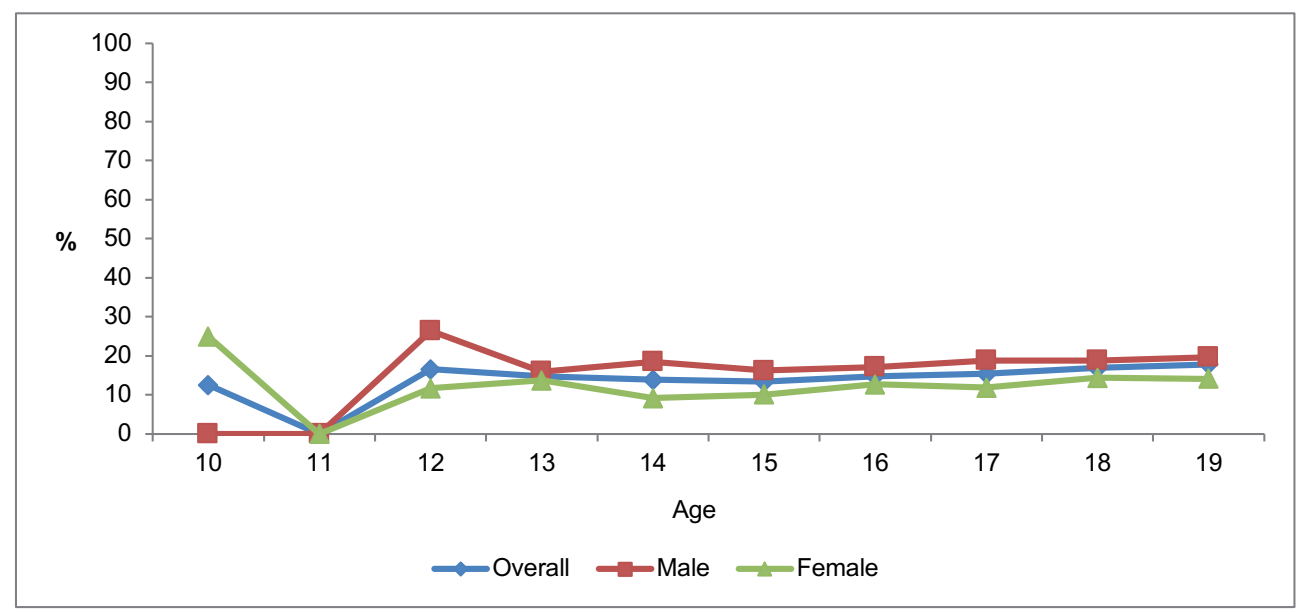

The relationship between body image perception, weight-loss behaviors, and weight status is summarized in Table 2. Underweight participants were more likely to report that they do not skip meals in the past 7 days. Forty-five percent of underweight participants said that they were happy with their body, not acknowledging that they need to gain weight, compared with $51.1 \%$ of healthy weight. This was further examined in Table 3 where the results were broken down based on age group and gender. It was found that underweight females between the ages of 10-14 were the most likely group to believe that they need to lose weight despite being underweight (16.0\%) followed by females aged $15-19$ years $(9.7 \%)$. Females aged 15-19 years were also most likely to believe they needed to gain weight (50.9\%). 
Table 2: Relationship between body image perception, weight-loss behaviors, and weight of the participants

\begin{tabular}{llll}
\hline \multicolumn{1}{c}{ Nutritional behavior } & Underweight & Normal weight & \\
\cline { 2 - 2 } & & & $p$-value \\
\hline Why did you skip some meals in the past seven days? & & & $<0.01$ \\
$\quad$ I did not skip meals & $695(38.2)$ & $2254(34.8)$ & \\
$\quad$ I did not feel hungry & $610(33.5)$ & $2009(31.0)$ & \\
I want to lose weight & $92(5.1)$ & $989(15.3)$ & \\
$\quad$ No food & $31(1.7)$ & $93(1.4)$ & \\
$\quad$ I did not feel comfortable to the available food & $168(9.2)$ & $531(8.2)$ & $<0.01$ \\
$\quad$ Other reasons & $223(12.3)$ & $598(9.2)$ & \\
What do you think about your weight/body? & & & \\
$\quad$ Happy with my body & $806(44.5)$ & $3296(51.1)$ & \\
$\quad$ I need to lose weight & $181(10.0)$ & $2271(35.2)$ & \\
$\quad$ I need to gain weight & $826(45.6)$ & $881(13.7)$ & \\
Are you following a diet plan? & & & \\
$\quad$ Yes & $182(10.1)$ & $766(11.9)$ & \\
$\quad$ No & $1627(89.9)$ & $5657(88.1)$ & \\
What do you do if you want to lose weight? & $1281(70.1)$ & $2823(44.1)$ & \\
I have not tried to reduce my weight & $272(14.9)$ & $2019(31.6)$ & \\
$\quad$ Decreased calorie intake & $258(14.1)$ & $1491(23.3)$ & \\
$\quad$ Exercise & $17(0.9)$ & $62(1.0)$ & \\
$\quad$ Purging &
\end{tabular}

Table 3: Body satisfaction and weight loss methods among underweight by age and gender

\begin{tabular}{|c|c|c|c|c|c|c|}
\hline & \multicolumn{3}{|c|}{ Underweight male } & \multicolumn{3}{|c|}{ Underweight female } \\
\hline & $10-14$ years & $15-19$ years & $p$-value & $10-14$ years & $15-19$ years & $p$-value \\
\hline Body satisfaction & & & NS & & & $<0.01$ \\
\hline Happy with my body & $134(49.4)$ & $365(45.2)$ & & $81(44.8)$ & $200(39.4)$ & \\
\hline I need to lose weight & $14(5.2)$ & $74(9.2)$ & & $29(16.0)$ & $49(9.7)$ & \\
\hline I need to gain weight & $123(45.4)$ & $369(45.7)$ & & 71 (39.2) & $258(50.9)$ & \\
\hline Weight loss methods & & & NS & & & $<0.05$ \\
\hline $\begin{array}{l}\text { I have not tried to } \\
\text { reduce my weight }\end{array}$ & $190(68.6)$ & $571(69.8)$ & & $120(65.9)$ & $378(74.9)$ & \\
\hline $\begin{array}{l}\text { Decreased calorie } \\
\text { intake }\end{array}$ & $43(15.5)$ & $107(13.1)$ & & $27(14.8)$ & $77(15.2)$ & \\
\hline Exercise & 41 (14.8) & $134(16.4)$ & & 32 (17.6) & $45(8.9)$ & \\
\hline Purging & $3(1.1)$ & $6(0.7)$ & & $3(1.6)$ & $5(1.0)$ & \\
\hline
\end{tabular}

NS - Not significant 
Furthermore, of all groups, underweight-females ages 10-14 years most commonly engaged in purging to lose weight (1.6\%). This was followed by underweight-females ages $15-19$ years (1.0\%). The latter group was also the one most likely to report never attempting to lose weight (74.9\%). In general, $13.1 \%$ to $15.5 \%$ of underweight participants reported trying to further decease their weights using caloric restriction.

Stepwise logistic regression was carried out to determine the independent predictors of underweight adolescents (Table 4). The strongest association was found with having a monthly family income of $<5000$ Saudi Riyals (OR 2.0, Cl 1.5-2.7) and having more than 5 siblings (OR 1.8, Cl 1.5-2.3), followed by being male (OR 1.6, $\mathrm{Cl} 1.4-1.7$ ). The effect of family income is more pronounced for females (OR 2.4, $\mathrm{Cl}$ 1.34.3) compared to males (OR 1.9, $\mathrm{Cl}$ 1.3-2.6) whereas the effect of number of siblings was similar for those with $>5$ siblings (OR 1.8 for both). 
Table 4: Factors associated with underweight among adolescents in Saudi Arabia by gender.

\begin{tabular}{|c|c|c|c|c|c|c|c|c|c|}
\hline & \multicolumn{3}{|c|}{ Both Genders } & \multicolumn{3}{|l|}{ Male } & \multicolumn{3}{|c|}{ Female } \\
\hline & OR & $95 \% \mathrm{Cl}$ & $p$-value & OR & $95 \% \mathrm{Cl}$ & $p$-value & OR & $95 \% \mathrm{Cl}$ & $p$-value \\
\hline \multicolumn{10}{|l|}{ Gender } \\
\hline Male & 1.6 & 1.4-1.7 & $<0.01$ & & & & & & \\
\hline \multicolumn{10}{|l|}{ Female (Ref.) } \\
\hline \multicolumn{10}{|l|}{ Age } \\
\hline $10-14$ & 0.9 & 0.8-1.1 & NS & 0.9 & $0.8-1.1$ & NS & 1.0 & $0.8-1.3$ & NS \\
\hline \multicolumn{10}{|l|}{ 15-19 (Ref.) } \\
\hline \multicolumn{10}{|l|}{ Areas of residence } \\
\hline Urban & 1.5 & $1.0-2.3$ & $<0.05$ & 2.0 & $1.1-3.5$ & $<0.05$ & 0.9 & $0.5-1.8$ & NS \\
\hline \multicolumn{10}{|l|}{ Rural (Ref.) } \\
\hline \multicolumn{10}{|l|}{ Grade } \\
\hline Intermediate & 0.9 & $0.8-1.1$ & NS & 1.0 & $0.9-1.2$ & NS & 0.7 & $0.6-0.9$ & $<0.05$ \\
\hline \multicolumn{10}{|l|}{ Secondary (Ref.) } \\
\hline \multicolumn{10}{|l|}{ Number of siblings } \\
\hline$>5$ & 1.8 & $1.5-2.3$ & $<0.01$ & 1.8 & $1.4-2.4$ & $<0.01$ & 1.8 & $1.3-2.6$ & $<0.01$ \\
\hline $3-5$ & 1.4 & $1.1-1.8$ & $<0.01$ & 1.3 & $1.0-1.8$ & $<0.05$ & 1.6 & $1.1-2.3$ & $<0.05$ \\
\hline \multicolumn{10}{|l|}{$<3$ (Ref.) } \\
\hline \multicolumn{10}{|l|}{ Monthly income } \\
\hline$<5000$ riyals & 2.0 & $1.5-2.7$ & $<0.01$ & 1.9 & $1.3-2.6$ & $<0.01$ & 2.4 & $1.3-4.3$ & $<0.01$ \\
\hline $5000-20000$ riyals & 1.5 & $1.2-2.0$ & $<0.01$ & 1.3 & $1.0-1.8$ & $<0.05$ & 2.2 & $1.2-3.9$ & $<0.01$ \\
\hline \multicolumn{10}{|l|}{ >20000 riyals (Ref.) } \\
\hline \multicolumn{10}{|l|}{ Engage in exercise } \\
\hline$>5$ days & 0.9 & $0.8-1.1$ & NS & 1.1 & $0.9-1.3$ & NS & 0.6 & $0.4-0.9$ & $<0.05$ \\
\hline 2-5 days & 0.8 & $0.7-0.9$ & $<0.05$ & 1.0 & $0.8-1.1$ & NS & 0.6 & $0.4-0.8$ & $<0.01$ \\
\hline \multicolumn{10}{|l|}{ <2 days (Ref.) } \\
\hline \multicolumn{10}{|l|}{ Chronic diseases } \\
\hline Yes & 1.1 & $0.9-1.4$ & NS & 1.3 & 1.1-1.7 & $<0.01$ & 0.8 & $0.6-1.2$ & NS \\
\hline \multicolumn{10}{|l|}{ No (Ref.) } \\
\hline \multicolumn{10}{|l|}{ Mental illness } \\
\hline No & 1.1 & $1.0-1.3$ & $<0.05$ & 1.3 & $1.0-1.6$ & $<0.05$ & 1.0 & $0.8-1.2$ & NS \\
\hline Yes (Ref.) & & & & & & & & & \\
\hline
\end{tabular}


Finally, logistic regression analysis was done to identify predictors of underweight after control for confound effects. Results showed that predisposing factors for underweight among adolescents include skipping meals (OR=1.1, 95\% $\mathrm{Cl}=1.0-1.2)$ and not being satisfied with body image $(\mathrm{OR}=1.7,95 \% \mathrm{Cl}=1.5$ 1.9) (Table 5).

Table 5: Predisposing factors for underweight among adolescents

\begin{tabular}{|c|c|c|c|c|}
\hline \multirow{2}{*}{ Nutritional behavior } & \multirow[t]{2}{*}{ Number (\%) } & \multirow{2}{*}{$\begin{array}{l}\text { Adjusted } \\
\text { ratio }^{a}\end{array}$} & \multicolumn{2}{|c|}{ Confidence limits (95\%) } \\
\hline & & & Lower & Upper \\
\hline Skipped meal & $7916(65.8)$ & 1.1 & 1.0 & 1.2 \\
\hline Not satisfied with body & $7184(60.0)$ & 1.7 & 1.5 & 1.9 \\
\hline Following a diet plan & $1677(14.0)$ & 1.0 & 0.8 & 1.2 \\
\hline
\end{tabular}

${ }^{a}$ Adjusted for age, gender, areas of residence

\section{Discussion}

This is the first national study to investigate the correlates of underweight among adolescents in KSA, including perceptions of body-image and weight-loss behaviors, and has such provided many valuable insights. The study shows that $14.9 \%$ of adolescents are underweight, which is alarmingly high compared to countries of similar socioeconomic and/or cultural landscape. A high proportion of underweight participants report being happy with their weight $(44.5 \%)$ or wanting to lose more weight $(10.0 \%)$ which should be addressed in the context of body image disturbance. Furthermore, we need to consider possible reasons for the high disparities in prevalence of underweight adolescents among different regions of the country which ranges from over $25 \%$ to under $10 \%$ among some regions in the country. Finally, being of low socioeconomic status (SES) was the strongest predictor of being underweight.

Similar studies done in KSA are limited but report similar trends. One such study done in Riyadh on 107 female adolescents aged 12-15 years found that $28.6 \%$ were underweight. ${ }^{12}$ Furthermore, high prevalence of underweight status was also found among university female students where a study of 663 randomly selected participants between ages $18-24$ years found $19.2 \%$ to be underweight. Number of 
siblings was also among the significantly associated factors along with age and presence of obese family members. ${ }^{14}$ Researchers in these studies agree that given the high prevalence of underweight compared to other countries, more emphasis should be given in future research to this understudied subject.

It is relevant to contrast these rates with those found in other counties in the Middle East and North African (MENA) region. A study in Qatar found that $8.6 \%$ and $5.8 \%$ of boys and girls respectively were underweight. ${ }^{15}$ Prevalence of underweight among adolescents aged 11-17 years in Egypt was 12.6\% based on WHO charts, with males more commonly affected. ${ }^{16}$ As for Palestine, underweight prevalence varied between $5 \%$ and $12 \%$ in two different cities respectively. ${ }^{17}$ One study in Istanbul found that $14.4 \%$ of boys and $11.1 \%$ of girls were underweight. ${ }^{18}$

As for studies done elsewhere, prevalence rates of moderate and severe thinness, as defined by WHO growth reference, across 61,603 girls from 40 low- and middle-income countries was $6.30 \% .{ }^{19}$ In European countries and Australia, the prevalence of underweight status among children and adolescents is about $4-8 \%,{ }^{20,21}$ Although these results may not be comparable due to the use of different methodology and cut offs. In one study the highest rates of underweight prevalence were found in China ( $11.5 \%$ in girls and $14.4 \%$ in boys) while the lowest were in the United States (3\% in girls and $3.6 \%$ in boys). Brazilian adolescents and Russian adolescents had values in between (6.5\% in girls, $10.6 \%$ in boys and $8.6 \%$ in girls, $7.7 \%$ in boys, respectively). ${ }^{22}$ These rates draw attention to the fact that rates in the KSA seem to be much higher and there is a definite need for intervention.

The peak at age of 12-13 years could be due to variable onset of puberty among pupils where the rate steadily goes down upon subsequent years. ${ }^{23}$ Age of puberty and hormonal profile were not assessed in this study, but other studies reported onset of puberty to be inversely associated with underweight as a higher proportion of the well-nourished were among those who have reached puberty in the sample. ${ }^{24}$ Our study also revealed that males have higher rates of underweight than females in Saudi Arabia. This trend seen in some other countries was substantiated by the findings of previous studies which suggest that adolescent girls may be more health-conscious and therefore more likely to follow dietary recommendations compared with similarly aged boys. ${ }^{25}$ The findings suggest that more effort should be done to spread awareness about the importance of maintaining healthy weights among boys as well as girls.

The study also demonstrates that $44.5 \%$ of those who are underweight were happy with their body, and $35.2 \%$ of those who have normal BMIs wanted to lose weight. Additionally, $10.1 \%$ of underweight 
participants reported being on a diet to lose weight, compared to $11.9 \%$ in normal weight participants. These rates are higher than those found in a similar study in Palestine where only $7 \%$ of underweight participants were on a diet to lose weight ${ }^{26}$; however, the Palestinian study also reported much higher rates of unhealthy weight control methods among underweight participants: $3.75 \%$ used pills/laxatives and $9.08 \%$ self-induced vomiting. In our study, only $0.9 \%$ used unhealthy purging methods. Although this is a good sign, it is difficult to draw a definitive conclusion due to the possibility of underreporting of this information which may be considered sensitive. Underweight females between the ages of 10-14 years were the most likely group to report being unsatisfied with their weight and wanting to lose more weight at $16.0 \%$ compared to $5.2 \%$ of males in the same age groups. One suggested reason for this disparity implicates mass media which promotes and glamourizes thinness as the standard of beauty rather than health. ${ }^{27}$ Studies suggest that women at the adolescent age can be particularly influenced by the unrealistic body ideals of the media which convey inaccurate messages. ${ }^{28}$ There is a lack of literature to suggest whether this is or is not the case in the KSA; however, the media that is available and viewed in Western countries, has now become the same media available locally. Future studies should investigate the role of mass media in the KSA and its effects on body perception among adolescents and increasing rates of eating disorders.

The disparities of underweight prevalence reported by the study may be due to several underlying factors such differences in socioeconomic conditions, urbanization, culture, and health-promoting behaviors, including diet and exercise. ${ }^{29}$ The findings provide a foundation for prioritizing these regions for intervention efforts and further research. It is also possible that students tend to be influenced by the weight status of the social majority in their schools, causing them to adapt to it. ${ }^{30} \mathrm{~A}$ statistically significant difference was also found for underweight prevalence among those residing in urban cities verses rural areas (OR 1.5, Cl 1.0-2.3) which suggests that the urban lifestyle may predispose adolescents to being underweight. Furthermore, there was no significant difference in the prevalence of underweight among Saudi and non-Saudis, which suggests that the role of the environment and lifestyle may be the main contributing factors over genetic factors in influencing the pattern of weight status.

In exploring the association between SES and underweight status, SES was inferred by using adolescentreported family income and number of siblings. The study showed that these two factors were the largest risk factors for underweight status, suggesting that SES plays a big role and should be targeted with intervention strategies. However, it should be noted that although these measures provide an indication, they cannot fully capture the various dimensions of family SES. The association with low SES should be 
put into context, as the finding does not necessarily imply that access to food is the only implicated factor. Other related factors such as parenting practices may explain a significant part of the difference as families with low SES may be less educated or have less time thus are unable to teach kids about nutrition. ${ }^{31,32}$

Some studies have found that poorer children who live in high SES neighborhoods have better educational outcomes and fewer behavioral problems than poor children who live in lower SES neighborhoods possibly suggesting that education and social norms are the dominant factors. ${ }^{33,34}$ This suggests that there is room for affective intervention beyond simply improving SES. The literature also suggests that in developing countries, high SES is sometimes associated with increased overweight status, however the opposite trend is seen in developed countries where low SES is associated with increased overweight status. ${ }^{35,36}$ Therefore, the literature supports the idea that low income individuals are more likely to be either underweight or overweight compared to high income peers. ${ }^{37}$

Given that the study is cross-sectional, we cannot establish causality between the dependent and independent variables; however, our study offers several possible risk factors associated with being an underweight adolescent in the KSA, more in-depth longitudinal studies should be done to better reflect on this situation to gain better understanding. Additionally, self-administered surveys may be associated with recall bias, and a high cognitive burden as physical activity and dietary assessment were based on individuals' assessments and memory and not objective measurements. Additionally, some of the information may have been considered sensitive, and despite repeated reassurance that confidentiality would be maintained, some items may have been under reported. Finally, hormonal profile of adolescents was not measured to be taken into consideration when evaluating heights and weights which may not be comparable among participates who have reached puberty and others who have not.

On the other hand, the large sample size and the generalizability of the results speak to its strengths, as the study explores underweight status and associated risk factors among a nationally representative sample of adolescents in the KSA. Furthermore, standardized protocols were used to obtain anthropometric measurements rather than relying on self-reported values. The questionnaire used had underwent several rounds of review by experts and was pilot-tested for clarity and appropriate wording to ensure comprehension amongst the target study group. The questions were formulated in congruence with those included in the Youth Risk Behavior Survey ${ }^{38}$ and the Global School-based Student Health Survey with cultural adaptations. ${ }^{39}$ 
Ministry of Health and School Health Programs should work concurrently to address underweight as it represents a substantial disease burden. The aim is to improve the overall health of the youth in the country and to prevent a multitude of health consequences in adults ${ }^{9}$ as well as reproductive complications for girls. ${ }^{8}$ It is important to note that while strategies to curb the rates of obesity among school aged children is also paramount, certain strategies may have a negative impact on children with normal or below normal weight and special attention should be taken to address the double burden of malnutrition with a holistic approach. ${ }^{40}$ This can be done through effective school and community-based interventions that are tailored to the Saudi cultural context.

In looking forward, research should aim to better our understanding of how factors within family SES, school SES and community SES interact to influence healthy nutritional status. Furthermore, the implementation of a surveillance program should be considered to observe changing trends and monitor results of intervention programs. It's suggested that underweight frequency is increasing in European countries ${ }^{11}$; further studies would need to be conducted to determine whether KSA is following a similar trend.

\section{Conclusion}

Underweight status is prevalent among adolescents in the KSA and deserves more attention as a public health issue. Although obesity is now seen as an epidemic, policy makers should not neglect the other extreme of malnutrition and adopt effective strategies and intervention programs to also tackle underweight. Our study demonstrates that there is an alarmingly high prevalence of underweight among adolescents in the KSA compared to other similar countries. Furthermore, it suggests that socioeconomic factors and body image disturbance play a dominant role. Though some knowledge has been generated from this study, many more questions have arisen. Are our adolescents simply seeking time-limited weight loss measures and fad diets or could there be a more serious underlying problem, such as an eating disorder, which has gone unnoticed? This is a topic which is under addressed and, in our opinion, lacks much awareness in the society. A holistic, evidence-based approach that is specifically tailored to the Saudi cultural context is in need to tackle this issue of underweight among adolescents through educational programs and policy driven interventions in schools and in high-risk subpopulations. 
Chapter 4

Implications and Contributions statement

Although adolescents constitute a significant portion of Saudi Arabia's population, little is known about the prevalence of correlates of underweight status. This nationally representative study has identified that the prevalence of underweight adolescence is alarmingly high and serves as evidence for possible educational programs and policy driven interventions. 


\section{List of abbreviations:}

KSA: Kingdom of Saudi Arabia

WHO: World Health Organization

BMI: Body Mass Index

CDC: Centers for Disease Control

SES: Socioeconomic status

MENA: Middle East and North Africa 


\section{References}

1. Unicef.org. https://www.unicef.org/sowc2011/pdfs/SOWC-2011-Main-Report EN 02092011.pdf Published 2019. Accessed January 9, 2019.

2. Mokdad A, Jaber S, Aziz M et al. The state of health in the Arab world, 1990-2010: an analysis of the burden of diseases, injuries, and risk factors. The Lancet. 2014;383(9914):309-320. doi:10.1016/s01406736(13)62189-3

3. Catalano R, Fagan A, Gavin L et al. Worldwide application of prevention science in adolescent health. The Lancet. 2012;379(9826):1653-1664. doi:10.1016/s0140-6736(12)60238-4

4. Unicef.org. https://www.unicef.org/adolescence/files/SOWC 2011 Main Report EN 02092011.pdf Published 2019. Accessed January 9, 2019.

5. Population Estimates. General Authority for Statistics. https://www.stats.gov.sa/en/43 Published 2019. Accessed January 9, 2019.

6. AlBuhairan F, Tamim H, Al Dubayee M et al. Time for an Adolescent Health Surveillance System in Saudi Arabia: Findings From "Jeeluna". Journal of Adolescent Health. 2015;57(3):263-269. doi:10.1016/j.jadohealth.2015.06.009

7. Kosaka S, Umezaki M. A systematic review of the prevalence and predictors of the double burden of malnutrition within households. British Journal of Nutrition. 2017;117(08):1118-1127. doi:10.1017/s0007114517000812

8. Han Z, Mulla S, Beyene J, Liao G, McDonald S. Maternal underweight and the risk of preterm birth and low birth weight: a systematic review and meta-analyses. Int J Epidemiol. 2010;40(1):65-101. doi:10.1093/ije/dyq195

9. McDonald C, Olofin I, Flaxman S et al. The effect of multiple anthropometric deficits on child mortality: meta-analysis of individual data in 10 prospective studies from developing countries. Am J Clin Nutr. 2013;97(4):896-901. doi:10.3945/ajcn.112.047639

10. Vasunilashorn S, Martinson M. Weight Status in Adolescence Is Associated With Later Life Functional Limitations. J Aging Health. 2013;25(5):758-775. doi:10.1177/0898264313491426 
11. Abarca-Gómez L, Abdeen Z, Hamid Z et al. Worldwide trends in body-mass index, underweight, overweight, and obesity from 1975 to 2016: a pooled analysis of 2416 population-based measurement studies in 128.9 million children, adolescents, and adults. The Lancet. 2017;390(10113):2627-2642. doi:10.1016/s0140-6736(17)32129-3

12. Al Muammar M, El Shafie M, Feroze A. Association between dietary habits and body mass index of adolescent females in intermediate schools in Riyadh, Saudi Arabia. Eastern Mediterranean Health Journal. 2014;20(1):39-45. doi:10.26719/2014.20.1.39

13. Growth Charts - Homepage. Cdc.gov. http://www.cdc.gov/growthcharts Published 2019. Accessed January 9, 2019.

14. Khalaf A, Westergren A, Berggren V, Ekblom Ö, Al-Hazzaa H. Prevalence and association of female weight status and dietary habits with sociodemographic factors: a cross-sectional study in Saudi Arabia. Public Health Nutr. 2014;18(05):784-796. doi:10.1017/s1368980014001797

15. Bener A. Prevalence of Obesity, Overweight, and Underweight in Qatari Adolescents. Food Nutr Bull. 2006;27(1):39-45. doi:10.1177/156482650602700106

16. Manyanga T, El-Sayed H, Doku D, Randall J. The prevalence of underweight, overweight, obesity and associated risk factors among school-going adolescents in seven African countries. BMC Public Health. 2014;14(1). doi:10.1186/1471-2458-14-887

17. Jildeh C, Papandreou C, Mourad T et al. Assessing the Nutritional Status of Palestinian Adolescents from East Jerusalem: a School-based Study 2002-03. J Trop Pediatr. 2010;57(1):51-58. doi:10.1093/tropej/fmq042

18. Yang L, Bovet $P, M a C$, Zhao M, Liang Y, Xi B. Prevalence of underweight and overweight among young adolescents aged 12-15 years in 58 low-income and middle-income countries. Pediatr Obes. 2018. doi:10.1111/ijpo.12468

19. Candler T, Costa S, Heys M, Costello A, Viner R. Prevalence of Thinness in Adolescent Girls in Low- and Middle-Income Countries and Associations with Wealth, Food Security, and Inequality. Journal of Adolescent Health. 2017;60(4):447-454.e1. doi:10.1016/j.jadohealth.2016.11.003 
20. Ferrar K, Olds T. Thin adolescents: Who are they? What do they do? Socio-demographic and use-oftime characteristics. Prev Med. 2010;51(3-4):253-258. doi:10.1016/j.ypmed.2010.07.001

21. Marques-Vidal P, Ferreira R, Oliveira J, Paccaud F. Is thinness more prevalent than obesity in Portuguese adolescents?. Clinical Nutrition. 2008;27(4):531-536. doi:10.1016/j.clnu.2008.04.002

22. Wang Y, Monteiro C, Popkin B. Trends of obesity and underweight in older children and adolescents in the United States, Brazil, China, and Russia. Am J Clin Nutr. 2002;75(6):971-977. doi:10.1093/ajcn/75.6.971

23. Coly A, Milet J, Diallo A et al. Preschool Stunting, Adolescent Migration, Catch-Up Growth, and Adult Height in Young Senegalese Men and Women of Rural Origin.J Nutr. 2006;136(9):2412-2420. doi:10.1093/jn/136.9.2412

24. Shi Z, Lien N, Nirmal Kumar B, Dalen I, Holmboe-Ottesen G. The sociodemographic correlates of nutritional status of school adolescents in Jiangsu Province, China. Journal of Adolescent Health. 2005;37(4):313-322. doi:10.1016/j.jadohealth.2004.10.013

25. Lattimore $\mathrm{P}$, Halford J. Adolescence and the diet-dieting disparity: Healthy food choice or risky health behaviour? Br J Health Psychol. 2003;8(4):451-463. doi:10.1348/135910703770238301

26. Al Sabbah H, Vereecken C, Abdeen Z et al. Weight control behaviors among overweight, normal weight and underweight adolescents in Palestine: Findings from the national study of Palestinian schoolchildren (HBSC-WBG2004). International Journal of Eating Disorders. 2009:NA-NA. doi:10.1002/eat.20698

27. Lee J, Lee Y. The association of body image distortion with weight control behaviors, diet behaviors, physical activity, sadness, and suicidal ideation among Korean high school students: a cross-sectional study. BMC Public Health. 2015;16(1). doi:10.1186/s12889-016-2703-z

28. MacCallum F, Widdows H. Altered Images: Understanding the Influence of Unrealistic Images and Beauty Aspirations. Health Care Analysis. 2016;26(3):235-245. doi:10.1007/s10728-016-0327-1

29. Pawlińska-Chmara R, Wronka I, Suliga E, Broczek K. Socio-economic factors and prevalence of underweight and overweight among female students in Poland. HOMO. 2007;58(4):309-318. doi:10.1016/j.jchb.2006.10.002 
30. Larson N, Wall M, Story M, Neumark-Sztainer D. Home/family, peer, school, and neighborhood correlates of obesity in adolescents. Obesity. 2013:n/a-n/a. doi:10.1002/oby.20360

31. Martínez-Vizcaíno V, Solera-Martínez M, Cavero-Redondo I et al. Association between parental socioeconomic status with underweight and obesity in children from two Spanish birth cohorts: a changing relationship. BMC Public Health. 2015;15(1). doi:10.1186/s12889-015-2569-5

32. Wronka I. Socioeconomic status, body mass index and prevalence of underweight and overweight among Polish girls aged 7-18: A longitudinal study.J Biosoc Sci. 2013;46(04):449-461. doi:10.1017/s002193201300031x

33. Ludwig J, Sanbonmatsu L, Gennetian L et al. Neighborhoods, Obesity, and Diabetes - A Randomized Social Experiment. New England Journal of Medicine. 2011;365(16):1509-1519. doi:10.1056/nejmsa1103216

34. Gurzkowska B, Kułaga Z, Grajda A, Góźdź M, Wojtyło M, Litwin M. The relationship between selected socioeconomic factors and thinness among Polish school-aged children and adolescents. Eur J Pediatr. 2017;176(6):797-806. doi:10.1007/s00431-017-2912-1

35. Sobal J, Stunkard A. Socioeconomic status and obesity: A review of the literature. Psychol Bull. 1989;105(2):260-275. doi:10.1037//0033-2909.105.2.260

36. Hanson M, Chen E. Socioeconomic Status and Health Behaviors in Adolescence: A Review of the Literature. J Behav Med. 2007;30(3):263-285. doi:10.1007/s10865-007-9098-3

37. Monteiro C, Conde W, Popkin B. Part I. What has happened in terms of some of the unique elements of shift in diet, activity, obesity, and other measures of morbidity and mortality within different regions of the world?. Public Health Nutr. 2002;5(1a). doi:10.1079/phn2001281

38. Kann L, Kinchen S, Williams B et al. Youth Risk Behavior Surveillance - United States, 1999. Journal of School Health. 2000;70(7):271-285. doi:10.1111/j.1746-1561.2000.tb07252.x

39. Global school-based student health survey (GSHS). World Health Organization. http://www.who.int/chp/gshs/en/ Published 2019. Accessed January 9, 2019. 
40. Doak C, Adair L, Bentley M, Monteiro C, Popkin B. The dual burden household and the nutrition transition paradox. Int J Obes. 2004;29(1):129-136. doi:10.1038/sj.ijo.0802824 


\section{Chapter 5 \\ Predictors of adolescents' mental health problems in Saudi Arabia}

This chapter has been published with the following citation:

Abou Abbas and AlBuhairan. Predictors of adolescents' mental health problems in Saudi Arabia: findings from the Jeeluna national study. Child Adolesc Psychiatry Ment Health 2017;11:52 DOI:10.1186/s13034-017-0188-x 


\begin{abstract}
Background: Depression and anxiety among adolescents require further attention as they have profound harmful implications on several aspects of adolescents' wellbeing and can be associated with life threatening risk behaviors such as suicide.
\end{abstract}

Objective: To examine the prevalence and underlying risk factors for symptoms suggestive of depression and anxiety among adolescents in Saudi Arabia

Methods: Data from Jeeluna ${ }^{\circledR}$ national survey was used. A cross-sectional, multi-stage, stratified, cluster random sampling technique was applied among a sample of students aged 10-19 years attending intermediate and secondary schools in Saudi Arabia. A self-administered questionnaire assessing several domains, including depression and anxiety, was used to collect data. Logistic regression models were fitted to determine the different factors associated with mental health.

Results: A sample of 12,121 students was included in this study. Symptoms of depression and anxiety were significantly more prevalent among females and older adolescents $(p<0.0001)$. The results showed that poor relationship with parents, negative body image, and chronic illness to be significantly associated with symptoms of depression and anxiety.

Conclusion: Mental health problems among adolescents in Saudi Arabia are prevalent and deserve special attention. Adopting effective strategies, including regular screening and intervention programs are highly needed to better address, detect, and control early signs of these problems.

Keywords: Adolescents, school, mental health, depression, anxiety, Saudi Arabia 


\section{Introduction}

Adolescents aged $10-24$ years comprise nearly $25 \%$ ( 1.8 billion) of the world's 7.3 billion population. Out of the 1.8 billion, almost 9 out of 10 live in less developed countries [1]. In the Arab region, the majority of the population is below the age of 25 years [2]. Likewise, in the Kingdom of Saudi Arabia (KSA), $20 \%$ out of a 28 million population is between the ages $10-19$ years [3].

Although it is believed that adolescence is a healthy time in an individual's life, around $15 \%$ of the global burden of disease accounted for by disability adjusted life years (DALYs) is in the 10-24 years old age group [4]. During adolescence, several biological, cognitive, physiological, psychological, emotional and social changes emerge, and certain risky behaviors arise and are linked to adolescents' health [4]. During this period, some mental health issues are also more likely to develop [5]. While mental disorders -in generalaccount for $45 \%$ of the burden of disease in 10-24 year olds [6], depression and anxiety are considered to be among its leading causes[7].

Mental health is an integral part of individuals' wellbeing that is influenced not only by individual attributes or behaviors, but also by the overall social and economic circumstances and environmental factors [5]. A study by Collishaw and colleagues (2010) [8] showed a significant increase in the proportion of adolescents reporting frequent feelings of depression and anxiety where the figures had doubled between the 1980s and the 2000s.

Research on mental health problems including depression and anxiety among adolescents has found it to be associated with poor familial bonds [9], smoking [10][11], substance use [12][13], bullying and physical violence [14], suicide ideation and behavior [15-17], and other factors that have direct impact on adolescents' health and wellbeing. Moreover, mental health problems during adolescence tend to persist into adulthood. Adults who suffer from depression during adolescence are at higher risk of developing major depressive disorders [18].

Although a major public health issue, adolescents' mental health has not been granted much attention within the Arab region [19]. Gender disparities in mental health conditions are wider in the region and the burden of mental health disease is expected to continue to grow with the recent increases in regional crises over the years [19-21]. Results of the analysis of the Global School-based Student Health Survey (GSHS) that was conducted among 104,614 students from 19 low and middle income countries including 
Arab countries such as Jordan, United Arab Emirates, Lebanon and Morocco showed that around 35\% of students reported having symptoms of depression [22]. In the KSA, individual studies have reported on the prevalence and risk factors of depression and/or anxiety [23-26] in subpopulations. The only nationally representative study addressing the prevalence of depression and anxiety among adolescents in the KSA is the Jeeluna ${ }^{\circledR}$ study, in which symptoms suggestive of depression and anxiety were found to be present among $14 \%$ and $6.7 \%$ of adolescents respectively [27]. With this current study, we aim to build on previous reports and identify the underlying correlates of symptoms of depression and anxiety among adolescents in the KSA, so as to better inform policy makers, plan suitable interventions, and find sustainable solutions.

\section{Methods}

Data for this study was taken from the 2012 Jeeluna ${ }^{\circledR}$ national cross-sectional study. Jeeluna ${ }^{\circledR}$ is the first national study to assess the health status and health needs of adolescents in the KSA. It was conducted during the 2011-2012 academic year using student population proportionate, stratified, multistage, cluster sampling method. The sampling occurred at the district level and the sample size per district was proportionate to the student population within that district. Male and female students aged 10 to 19 years and attending intermediate and secondary schools in public and private schools throughout the 13 regions of Saudi Arabia were invited to participate in the study, yielding a school response rate of $92.5 \%$ and a student response rate of $32 \%$. Evening schools and schools serving special needs students were excluded. Data was weighted to ensure that it was nationally representative. The detailed methodology of Jeeluna ${ }^{\circledR}$ study was published earlier $[27,28]$.

Mental health domain is one of many other domains that were addressed in the Jeeluna ${ }^{\circledR}$ questionnaire. The questions were self-reported, and most of them were guided by the Global School-based Student Health Survey (GSHS) as well as the Youth Risk Behavior Surveillance System (YRBSS). For the current study, different variables including socio-demographics, chronic illness, relationship with parents, and others were extracted and analyzed. Symptoms of depression was measured with the question "during the past 12 months, how often did you feel excessively sad or hopeless daily for 2 weeks or more to the extent that you stopped doing your usual activities?", whereas symptoms of anxiety was measured with the question "during the past 12 months, how often have you felt so worried about something to the extent that you stopped doing your usual activities?". These questions have been used in the past in adolescent health surveys [29] and are guided by the Diagnostic and Statistical Manual (DSM) of Mental 
Disorders criteria for identifying underlying mental health disease. Answers were categorized as most of the time/always; or never/rarely/sometimes. Those who answered always or most of the time to those questions were considered as having symptoms of depression/anxiety. Because response to these questions alone is not diagnostic of depression or anxiety respectively, we refer to responses to these questions as symptoms of depression or anxiety throughout the paper.

Data were weighted to account for the probability of selection of students within each school, hence obtaining unbiased results. Statistical analysis was performed using STATA 14. P-values less than 0.05 were considered to be statistically significant. Descriptive statistics were obtained for the whole sample and results were reported in terms of percentages. Bivariate analysis was then performed to test for all possible associations between the dependent and independent variable. Adjusted and unadjusted odds ratios were then generated and presented.

Ethical approval for the study was obtained from the Institutional Review Board (IRB) at King Abdullah International Medical Research Center (KAIMRC), as well as the Ministry of Education. Consent and assent forms were obtained from parents and students respectively, prior to participation in the study.

\section{Results}

\section{Sample characteristics}

Table 1 shows participants' demographics. For the purpose of this paper, a secondary data analysis was conducted and a total number of 12,121 observations were considered. Fifty three percent were males, and $53 \%$ were above 15 years of age. The mean age was $15.7 \pm 3.4$ years. The majority of participants were Saudis (86\%). Most of the students (53\%) were in intermediate schools and (46\%) were in secondary schools. The distribution of the students differed across the four regions in proportion to the student population per region. As for the relationship with father and mother, the majority reported having a good relationship with $84 \%$ and $93 \%$ respectively. Overall, $14 \%$ reported having symptoms of depression and $6 \%$ reported having symptoms of anxiety during the past 12 months prior the survey. When it comes to symptoms of depression, more females (62\%) and older adolescents ( $>15$ years of age) (59\%) reported having symptoms of depression. The same thing applies to symptoms of anxiety that was found to be more common among females and older adolescents ( $63 \%$ and $66 \%$ respectively) (all $p$ values $<0.001)$. Symptoms of depression and anxiety were more common among Saudis vs non-Saudis. On the other hand, region showed no significant association with symptoms of depression or anxiety. 


\section{Association of symptoms of depression and anxiety with the different variables}

At the bivariate level, our results revealed that age, gender, relationship with father and mother, chronic illness, body image, and exercise to be significantly associated with symptoms of depression and anxiety (all $p$ values $<0.005$ ). Nationality was not significantly associated with symptoms of depression, yet it was significantly associated with symptoms of anxiety $(p<0.05)$ (Table 2$)$.

\section{Depression}

At the multivariate level, the associations revealed that females and older adolescents are more likely to suffer from symptoms of depression with (OR: 1.94; 95\% Cl: $1.69-2.23$ ) and (OR: 1.18; $95 \% \mathrm{Cl}: 1.00-$ 1.40) respectively. Moreover, adolescents who had "neither good nor bad" and "poor" relationship with father had higher odds of having symptoms of depression as compared to those who had a good relationship with father (OR=1.77; 95\% Cl: $1.44-2.16)$ and (OR=3.44; 95\% Cl: $2.65-4.47$ ) respectively. The same trend continues when it comes to the relationship with mother, the poorer the relationship was, the higher the odds of having symptoms of depression, as compared to those who had a good relationship with mother. Adolescents who believed they needed to lose weight were more likely to have symptoms of depression as compared to those who were happy with their bodies. Chronic illness was also positively associated with symptoms of depression. Adolescents who self- reported having chronic illness had more than twice the odds of reporting symptoms of depression (OR: $2.31 ; 95 \% \mathrm{Cl}: 1.86-2.87$ ).

\section{$\underline{\text { Anxiety }}$}

In terms of statistical significance, results for the correlates of anxiety symptoms did not differ much from those of the depression symptoms. In particular, females (OR: 1.88; $95 \% \mathrm{Cl}: 1.56-2.28$ ) and older adolescents (OR: $1.56 ; 95 \% \mathrm{Cl}: 1.25-1.94)$ were at higher odds of having symptoms of anxiety as compared to males and younger adolescents. Adolescents who had a poor relationship with father or mother had respectively 4.3 and 2.64 times the risk of having symptoms of anxiety as compared to those who had a good relationship with father or mother. As for nationality, our results showed that non-Saudis had higher odds of anxiety symptoms as compared to Saudis (OR: $1.395 \% \mathrm{Cl}: 1.04-1.63$ ). Symptoms of anxiety was also significantly associated with chronic illness, with adolescents with chronic illness having twice the risk of having symptoms of anxiety as compared to those who were generally healthy. On the other hand, body image, exercise and region showed no statistical significance at the multivariate level. 
Table 1: Sample characteristics

\begin{tabular}{|c|c|}
\hline Variable & $\begin{array}{r}\mathrm{N}=12,121 \\
\%(95 \% \mathrm{Cl})\end{array}$ \\
\hline \multicolumn{2}{|l|}{ Age (years) } \\
\hline$\leq 15$ & $46.83(41.34-52.39)$ \\
\hline$>15$ & $53.17(47.61-58.66)$ \\
\hline \multicolumn{2}{|l|}{ Gender } \\
\hline Male & $52.97(43.82-61.93)$ \\
\hline Female & $47.03(38.07-56.18)$ \\
\hline \multicolumn{2}{|l|}{ Nationality } \\
\hline Saudi & $86.33(83.09-89.03)$ \\
\hline Non-Saudi & $13.67(10.97-16.91)$ \\
\hline \multicolumn{2}{|l|}{ Grade } \\
\hline Intermediate & $53.44(46.68-60.07)$ \\
\hline Secondary & $46.56(39.93-53.32)$ \\
\hline \multicolumn{2}{|l|}{ Region } \\
\hline Central & $25.90(22.47-29.66)$ \\
\hline Western & $32.36(27.85-37.22)$ \\
\hline Eastern & $14(10.33-18.70)$ \\
\hline Northern & $10.42(6.84-15.58)$ \\
\hline Southern & $17.32(13.70-21.66)$ \\
\hline \multicolumn{2}{|l|}{ Chronic illness } \\
\hline No & $91.61(91.0-92.18)$ \\
\hline Yes & $8.39(7.82-9.0)$ \\
\hline \multicolumn{2}{|l|}{ Relationship with mother } \\
\hline Good & $93.12(92.37-93.79)$ \\
\hline Neither good nor bad & $5.26(4.69-5.89)$ \\
\hline Poor & $1.63(1.37-1.93)$ \\
\hline Relationship with father & $84.75(83.58-85.85)$ \\
\hline Good & $11.2(10.33-12.12)$ \\
\hline Neither good nor bad & $4.05(3.56-4.62)$ \\
\hline \multicolumn{2}{|l|}{ Poor } \\
\hline \multicolumn{2}{|l|}{ Body image } \\
\hline Happy with my body & $39.65(38.18-41.14)$ \\
\hline Need to lose weight & $45.04(43.31-46.78)$ \\
\hline Need to gain weight & $15.31(14.44-16.23)$ \\
\hline \multicolumn{2}{|l|}{ Exercise during last week } \\
\hline None & $44.28(41.27-47.34)$ \\
\hline$\leq 3$ times & $33.93(32.39-35.50)$ \\
\hline$>3$ times & $21.79(19.84-23.86)$ \\
\hline \multicolumn{2}{|l|}{ Symptoms of Depression } \\
\hline No & $85.75(84.42-86.98)$ \\
\hline Yes & $14.25(13.02-13.02)$ \\
\hline \multicolumn{2}{|l|}{ Symptoms of Anxiety } \\
\hline No & $93.34(92.51-94.09)$ \\
\hline Yes & $6.66(5.91-7.49)$ \\
\hline
\end{tabular}


Table 2: Adjusted and Un-adjusted Odds Ratios (OR) for Depression and Anxiety

\begin{tabular}{|c|c|c|c|c|c|c|c|c|}
\hline & \multicolumn{4}{|c|}{ Symptoms of Depression } & \multicolumn{4}{|c|}{ Symptoms of Anxiety } \\
\hline & U-OR & $95 \% \mathrm{Cl}$ & A-OR & $95 \% \mathrm{Cl}$ & U-OR & $95 \% \mathrm{Cl}$ & A-OR & $95 \% \mathrm{Cl}$ \\
\hline \multicolumn{9}{|l|}{ Age (years) } \\
\hline$\leq 15$ & 1 & & 1 & & 1 & & 1 & \\
\hline$>15$ & $1.35^{*}$ & $1.11-1.65$ & $1.18^{*}$ & $1.00-1.40$ & $1.75^{*}$ & $1.39-2.21$ & $1.56^{*}$ & $1.25-1.94$ \\
\hline \multicolumn{9}{|l|}{ Gender } \\
\hline Male & 1 & & 1 & & 1 & & 1 & \\
\hline Female & $2.08^{*}$ & $1.81-2.39$ & $1.94 *$ & $1.69-2.23$ & $2.02^{*}$ & $1.65-2.47$ & $1.88^{*}$ & $1.56-2.28$ \\
\hline \multicolumn{9}{|l|}{ Nationality } \\
\hline Saudi & 1 & & 1 & & 1 & & 1 & \\
\hline Non-Saudi & 1.07 & $0.90-1.29$ & 1.11 & $0.93-1.32$ & $1.26^{*}$ & $1.00-1.60$ & $1.30 *$ & $1.04-1.63$ \\
\hline \multicolumn{9}{|l|}{ Region } \\
\hline Central & 1 & & 1 & & 1 & & 1 & \\
\hline Western & 0.79 & $0.60-1.0$ & 0.77 & $0.64-0.93$ & 0.82 & $0.57-1.16$ & 0.82 & $0.62-1.08$ \\
\hline Eastern & 0.80 & $0.57-1.11$ & 0.75 & $0.59-0.93$ & 0.90 & $0.61-1.31$ & 0.88 & $0.65-1.20$ \\
\hline Northern & 0.79 & $0.52-1.21$ & 0.87 & $0.63-1.21$ & 0.58 & $0.56-1.29$ & 0.94 & $0.66-1.35$ \\
\hline Southern & 0.82 & $0.60-1.11$ & 0.82 & $0.68-1.00$ & 0.89 & $0.59-1.33$ & 0.93 & $0.66-1.30$ \\
\hline \multicolumn{9}{|l|}{ Chronic illness } \\
\hline No & 1 & & 1 & & 1 & & 1 & \\
\hline Yes & $2.14^{*}$ & $1.75-2.61$ & $2.31 *$ & $1.86-2.87$ & $2.74^{*}$ & $2.16-3.47$ & $2.79 *$ & $2.15-3.62$ \\
\hline \multicolumn{9}{|l|}{ Relationship with father } \\
\hline Good & 1 & & 1 & & 1 & & 1 & \\
\hline Neither good nor poor & $2.13^{*}$ & $1.77-2.56$ & $1.77 *$ & $1.44-2.16$ & $2.07 *$ & $1.62-2.64$ & $1.74 *$ & $1.34-2.26$ \\
\hline Poor & $4.58^{*}$ & $3.65-5.72$ & $3.44^{*}$ & $2.65-4.47$ & $5.99 *$ & $4.51-7.95$ & $4.30^{*}$ & $3.22-5.74$ \\
\hline \multicolumn{9}{|c|}{ Relationship with mother } \\
\hline Good & 1 & & 1 & & 1 & & 1 & \\
\hline Neither good nor poor & $2.30^{*}$ & $1.86-2.85$ & $1.47^{*}$ & $1.13-1.92$ & $2.36^{*}$ & $1.76-3.15$ & $1.47^{*}$ & $1.05-2.04$ \\
\hline Poor & $4.91^{*}$ & $3.57-6.77$ & $2.72^{*}$ & $1.85-4.02$ & $6.01^{*}$ & $3.95-9.17$ & $2.64^{*}$ & $1.60-4.36$ \\
\hline \multicolumn{9}{|l|}{ Body Image } \\
\hline Happy with my body & 1 & & 1 & & 1 & & 1 & \\
\hline Need to lose weight & $1.48^{*}$ & $1.32-1.66$ & $1.38^{*}$ & $1.22-1.56$ & $1.45^{*}$ & $1.20-1.76$ & 1.29 & $1.06-1.57$ \\
\hline Need to gain weight & $1.33^{*}$ & $1.13-1.58$ & $1.23 *$ & $1.02-1.49$ & $1.34^{*}$ & $1.07-1.69$ & 1.13 & $0.89-1.44$ \\
\hline \multicolumn{9}{|l|}{ Exercise during last week } \\
\hline None & 1 & & 1 & & 1 & & 1 & \\
\hline$\leq 3$ times & $0.63^{*}$ & $0.57-0.71$ & 0.78 & $0.70-0.88$ & $0.69 *$ & $0.58-0.83$ & 0.88 & $0.72-1.08$ \\
\hline$>3$ times & $0.68^{*}$ & $0.57-0.80$ & 0.93 & $0.77-1.12$ & $0.70^{*}$ & $0.56-0.88$ & 0.94 & $0.72-1.22$ \\
\hline
\end{tabular}




\section{Discussion}

The prevalence rate of depression (14\%) and anxiety (6\%) symptoms previously reported by the Jeeluna ${ }^{\circledR}$ [27] fall within the wide range reported by different studies on depression and anxiety in the region [25, $30,31]$ which made us realize the importance highlighting this issue and further investigating its underlying risk factors.

Our findings of symptoms of depression and anxiety being more prevalent among females and older adolescents, was found to be consistent with others' findings [32-34]. This was also supported by results reported by the analysis of the GSHS data that was conducted across 19 low and middle income countries including Morocco, Lebanon, Jordan and United Arab Emirates [22] The higher prevalence rates among females can be attributed to different factors including genetics, biological, psychological or behavioral factors [35].

Poor family relationships or conflictual interactions within a family environment, as well as the lack of affection and support are correlated with depressive symptoms [36], as it is with other risk behaviors, such as bullying and violence [14]. This was also shown in our study, where poor relationship with mother or father were found to be significant risk factors for symptoms of depression and anxiety among adolescents in the KSA. The poorer the relationship with parents was, the higher the odds of having symptoms of depression and anxiety. Those results are aligned with the literature on this issue [26, 36, 37]. A study conducted among female adolescents in Riyadh has shown depression to be more prevalent among those who had bad relationship with their family members [26]. Other studies have also documented the importance of family roles in protecting adolescents from risky behaviors. For example, a national study about suicide ideation among adolescents in Lebanon showed that parental understanding was a protective factor against suicide ideation [15]. A regional study about adolescent and family connectedness among eight Arab societies, including Saudi Arabia, found that Arab adolescents, despite the social and cultural disparities among these societies, scored high on the connectedness to their families with females showing more connectedness than males [38].These findings highlight the opportunity to capitalize on family relationships and connectedness and work towards focusing on building positive, strong and effective parenting and communication skills through launching awareness and educational campaigns or programs that target parents. Such programs may aim at enhancing parenting matters through equipping parents with the necessary knowledge about adolescents' physical, emotional and mental development. After all, knowledge is a key variable in this equation; if parents are 
made aware of the protective impact of positive relationship with children, and their significant role in shaping their children's well-being, they might become more engaged and more willing to take a step forward and make a difference.

Similar to other reports from different parts of the world [39-41], body image has been found to be a significant predictor of depression and anxiety among adolescents; those who thought they need to gain weight or lose weight were more likely to be depressed. Similarly, a longitudinal study among 2139 U.S. adolescent boys conducted between 1996 and 2009 found that distorted body image to be a risk factor for elevated depressive symptoms and tend to persist to adulthood [39]. This result is not surprising in a time where people have become deeply immersed in social media and so influenced by the 'perfect-body' image that may eventually affect their satisfaction with their bodies.

As for adolescents with chronic illnesses, our findings showed it to be significantly associated with mental health; similarly, a huge body of literature have documented the serious effects that chronic illness has on adolescents' mental health [42, 43]. In their meta-analysis, Pinquart and colleagues [44] had shown that children and adolescents with chronic physical illnesses had higher levels of depressive symptoms as compared to their healthy peers. This was also documented in a study among a subpopulation of high school students in KSA, in which they found chronic illness to be a significant risk factor for depression [24].

Given the cross-sectional nature of this study, the causal inference between the dependent and independent variables cannot be established; however, our study reveals several underlying risk factors for both depression and anxiety symptoms among adolescents in the KSA and sets the ground for more in-depth longitudinal studies that can better reflect on this situation. On the other hand, the strength of this study resides in the generalizability of the results being the first study to address mental health and associated risk factors among a nationally representative sample of adolescents in Saudi Arabia, which in turn sets a baseline for research on adolescents' mental health in the country. Adolescents' mental health is an important issue that is, unfortunately, being widely underestimated. A huge body of research unveils the deleterious effects that depression during adolescence has on their wellbeing, not only as adolescents but as future adults too. This can be avoided through early detection of symptoms when present and effective school and community-based interventions that are tailored to the Saudi cultural context where, as in many other Middles Eastern countries, mental health problems are still stigmatized [45]. Accordingly, 
mental health interventions in the Middle East should take into account the fundamental role of families, adolescent-family connectedness and stigma associated with mental health $[38,46]$.

Ministry of Health and School Health Programs should work hand in hand in planning public awareness campaigns and training programs that target adolescents, parents and teachers. Parents should be well educated about the importance of positive communications with adolescents, and this should not be difficult for an Arab country like Saudi Arabia, where family ties are highly cherished, and families are considered to be the first line of support and protection.

Annual screening for depression, as recommended by the United States Preventive Services Task Force [47] should be implemented in schools. Effective professional counseling services should be implemented at all schools to help support students better cope with their problems, be it social, emotional or behavioral. Attention to capacity building in adolescent health, including adolescent mental health, is much needed [48] and will provide healthcare providers with the necessary knowledge, awareness, and skills for addressing adolescents' health needs. Though some attention to this has begun with the first Adolescent Health and Medicine Capacity Building Workshop in the Region in 2016 (AlBuhairan, unpublished), much more is needed. Lastly, the civil society should also be held accountable for planning prevention programs that promote positive mental health and creating a supporting environment so as to overcome shame and stigma linked to mental health.

\section{Conclusion}

Mental health issues are a major public health concern that have serious implications on adolescents' wellbeing. This study reveals the underlying risk factors of symptoms of depression and anxiety among adolescents in Saudi Arabia and highlights the importance of taking the necessary actions and planning suitable interventions that can lessen its harmful impact if not preventing it. Further in-depth research studies that assess adolescents' mental health using diagnostic tools for depression and anxiety are needed. Also, parents-adolescents research in Saudi Arabia is missing and requires closer investigation. 
Chapter 5

\section{Abbreviations}

$\mathrm{Cl} \quad$ Confidence interval

KSA: Kingdom of Saudi Arabia

OR: Odds ratio

PV: Physical violence

GSHS: Global School-based Student Health Survey 


\section{References}

1. United Nations Population Funds. The power of 1.8 billion adolescents, youth and the transformation of the future. United Nations Population Funds; 2014. http://www.unfpa.org/sites/default/files/pubpdf/ENSWOP14-Report_FINAL-web.pdf. Accessed 23 Feb 2017.

2. UNPY. Regional overview: youth in the Arab region. New York: United Nations Economic and Social Commission for Western Asia and the United Nations Programme on Youth (UNPY).

3. US Census Bureau. International Programs. International Data Base. 2016.

Accessed 23 Feb 2017.

4. Sawyer SM, Afifi RA, Bearinger LH, Blakemore S-J, Dick B, Ezeh AC, et al. Adolescence: a foundation for future health. Lancet.2012;379:1630-40.

5. World Health Organization. Risks to mental health: an overview of vulnerabilities and risk factors. Geneva: WHO; 2012.

6. Gore FM, Bloem PJ, Patton GC, Ferguson J, Joseph V, Coffey C, et al. Global burden of disease in young people aged 10-24 years: a systematic analysis. Lancet. 2011;377:2093-102.

7. Patel V. Why adolescent depression is a global health priority and what we should do about it. J Adolesc Health. 2013;52:511.

8. Collishaw S, Maughan B, Natarajan L, Pickles A. Trends in adolescent emotional problems in England: a comparison of two national cohorts twenty years apart. J Child Psychol Psychiatry. 2010;51:885-94.

9. Séguin M, Manion I, Cloutier P, Mcevoy L, et al. Adolescent depression, family psychopathology and parent/child relations: a case control study. Can Child Adolesc Psychiatr Rev. 2003;12:2-9.

10. Fergusson DM, Goodwin RD, Horwood L. Major depression and cigarette smoking: results of a 21year longitudinal study. Psychol Med. 2003;33:1357-67. 
11. Johnson JG, Cohen P, Pine DS, Klein DF, Kasen S, Brook JS. Association between cigarette smoking and anxiety disorders during adolescence and early adulthood. JAMA. 2000;284:2348-51.

12. Skogen JC, Sivertsen B, Lundervold AJ, Stormark KM, Jakobsen R, Hysing M. Alcohol and drug use among adolescents: and the co-occurrence of mental health problems. Ung@hordaland, a populationbased study. BMJ Open. 2014;4:e005357.

13. Wu P, Goodwin RD, Fuller C, Liu X, Comer JS, Cohen P, et al. The relationship between anxiety disorders and substance use among adolescents in the community: specificity and gender differences. $J$ Youth Adolesc. 2010;39:177-88.

14. AlBuhairan F, Abbas OA, El Sayed D, Badri M, Alshahri S, de Vries N. The relationship of bullying and physical violence to mental health and academic performance: a cross-sectional study among adolescents in Saudi Arabia. Int J Pediatr Adolesc Med. 2017;4:61-5.

15. Mahfoud ZR, Afifi RA, Haddad PH, Dejong J. Prevalence and determinants of suicide ideation among Lebanese adolescents: results of the GSHS Lebanon 2005. J Adolesc. 2011;34:379-84.

16. Fotti SA, Katz LY, Afifi TO, Cox BJ. The associations between peer and parental relationships and suicidal behaviours in early adolescents. Can J Psychiatry. 2006;51:698-703.

17. Thompson EA, Mazza JJ, Herting JR, Randell BP, Eggert LL. The mediating roles of anxiety, depression, and hopelessness on adolescent suicidal behaviors. Suicide Life Threat Behav. 2005;35:14-34.

18. Pine DS, Cohen P, Gurley D, Brook J, Ma Y. The risk for early-adulthood anxiety and depressive disorders in adolescents with anxiety and depressive disorders. Arch Gen Psychiatry. 1998;55:56-64.

19. Obermeyer CM. Adolescents in Arab countries: health statistics and social context. DIFI Fam Res Proc. $2015 ; 1$.

20. AlBuhairan FS. Adolescent and young adult health in the Arab region: where we are and what we must do. J Adolesc Health. 2015;57:249-51. doi:10.1016/j.jadohealth.2015.06.010. 
21. World Health Organization. Health for the world's adolescents: a second chance in the second decade. Geneva: World Health Organization; 2014.

22. Fleming LC, Jacobsen KH. Bullying among middle-school students in low and middle income countries. Health Promot Int. 2010;25:73-84. doi:10.1093/heapro/dap046.

23. Al Gelban K. Prevalence of psychological symptoms in Saudi secondary school girls in Abha, Saudi Arabia. Ann Saudi Med. 2009;29:275.

24. Abdel-Fattah MM, Asal ARA. Prevalence, symptomatology, and risk factors for depression among high school students in Saudi Arabia. Neurosciences. 2007;12:8-16.

25. Mahfouz AA, Al-Gelban KS, Al Amri H, Khan MY, Abdelmoneim I, Daffalla AA, et al. Adolescents' mental health in Abha city, southwestern Saudi Arabia. Int J Psychiatry Med. 2009;39:169-77.

26. Raheel H. Depression and associated factors among adolescent females in Riyadh, Kingdom of Saudi Arabia, a cross-sectional study. Int J Prev Med. 2015;6:90.

27. AlBuhairan FS, Tamim H, Al Dubayee M, AlDhukair S, Al Shehri S, Tamimi W, et al. Time for an adolescent health surveillance system in Saudi Arabia: findings from "Jeeluna". J Adolesc Health. 2015;57:263-9. doi:10.1016/j.jadohealth.2015.06.009.

28. AlBuhairan FS. Jeeluna study: national assessment of the health needs of adolescents in Saudi Arabia. Riyadh: King Abdullah International Medical Research Center; 2016.

29. Centers for Disease Control and Prevention. YRBSS|Youth Risk Behavior Surveillance System|Data|Adolescent and Health|CDC. https://www.cdc.gov/healthyyouth/data/yrbs/index.htm. Accessed 13 June 2017.

30. Ismayilova L, Hmoud O, Alkhasawneh E, Shaw S, El-Bassel N. Depressive symptoms among Jordanian youth: results of a national survey. Community Ment Health J. 2013;49:133-40. 
31. World Health Organization. Maternal, child and adolescent mental health: challenges and strategic directions 2010-2015. Geneva: World Health Organization; 2010.

32. Hankin BL, Mermelstein R, Roesch L. Sex differences in adolescent depression: stress exposure and reactivity models. Child Dev. 2007;78:279-95.

33. Bennett DS, Ambrosini PJ, Kudes D, Metz C, Rabinovich H. Gender differences in adolescent depression: do symptoms differ for boys and girls? J Affect Disord. 2005;89:35-44.

34. Lewinsohn PM, Gotlib IH, Lewinsohn M, Seeley JR, Allen NB. Gender differences in anxiety disorders and anxiety symptoms in adolescents. J Abnorm Psychol. 1998;107:109-17.

35. Piccinelli M, Wilkinson G. Gender differences in depression. Br J Psychiatry. 2000;177:486-92.

36. Sheeber L, Hops H, Davis B. Family processes in adolescent depression. Clin Child Fam Psychol Rev. 2001;4:19-35.

37. Sheeber LB, Davis B, Leve C, Hops H, Tildesley E. NIH public access. J Abnorm Psychol. 2007;116:14454.

38. Dwairy M, Achoui M, Abouserie R, Farah A. Adolescent-family connectedness among Arabs: a second cross-regional research study. J Cross Cult Psychol. 2006;37:248-61. doi:10.1177/0022022106286923.

39. Blashill AJ, Wilhelm S. Body image distortions, weight, and depression in adolescent boys: longitudinal trajectories into adulthood. Psychol Men Masc. 2014;15:445-51.

40. Ozmen D, Ozmen E, Ergin D, Cetinkaya AC, Sen N, Dundar PE, et al. The association of self-esteem, depression and body satisfaction with obesity among Turkish adolescents. BMC Public Health. 2007;7:80.

41. Marcotte D, Fortin L, Potvin P, Papillon M. Gender differences in depressive symptoms during adolescence: role of gender-typed characteristics, self-esteem, body image, stressful life events, and 
pubertal status. J Emot Behav Disord. 2002;10:29-42.

42. Greydanus D, Patel D, Pratt H. Suicide risk in adolescents with chronic illness: implications for primary care and specialty pediatric practice: a review. Dev Med Child Neurol. 2010;52:1083-7.

43. Haarasilta L, Marttunen M, Kaprio J, Aro H. Major depressive episode and physical health in adolescents and young adults: results from a population-based interview survey. Eur J Public Health. 2005;15:489-93.

44. Pinquart M, Shen Y. Depressive symptoms in children and adolescents with chronic physical illness: an updated meta-analysis. J Pediatr Psychol. 2011;36:375-84.

45. Sewilam AM, Watson AMM, Kassem AM, Clifton S, McDonald MC, Lipski R, et al. Roadmap to reduce the stigma of mental illness in the Middle East. Int J Soc Psychiatry. 2015;61:111-20. doi:10.1177/0020764014537234.

46. Almakhamreh S, Hundt GL. An examination of models of social work intervention for use with displaced Iraqi households in Jordan. Eur J Soc Work. 2012;15:377-91.

47. US Preventive Services Task Force (USPSTF). Final recommendation statement: depression in children and adolescents: screening. 2016. https://www.uspreventiveservicestaskforce.org/Page/Document/RecommendationStatementFinal/ depression-in-children-and-adolescents-screening1. Accessed 14 Mar 2017.

48. AlBuhairan FS, Olsson TM. Advancing adolescent health and health services in Saudi Arabia: exploring health-care providers' training, interest, and perceptions of the health-care needs of young people. Adv Med Educ Pract. 2014;5:281-7. doi:10.2147/AMEP.S66272. 


\section{Chapter 6 \\ The relationship of bullying and physical violence to mental health and academic performance}

This chapter has been published with the following citation:

AlBuhairan, F., Abou Abbas, O., El Sayed, D., Badri, M. Alshahri, S., de Vries, N. The relationship of bullying and physical violence to mental health and academic performance: A cross-sectional study among adolescents in Saudi Arabia. International Journal of Pediatrics and Adolescent Medicine 2017;4:61-65. 


\begin{abstract}
Background: Bullying and physical violence are serious public health concerns witnessed during adolescence and are associated with several health and behavioral problems that can persist into adulthood. The relationship between bullying/physical violence and mental health/academic performance in Saudi Arabia is unknown. This study aims at filling this gap through identifying the association of these health risk behaviors and mental health and academic performance.
\end{abstract}

Methods: A cross-sectional national survey was conducted in Saudi Arabia between 2011 and 2012. Adolescents attending intermediate and secondary schools were invited to participate through a multistage, stratified, cluster random sampling technique. A self-administered questionnaire was used to collect data. Data was analyzed using chi-square tests to identify associations and odds ratios were calculated.

Results: A total of 9,073 students participated. Twenty-six percent of adolescents reported exposure to bullying in the preceding 30 days, and one out of every three adolescents reported exposure to physical violence at school during the past year. More males than females, and more older adolescents were exposed to bullying. Exposure to physical violence and bullying were both associated with higher odds of having more frequent symptoms of depression and anxiety. Those exposed to physical violence were at higher odds of having poorer academic performance. Bullying and physical violence among adolescent students in Saudi Arabia is prevalent and deserves special attention due to its harmful impact on the other aspects of students' wellbeing.

Keywords: Aggression, school, bullying, adolescents, academic performance, depression, anxiety, mental health, Saudi Arabia 


\subsection{Introduction}

Identified as a significant public health concern, bullying among adolescents has been granted much attention at the global level. Systematic intervention research on bullying dates back to the eighties of the last century when the Norwegian researcher Olweus [1], [2] first shed light on this issue following an incident of three young Scandinavian boys who committed suicide after being severely bullied at school.

Bullying is a repeated aggressive behavior, involving power imbalance between the bully and the bullied [3]. Bullying behaviors can take several forms including: 1. physical, e.g. hitting, pushing, kicking, 2. verbal, e.g. name-calling, teasing, threatening, 3. relational/social, e.g. rumors, exclusion [4] and 4. cyber bullying [5].

There are important negative consequences to victims, perpetrators, schools, families and communities at large. Several studies have shown that victims of bullying are at increased odds of adverse outcomes including physical health problems [6], emotional and behavioral consequences [3], and psychiatric disorders [7]. Bullied students have been shown to have poor or impaired academic performance [8], [9]. At the mental health level, evidence has linked bullying victims to higher rates of depression, insomnia, feelings of hopelessness, loneliness [10], [11] , low self-esteem [12] , suicide ideation and attempt [13] . Similarly, bully-victims are also at higher risk of suicide ideation [14] and suicidal behaviors [7] .

The negative consequences of bullying do not stop at the actual incidence itself but persist beyond and may be carried into adulthood in various forms including, borderline personality disorder (BPD) [15], emotional disorders for victims, increased suicide ideation for victim-bullies [7] and increased risk of antisocial personality disorder and adult intimate partner violence perpetration for bullies [7], [16]. Likewise, PV can profoundly impact victims' integrity, social relationships and victims' social integration ability as well. PV can also trigger violent behavior among the victims that can be directed towards peer and even teachers which also impacts the classroom environment and hence the overall learning process [17].

This life changing experience has drastically affected more than a third of adolescents in schools globally [18]. In the Arab region, only few studies have tackled the issue of bullying and physical violence (PV) in schools; they found varying prevalence rates across countries ranging from $20.9 \%$ in the United Arab Emirates to $44.2 \%$ in Jordan [10]. Similar rates (31\%) have been reported from a nationally representative 
sample of Egyptian adolescents [19]. In the Kingdom of Saudi Arabia (KSA), the first nationally representative sample of adolescents was recently reported to have a prevalence of $25.0 \%$ of bullying and $20.8 \%$ of PV at schools [20]. The available local and regional literature has focused on prevalence rates. Attention now needs to be given to the seriousness and potential impact that bullying has on adolescents' health and academic achievements. The aim of this study was to assess the relationship between exposure to bullying/PV and adolescents' mental health and academic performance among adolescents in Saudi Arabia.

\subsection{Methods}

Data from the Jeeluna study was utilized for this analysis. Jeeluna is a national study addressing the health needs of adolescents in the KSA. Through student population proportionate sampling and a complex, multistage, stratified random sampling technique, adolescents from various regions across the country participated in this school-based study in 2011-2012. Participants included male and female intermediate (grades 7-9) and secondary (grades 10-12) grade students. Multiple domains were addressed in Jeeluna, including bullying and PV at schools [20]. A detailed methodology of Jeeluna was published earlier [20] .

Data for variables addressing bullying, PV at schools, mental health symptoms, academic performance, and socio-demographics were extracted. Many of the questions addressing these variables were guided by the Global School-based Health Survey [21]. 'Bullying' refers to reported verbal/emotional forms of bullying during the preceding 30 days (yes/no), and PV refers to reported exposure to physical forms of bullying during the preceding 12 months (yes/no). Mental health was assessed by adolescent self-reports of depression and/or anxiety symptoms. Depression was assessed by the response to the following question: "During the past 12 months, how often did you feel excessively sad or hopeless daily for 2 weeks or more to the extent that you stopped doing your usual activities (e.g., prevented you from going to school or to your social activities)?" Anxiety was assessed by the response to the following question: "During the past 12 months, how often have you felt so worried about something to the extent that you stopped doing your usual activities?" Any indication of having such feelings were reported as being positive for depression and/or anxiety symptoms. Academic performance was based on self-reports of academic achievement during the preceding academic semester (average or below/above average, based on school letter grading system). 
Sub sample analysis was conducted using Jeeluna data to examine the association between the main outcome variable Bullying and PV with the each of the independent variables including sociodemographics, academic performance, depression, anxiety and any mental health problem (i.e. depression and/or anxiety). Descriptive statistics were obtained for the whole sample. Bivariate analysis was then performed to test the association between the dependent and the independent variables. Multivariate logistic regression models were fitted and odds ratios were conducted adjusting for age and gender. Data was analyzed using the Statistical Package for Social Sciences (SPSS) version 22; $p$-values $\leq$ 0.05 were considered to be statistically significant at the bivariate and multivariate levels.

This study was reviewed and approved by the Ethical Review Committee at the King Abdullah International Medical Research Center.

\subsection{Results}

\subsection{Participant characteristics}

A total of 9073 students answered the bullying and PV questions. The sample included slightly more males (52.6\%). The majority were of Saudi Arabian origin (86.7\%). Students in the sample were almost equally distributed among intermediate (49.1\%) and secondary schools (50.9\%). The mean age of students was $15.80 \pm 1.842$ years. Twenty-six percent of adolescents reported exposure to bullying in the preceding 30 days. The prevalence to any past year PV at school was $33.3 \%$, with $21.2 \%$ reported being a victim (bullied) and $24.3 \%$ being a perpetrator (bully). $12.3 \%$ of the students were both, victims and perpetrators of PV and $11.5 \%$ reported being involved with bullying and PV at the same time. The majority of students (95.2\%) reported having above average academic performance in the preceding semester. Among the sample, $53.2 \%$ and $36.4 \%$ of students reported having any feelings of excessive sadness/hopelessness or worry/anxiety during the preceding year respectively.

\subsection{Association of bullying and physical violence with socio-demographic characteristics}

Table 1 shows the association of bullying and PV with adolescents' socio-demographics. Exposure to bullying was more common among males and older adolescents, whereas PV was more common among males and younger adolescents (all $p^{\prime} s<0.001$ ). Exposure to bullying or PV was more common among 
adolescents with a chronic illness ( $p<0.001$ ). Exposure to bullying, but not PV, was significantly associated with school absenteeism.

Mother's educational level was associated with both bullying and PV; adolescents whose mothers had completed higher education were more frequently exposed to bullying or PV. Higher paternal education was only positively associated with adolescents' exposure to bullying. Poor adolescent relationship with mother or father was strongly associated with exposure to bullying or PV (Table 1).

Table1. Association of bullying and physical violence with socio-demographic characteristics among adolescents in Saudi Arabia, $\mathrm{N}=9073$.

\begin{tabular}{|c|c|c|c|c|c|c|}
\hline & \multicolumn{2}{|c|}{$\begin{array}{l}\text { Bullying }{ }^{+} \\
(\%)\end{array}$} & \multicolumn{4}{|c|}{$\begin{array}{l}\text { Physical violence } \neq \\
\text { (\%) }\end{array}$} \\
\hline & No & Yes & P value* & No & Yes & P value* \\
\hline \multicolumn{7}{|l|}{ Gender } \\
\hline Male & 51.8 & 57.4 & $<0.001$ & 43.1 & 73.3 & $<0.001$ \\
\hline Female & 48.2 & 42.6 & & 56.9 & 26.7 & \\
\hline \multicolumn{7}{|l|}{ Age } \\
\hline$\leq 15$ & 45.2 & 40.2 & $<0.001$ & 38.8 & 54.1 & $<0.001$ \\
\hline$>15$ & 54.8 & 59.8 & & 61.2 & 45.9 & \\
\hline \multicolumn{7}{|l|}{ Father's educational level } \\
\hline Illiterate/completed primary school education & 26.2 & 23.6 & 0.060 & 25.7 & 24.7 & 0.64 \\
\hline Completed intermediate/secondary school education & 42.7 & 43.4 & & 42.8 & 43.6 & \\
\hline Completed college/university/post graduate education & 31.1 & 33.0 & & 31.5 & 31.6 & \\
\hline \multicolumn{7}{|l|}{ Mother's educational level } \\
\hline Illiterate/completed primary school education & 40.3 & 38.2 & 0.016 & 40.9 & 37.6 & 0.017 \\
\hline Completed intermediate/secondary school education & 37.2 & 36.2 & & 36.2 & 38.4 & \\
\hline Completed college/university/post graduate education & 22.5 & 25.6 & & 22.8 & 24.0 & \\
\hline \multicolumn{7}{|l|}{ Relationship with father } \\
\hline Very poor/poor & 2.9 & 6.0 & $<0.001$ & 3.5 & 4.1 & 0.082 \\
\hline Average & 9.6 & 15.1 & & 10.6 & 11.8 & \\
\hline Good/very good & 87.4 & 79.0 & & 85.9 & 84.1 & \\
\hline \multicolumn{7}{|l|}{ Relationship with mother } \\
\hline Very poor/poor & 1.1 & 2.6 & $<0.001$ & 1.4 & 1.6 & 0.029 \\
\hline Average & 4.5 & 7.5 & & 4.9 & 6.2 & \\
\hline Good/very good & 94.4 & 89.9 & & 93.7 & 92.2 & \\
\hline \multicolumn{7}{|l|}{ Absenteeism } \\
\hline No & 95.8 & 92.3 & $<0.001$ & 95.0 & 94.6 & 0.476 \\
\hline Yes & 4.2 & 7.7 & & 5.0 & 5.4 & \\
\hline \multicolumn{7}{|l|}{ Chronic illness } \\
\hline No & 92.6 & 87.7 & $<0.001$ & 92.7 & 88.5 & $<0.001$ \\
\hline Yes & 7.4 & 12.3 & & 7.3 & 11.5 & \\
\hline
\end{tabular}

† Past 30 days verbal/emotional; ¥ Past-year 


\subsection{Association of bullying and physical violence with academic performance and mental health}

Bullying was significantly associated with poor academic performance $(p=0.012)$ and mental health problem (depression and/or anxiety) $(p<0.001)$. Table 2 shows the adjusted and un-adjusted odds ratios of bullying and academic performance and mental health problem. When adjusting for age and gender, our results indicate that students who were bullied were $20 \%$ (OR: $0.81,95 \% \mathrm{Cl}: 0.653-1.011 \%$ ) less likely to have an academic performance that was at least average. Bullied students had 2.66 (95\% Cl: 2.399$2.959)$ and 2.89 (95\% Cl: 2.699 - 3.309) the odds of suffering from depression and anxiety symptoms respectively, as compared to students that were not bullied. Likewise, bullied students had 3.44 times higher risk of having mental health problem as compared to non-bullied students (95\% $\mathrm{Cl}$ : 3.063-3.865).

As for past year PV, after adjusting for age and gender, students who were involved in any PV were around $50 \%$ less likely to have 'average' or 'above average' academic performance as compared to those who were not involved in any PV $(95 \% \mathrm{Cl} 0.436-0.667)$. Further, these students were significantly more likely to report experiencing depression (OR: 1.7; 95\% Cl 1.535-1.869), anxiety (OR: 1.48; 95\% Cl: 1.333- 1.633) or mental health problem (OR: $1.84 ; 95 \% \mathrm{Cl} 1.662$ - 2.037) as compared to those who were not involved in any PV in the past year (Table 2).

Table 2. Adjusted and Un-adjusted Odds Ratios of Academic Performance and Mental Health with Bullying and PV

\begin{tabular}{|c|c|c|c|c|c|c|c|c|}
\hline & \multicolumn{4}{|c|}{ Bullying } & \multicolumn{4}{|c|}{ Physical Violence } \\
\hline & U-OR (95\%Cl) & P Value & A-OR(95\%Cl) & P Value & U-OR (95\%Cl) & P Value & A-OR(95\%Cl) & P Value \\
\hline \multicolumn{9}{|l|}{$\begin{array}{l}\text { Academic } \\
\text { Performance }\end{array}$} \\
\hline $\begin{array}{l}\text { Average or } \\
\text { below }\end{array}$ & Ref & & Ref & & Ref & $<0.001$ & Ref & $<0.001$ \\
\hline Above average & $0.76(0.609-0.940)$ & 0.012 & $0.81(0.653-1.011)$ & 0.062 & $0.52(0.442-0.629)$ & & $0.54(0.436-0.667)$ & \\
\hline \multicolumn{9}{|l|}{ Depression } \\
\hline No & Ref & $<0.001$ & Ref & $<0.001$ & Ref & $<0.001$ & Ref & $<0.001$ \\
\hline Yes & $2.56(2.313-2.842)$ & & $2.66(2.399-2.959)$ & & $1.26(1.151-1.378)$ & & $1.694(1.535-1.869)$ & \\
\hline \multicolumn{9}{|l|}{ Anxiety } \\
\hline No & Ref & $<0.001$ & Ref & $<0.001$ & Ref & 0.04 & Ref & $<0.001$ \\
\hline Yes & $2.86(2.589-3.157)$ & & $2.89(2.699-3.309)$ & & $1.1(1.003-1.207)$ & & $1.476(1.333-1.633)$ & \\
\hline \multicolumn{9}{|l|}{ Mental Health } \\
\hline \multicolumn{9}{|l|}{ Problems } \\
\hline No & Ref & $<0.001$ & Ref & $<0.001$ & Ref & $<0.001$ & Ref & $<0.001$ \\
\hline Yes & $3.28(2.924-3.673)$ & & $3.44(3.063-3.865)$ & & $1.33(1.208-1.455)$ & & $1.84(1.662-2.037)$ & \\
\hline
\end{tabular}




\subsection{Discussion}

This study indicates that PV and bullying are serious issues affecting one out of three or four adolescent students respectively in the KSA. Our rates are more or less similar to those reported earlier in the region [10], [19]. Our findings of bullying being more prevalent among older adolescent and PV among younger adolescents may be related to older adolescents' ability to address conflicts in a more assertive manner due to more advanced social and developmental skills.

Similar to other reports, exposure to bullying has been found to be associated with chronic illness [22] . Surprisingly though, we found higher maternal education to be associated with bullying and PV, though others have found higher parental education to be protective of bullying [22]. The reason for this is unclear. Students whose mothers had higher education represented a minority (23.3\%). Whether or not these kids for some reason stand out as targets because they are a minority is unknown; however, this is certainly an area worth exploring in future studies. Whether or not highly educated mothers label the behavior of peers differently than other mothers is unknown and should also be explored.

Consistent with others' findings, an adolescent's poor relationship with mother or father was found to be associated with bullying and/or PV. Poor negotiating relationships with parents have been found to be predictors for bullying victimization among adolescents [23]. It has been found that such children are sometimes less empowered by their parents and possibly lack confidence or are subject to poor role modeling [24], [25], [26]. The importance of building parenting skills and effective family communication may well extend beyond the home.

The long term implications, including mental health disease [12] , are serious and reflect the importance of addressing and preventing bullying and peer violence at a young age. Increased risk of mental health diseases with exposure to bullying has been found in other parts of the world [6], [7], [11], [22], [27]. Though it comes as no surprise that we have similar findings, this is the first documentation of such in the KSA.

Insufficient attention has been given to the issue of bullying among students in Saudi Arabia. The first national study addressing this was conducted a few years ago [20]. Subsequently, only a few awareness campaigns conducted in only few communities in the country were carried out. The Ministry of Education (MOE) has shown some interest in implementing a national bullying prevention program. Though bullying is included in the MOE's policy manual, it is mentioned alongside many other student behavioral issues 
without clear and concrete protocols of how to deal with or manage such situations [28]. Having an exclusive national policy for bullying along with concurrent widespread awareness and training programs is necessary. Much may be learned from countries that have been successful in having low rates of bullying such as Sweden, who implemented national policies and interventions early on [22].

Though the nature of our study does not allow for identifying causality and temporality, our findings have highlighted the serious associations that bullying and PV have. Future studies are needed to understand some of the determinants in more depth, and longitudinal studies will allow identification of causality as well as continued long-term implications and adversities. Nevertheless, school teachers, counselors, and parents need to be attuned to changes in academic performance as well as changes in mood or anxiety. Health services and providers also need to keep an opportunistic eye open for bullying and other forms of aggression when providing general care to their patients. Prevention, identification, and/or management of bullying and peer violence are important roles for the health care provider [29], and any contact with a young patient should be viewed as an opportunity to address some of these potentially missed issues.

\subsection{Conclusion}

Bullying and physical violence are serious and major public health issues that have a negative impact and are negatively associated with adolescents' wellbeing and require special attention at the family, school, and community level. National policy and intervention are much needed with concurrent awareness programs reaching all levels of society. Emphasis needs to be put on the serious relationship with poor academic performance and mental health and the importance of building and strengthening positive child-parent relationships. 
Chapter 6

\section{Abbreviations}

$\mathrm{Cl}$ confidence interval

KSA: Kingdom of Saudi Arabia

MOE: Ministry of Education

OR: odds ratio

PV: physical violence 


\section{References}

[1] Olweus D. Bully/victim problems among school children: Basic effects of a school-based intervention program. In D. Pepler and K.Rubin (Eds); 1991.

[2] Olweus D. Bullying at school: What we know and what we can do. Cambridge MA: Blackwell Publishers; 1993.

[3] Nansel, Tonja R. Overpeck Mary, Pilla Ramani S., Ruan June, Simons-Morton Bruce SP. Bullying Behaviors Among US Youth: Prevalence and Association With Psychological Adjustment. JAMA. 2001;285(16):2049-100.

[4] The Centers for Disease Control and Prevention. Understanding Bullying Fact Sheet 2013. 2011;45. Available from: http://www.cdc.gov/violenceprevention/pdf/bullyingfactsheet2014-a.pdf

[5] Wang J, lannotti RJ, Nansel TR. School Bullying Among Adolescents in the United States: Physical, Verbal, Relational, and Cyber. J Adolesc Heal [Internet]. Elsevier Ltd; 2009;45(4):368-75. Available from: http://dx.doi.org/10.1016/j.jadohealth.2009.03.021

[6] Biebl SJW, DiLalla LF, Davis EK, Lynch K a, Shinn SO. Longitudinal Associations Among Peer Victimization and Physical and Mental Health Problems. J Pediatr Psychol [Internet]. 2011;36(8):868-77. Available from: <Go to ISI>://WOS:000294121800004

[7] Copeland WE, Wolke D, Angold A, Costello EJ. Adult psychiatric outcomes of bullying and being bullied by peers in childhood and adolescence. JAMA psychiatry [Internet]. 2013;70(4):419-26. Available from: http://www.pubmedcentral.nih.gov/articlerender.fcgi?artid=3618584\&tool=pmcentrez\&rendert ype=abstract

[8] Loveland JM, Lounsbury JW, Welsh D, Buboltz WC. The validity of physical aggression in predicting adolescent academic performance. Br J Educ Psychol. 2007;77(Pt 1):167-76.

[9] Holt MK, Finkelhor D, Kantor GK. Multiple victimization experiences of urban elementary school students: Associations with psychosocial functioning and academic performance. Child Abus Negl. 2007;31(5):503-15. 
[10] Fleming LC, Jacobsen KH. Bullying among middle-school students in low and middle income countries. Health Promot Int. 2009;25(1):73-84.

[11] Brunstein Klomek A, Marrocco F, Kleinman M, Schonfeld IS GM. Bullying, depression, and suicidality in adolescents. J Am Acad Child Adolesc Psychiatry. 2007;46(1):40-9.

[12] Sourander A, Jensen P, Rönning J a, Niemelä S, Helenius H, Sillanmäki L, et al. What is the early adulthood outcome of boys who bully or are bullied in childhood? The Finnish "From a Boy to a Man" study. Pediatrics. 2007;120(2):397-404.

[13] Brunstein Klomek a, Sourander a, Gould M. The Association of Suicide and Bullying in Childhood Longitudinal Research Findings. Can J Psychiatry. 2010;55(5):282-8.

[14] Rigby K SP. Suicidal ideation among adolescent school children, involvement in bully-victim problems, and perceived social support. Suicide Life-threatening Behav. 1999;29(2):119-30.

[15] Sansone R a., Lam C, Wiederman MW. Being bullied in childhood: Correlations with borderline personality in adulthood. Compr Psychiatry [Internet]. Elsevier Inc.; 2010;51(5):458-61. Available from: http://dx.doi.org/10.1016/j.comppsych.2010.02.002

[16] Falb KL, McCauley HL, Decker MR, Gupta J, Raj a., Silverman JG. School Bullying Perpetration and Other Childhood Risk Factors as Predictors of Adult Intimate Partner Violence Perpetration. Arch Pediatr Adolesc Med. 2011;165(10):890-4.

[17] Estévez E, Jiménez TI, Musitu G, Valencia U De, Olavide UP De. V IOLENCE AND V ICTIMIZATION AT S CHOOL IN A DOLESCENCE. Molina DH, editor. Nova Science Publishers, Inc; 2008. 79-115 p.

[18] (United Nations Children's Fund). Hidden in Plain Sight: A statistical analysis of violence against children. New York; 2014.

[19] Celedonia KL, Wilson ML, El Gammal H a, Hagras AM. Physical fighting among Egyptian adolescents: social and demographic correlates among a nationally representative sample. PeerJ [Internet]. 2013;1:e125. Available from: http://www.pubmedcentral.nih.gov/articlerender.fcgi?artid=3746957\&tool=pmcentrez\&rendert ype $=$ abstract 
[20] AlBuhairan FS, Tamim H, Al Dubayee M, AlDhukair S, Al Shehri S, Tamimi W, et al. Time for an Adolescent Health Surveillance System in Saudi Arabia: Findings From "Jeeluna." J Adolesc Heal [Internet]. Elsevier Inc.; 2015;57(3):263-9. Available from: http://linkinghub.elsevier.com/retrieve/pii/S1054139X15002542

[21] World Health Organization. Global school-based student health survey [Internet]. [cited 2015 Sep 1]. Available from: http://www.who.int/chp/gshs/en/

[22] Nordhagen R, Nielsen a., Stigum H, Köhler L. Parental reported bullying among Nordic children: A population-based study. Child Care Health Dev. 2005;31(6):693-701.

[23] NATION MAURY VA, , PERKINS DOUGLAS D. SM. Bullying in School and Adolescent Sense of Empowerment: An Analysis of Relationships with Parents, Friends, and Teachers. J Community Appl Soc Psychol. 2008;18:211-32.

[24] Olweus D. Bullying at school: Basic facts and effects of a school based intervention program. J Child Psychol Psychaitry. 1994;35:1171-90.

[25] Ladd GW LB. Parenting behaviors and parent-child relationships: correlates of peer victimization in kindergarten? Dev Psychol. 1998;34(6):1450-8.

[26] Schwartz David, Dodge Kenneth A. ,Pettit Gregory S. BJE. The Early Socialization of Aggressive Victims of Bullying. Child Dev. 1997;68(4):665-75.

[27] Seals D YJ. Bullying and victimization: prevalence and relationship to gender, grade level, ethnicity, self-esteem, and depression. Adolescence. 2003;38(152):735-47.

[28] Dafer A. Offically in the Kingdom's Schools: Bullying entails suspension or transfer. Riyadh; 2013 Jan 18; Available from: http://alhayat.com/OpinionsDetails/583689

[29] AAP. Policy statement--Role of the pediatrician in youth violence prevention. Pediatrics. 2009;124(1):393-402. 


\section{Chapter 7}

\section{Relationship of media exposure to}

substance use among adolescents in Saudi Arabia

This chapter has been published with the following citation:

AlSayyari, A. and AlBuhairan, F. Relationship of Media Exposure to Substance Use Among Adolescents in Saudi Arabia: Results from a National Study. Drug and Alcohol Dependence 2018.

DOI: https://doi.org/10.1016/j.drugalcdep.2018.01.025 
Chapter 7 


\section{Background}

With limited social options, young Saudis are increasingly relying on media for entertainment. The media impact has been greatest among the younger generation, which constitutes half of the population of the Kingdom of Saudi Arabia (KSA). Therefore, this study aims to examine the association between exposure to varied types of media and substance use among adolescents in the KSA and explores whether these associations differ by gender.

\section{Methods}

Data were obtained from a national cross-sectional survey of school students aged ten to 19 years ( $N=12121)$. A self-administered questionnaire was used to assess exposure to three types of media: television, the Internet and video games with the use of legal substances such as cigarette/shisha smoking, solvent sniffing and misuse of medications, and illegal substances, such as alcohol, marijuana and other illicit drugs.

\section{Results}

Logistic regression analyses revealed that the odds of using tobacco, legal and illegal substances were higher for students who were watching television, surfing the Internet, or playing video games for more than two hours compared with their peers who watched less than two hours $(P<0.05)$. For males, results showed heavy and light use of the Internet were both significantly associated with smoking. Whereas for females, only excessive use of the Internet was associated with smoking.

\section{Conclusion}

Despite the conservative nature of the Saudi society, findings showed a significant association between tobacco or substance use and media exposure among adolescents. This suggests increased attention to the growing role media might play in shaping adolescents health risk behaviors in the KSA.

Keywords: Media, Adolescents, Tobacco, Substance use, Saudi Arabia 


\section{Introduction}

Adolescents today are living and growing up in a media-rich environment. The use of diverse technological platforms has become an everyday routine for many children and adolescents around the world. A typical adolescent in the Kingdom of Saudi Arabia (KSA) frequently spends a substantial amount of time daily watching television, surfing the Internet or playing video games (AlBuhairan, 2016), where they are provided with a constant flow of messages on a wide range of different subjects, including tobacco and substance use. Concerns have grown over the last several years of frequent media portrayals of substance use and their possible impact on young viewers' behaviors around tobacco, common household products, alcohol and other illegal substances.

In the last decade, the population of Saudi Arabia has grown to over 32 million. This is an increase of almost $40 \%$ compared with the previous decade (KSAGASTAT, 2004). As a consequence of the high growth rate, the majority of the population is young with more than $14 \%$ of the population of the KSA being adolescents aged 10-19 (KSAGASTAT, 2017). This represents a distinct bulge in the youth population. At the same time, availability and access to cable television and the Internet have become widespread in the KSA compared to the recent past when the only sources of media available were traditional television, with only two channels, monitored radio, and newspapers.

The vast majority of published studies that examined media content, found an association between certain media exposure and negative outcomes (Villani, 2001). Many studies have linked media to smoking (DiFranza et al., 2006), drinking (Van den Bulck \& Beullens, K., 2005), and marijuana use (Primack et al., 2009). This media effect seems to apply to adolescents from other countries and not to be confined to the United States (US) only (Brunborg et al., 2017; Dahal et al., 2015; Hanewinkel and Sargent, 2009; McCool et al., 2014). However, little research has looked beyond tobacco, alcohol, and marijuana to examine the association between media exposure and other substances. The only study that addressed the relationship between media exposure and solvents found an association between excessive viewing of television and video games and increased use of solvents and alcohol (Armstrong et al., 2010).

Media plays a critical role and less understood influence on adolescents' health and behavior in the KSA. Evidence comes primarily from studies conducted within Western nations rather than Middle Eastern countries, where tobacco and substance consumption among youth has been rising for the past few decades (Sweileh et al., 2014). A review study showed that cigarette smoking among school and university students in the KSA ranges between $12 \%$ and $37 \%$ in different regions around the country, reaching more 
than $50 \%$ among adults in some studies, with most of them reporting initiation of cigarette smoking at a young age (Bassiony, 2009). Annually, more than 70,000 Saudis die from smoking-related diseases only (KSAMOH, 2017). Furthermore, another report found that alcohol was used by $9 \%$ of male secondary school students at Abha, in the South of the KSA, and more than $8 \%$ of students were other substance abusers (Al-Musa and Al-Montashri, 2016). Yet, in the area of media research, only a few studies have come from the Arab world, and looked at tobacco only. In 2005, a study on adolescents aged 11 to 18 years and living in Tabouk, in the north of the KSA, linked smoking with watching and reading pro-tobacco advertisements; particularly in movies and at sports events (Abdalla et al., 2012). This correlates with a recent study from another Northern city that reported a similar association between media and smoking behavior among Saudi females (Kilase et al., 2013). An Egyptian study also found that exposure to Western media was positively associated with smoking in both Egyptian males and females (Islam and Johnson, 2007).

In many Middle Eastern countries, including the KSA, the prevalence of smoking among female adolescents is consistently reported to be lower than male adolescents, where females are traditionally more stigmatized for using tobacco and substances (Abdalla et al., 2007; Mandil et al., 2010). However, females are just as likely as male to become addicted (Anthony et al., 1994). Several studies have examined gender differences among adolescents in media influence. To date, the results have been mixed. For example, a number of studies have shown that video games are associated with increased male aggression but not for females (Shibuya et. Al, 2008), whereas other studies have found no link between aggression and video games (Ferguson, 2007). Similarly, media has been found to be associated with dieting and body dissatisfaction among females (Groesz, 2002), whereas other research suggests that there is no clear association between media exposure and body dissatisfaction (Calado, 2011).

The search for an explanation for the association between media exposure and tobacco or substance use among youth is complicated. There are myriad influences on adolescents' attitudes toward health risk behaviors. The socio-ecological theory provides a framework for understanding these forces, in that it suggests that adolescents develop in multilayered contexts. These contexts include individual, community, and environmental factors such as media (Twombly and Holtz, 2008). According to Kilbourne, adolescents are particularly vulnerable to the messages and images conveyed through different kinds of media because they are young and inexperienced and are the prime target of many programs (Kilbourne, 2011). In 1995, Strasburger contended that display of risk behaviors on media could function as a superpeer (Strasburger, 1995). The super-peer theory suggests that media is a powerful factor in defining social 
norms for adolescents. Therefore, the consumption of cigarettes, alcohol and drugs in movies and music videos may increase acceptance of smoking and using substances as normative and encourage initiation (Brown et al., 2005).

The public health approach emphasizes prevention, early detection of those at risk, and effective programs. Therefore, it is important to understand why adolescents initiate tobacco or substance use, and why they sometimes escalate in abusing them and subsequently develop abuse related problems. Such an understanding is a key in preventing morbidity and mortality associated with tobacco and substance abuse (Wang et al., 2014). Faced with the considerations presented, this study aims to explore the association between exposure to various types of media and tobacco/substance use among adolescents in the KSA. Two main questions are investigated:

1) Is there a relationship between three types of media exposure: television, the Internet and video games with the use of legal substances such as cigarette/shisha smoking, solvent sniffing and misuse of medications, and illegal substances, such as alcohol, marijuana and other illicit drugs?

2) Do these associations differ by gender?

\section{Methods}

\subsection{Subjects}

Data for this study were obtained from Jeeluna ${ }^{\circ}$, a national cross-sectional study conducted in $2011 / 2012$ in all 13 regions of the KSA to produce a nationally representative sample. A total of 12,121 adolescents from a representative sample of 278 middle and secondary schools were selected by a multi-stage, stratified, cluster random sampling technique based on the school grade (middle or secondary) and gender of students, as schools in the KSA are gender segregated.

\subsection{Measures}

A self-administered survey was used to collect data on a range of demographic variables, tobacco/substance use behaviors, media exposure and risk factors associated with adolescents' tobacco/substance use. Data were weighted to produce national estimates. A detailed methodology of 
Jeeluna ${ }^{\circledR}$ was published earlier (AlBuhairan et al., 2015). This study was reviewed and approved by the Institutional Review Board (IRB) at the King Abdullah International Medical Research Center (KAIMRC).

2.2.1. Covariates: Analyses controlled for age ( $\leq 15$ and $>15$ years old); gender; geographical region (regions grouped based on geographical location: Central, Western, Eastern, Northern, and Southern); relationship with the father/mother (good, average, and poor); father's/mother's education (illiterate/primary, intermediate/secondary, and graduate/post-graduate); family total monthly income (low= Saudi Arabian Riyal (SAR) $<10,000$, average $=$ SAR 10,000 to 14,999, and high $=$ SAR $>14,999$ fbased on USD $1.00=$ SAR 3.75\}); and adolescents' perception of family financial status compared to other students (poorer than others, like others, and richer than others). Additional risk/protective factors included whether students are engaged in physical activity during the school day or not; the number of days per week they engaged in exercise for at least 30 minutes (none, 1-2 days, 3-5 days, 6-7 days); and whether they had experienced symptoms reflective of depression during the past 12 months "hereafter referred to as depression"; or have a chronic illness that require health care follow-up.

2.2.2. Tobacco/Substance use: Smoking was defined as having tried a cigarette or shisha (waterpipe/hookah) at least once in a lifetime. Use of legal substances considered sniffing home solvent products such as glue, gasoline and aerosols or taking medications for non-medicinal reasons at least once over the last 30 days. Illegal substance use included using alcohol, which is illegal in the KSA, marijuana, or other illicit drugs at least once in a lifetime. Respondents answered yes or no; a positive response classified the student as a user or a smoker.

2.2.3. Media exposure: Separate items used to assess adolescents' exposure to television, the Internet, and video games. The students were asked the following questions, 'How much time do you usually spend watching the television daily?', 'How much time do you usually spend on the Internet (not related to school work) daily?" and "How much time do you usually spend playing video games (not on the Internetoffline) daily?" to which they could answer \{none, less than 1 hour, 1-2 hours, 2.1-4 hours, 4.1-5 hours, and $>5$ hours\}. Based on the earlier American Academy of Pediatrics (AAP) recommendations of twohour daily limit of screen time (Strasburger and Hogan, 2013), responses were grouped into (Never, $\leq 2-$ hours, and $>2$-hours). 


\subsection{Data Analysis}

Data were analyzed using statistical procedures contained in STATA 14 for Windows. Descriptive statistics conducted included frequencies and proportions. Chi- squared tests were used to examine gender differences in substance use (smoking and use of legal and illegal substances) and three types of media exposure (television, the Internet and video games). A multivariate logistic regression model was used to assess the independent association between each independent variable of media exposure, and each dependent variable of the substances used. Age ( $\leq 15$ and $>15$ ), gender, chronic illness, depression, relationship with father/mother, fathers' and mothers' highest educational level, household income, adolescents' perception of family financial status, physical activity at school and exercises frequency per week were used as covariates to investigate if the relationship between each type of media and substance use were independent of all the above-mentioned factors. In addition, multivariate logistic regression models were run separately for males and females to examine gender-specific differences. We used a significance level of $P<0.05$ for all statistical tests. Figure 1 shows the conceptual framework of the research.

Figure 1: The conceptual framework of the research

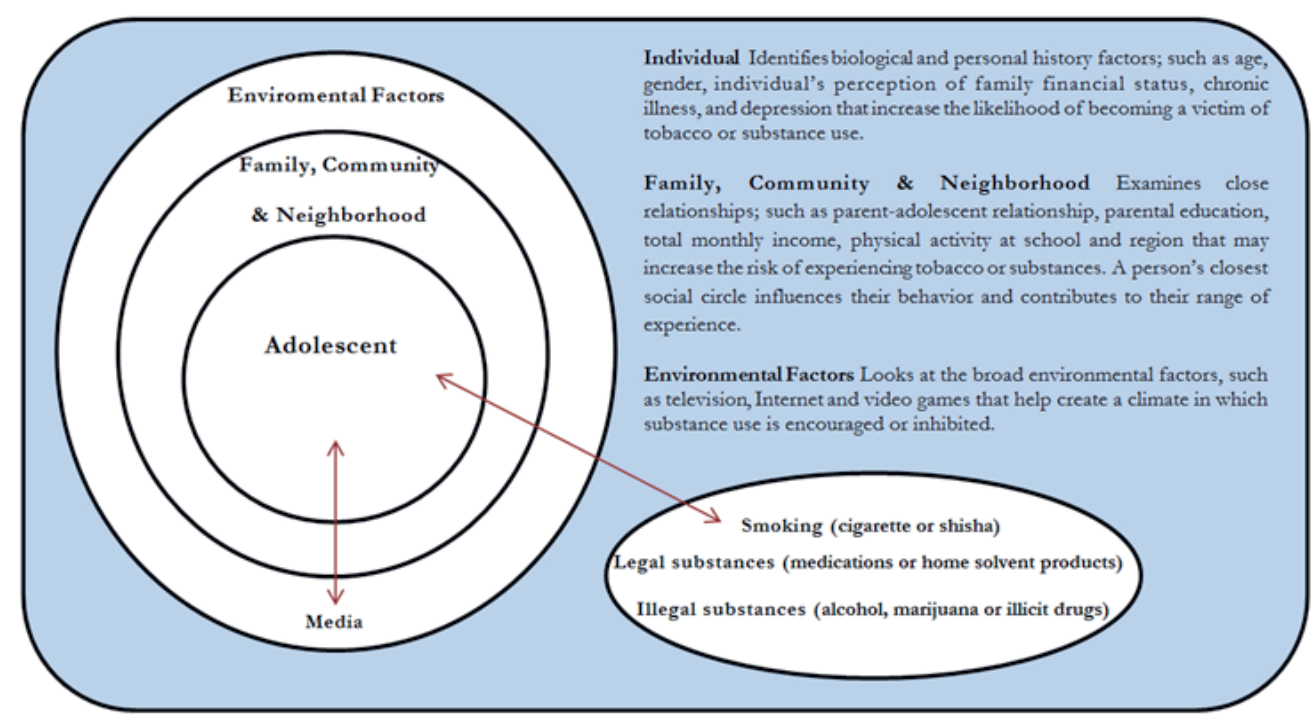




\section{Results}

\subsection{Socio-Demographics}

A total of 12,121 adolescents, divided almost equally between males and females and with a mean age of 15.6 years $(S D=1.8)$, participated in this study. Socio-demographics and covariates for the sample are described in Table 1.

Table 1: Participant's characteristics $(\mathrm{N}=12,121)$

\begin{tabular}{|c|c|c|}
\hline Covariate & Total number of responses & $\%$ \\
\hline $\begin{array}{l}\text { Gender } \\
\text { Male } \\
\text { Female }\end{array}$ & $\begin{array}{l}6290 \\
5831 \\
\end{array}$ & $\begin{array}{l}52.97 \\
47.03 \\
\end{array}$ \\
\hline $\begin{array}{l}\text { Age } \\
=<15 \\
>15\end{array}$ & $\begin{array}{l}5275 \\
6846 \\
\end{array}$ & $\begin{array}{r}46.83 \\
53.17 \\
\end{array}$ \\
\hline $\begin{array}{l}\text { Geographical region } \\
\text { Central } \\
\text { Western } \\
\text { Eastern } \\
\text { Northern } \\
\text { Southern }\end{array}$ & $\begin{array}{l}3306 \\
3737 \\
1841 \\
1277 \\
1960 \\
\end{array}$ & $\begin{array}{c}25.9 \\
32.36 \\
14 \\
10.42 \\
17.32 \\
\end{array}$ \\
\hline $\begin{array}{l}\text { Relationship with mothe } \\
\text { Poor } \\
\text { Average } \\
\text { Good }\end{array}$ & $\begin{array}{c}194 \\
621 \\
10916 \\
\end{array}$ & $\begin{array}{c}1.66 \\
5.2 \\
93.14 \\
\end{array}$ \\
\hline $\begin{array}{l}\text { Relationship with father } \\
\text { Poor } \\
\text { Average } \\
\text { Good } \\
\end{array}$ & $\begin{array}{c}476 \\
1312 \\
9859 \\
\end{array}$ & $\begin{array}{c}4.05 \\
11.2 \\
84.75 \\
\end{array}$ \\
\hline $\begin{array}{l}\text { Father's highest level of } \\
\text { Illiterate/primary } \\
\text { Intermediate/secondary } \\
\text { University/Post }\end{array}$ & $\begin{array}{l}2531 \\
4345 \\
3570 \\
\end{array}$ & $\begin{array}{l}23.73 \\
42.16 \\
34.11 \\
\end{array}$ \\
\hline $\begin{array}{l}\text { Mother's highest level of } \\
\text { Illiterate/primary } \\
\text { Intermediate/secondary } \\
\text { University/Post }\end{array}$ & $\begin{array}{l}4173 \\
3977 \\
2684 \\
\end{array}$ & $\begin{array}{l}38.25 \\
37.14 \\
24.61 \\
\end{array}$ \\
\hline $\begin{array}{l}\text { Income }^{\text {a }} \\
\text { Low } \\
\text { Average } \\
\text { High }\end{array}$ & $\begin{array}{l}3127 \\
1393 \\
1792 \\
\end{array}$ & $\begin{array}{l}49.61 \\
22.05 \\
28.34 \\
\end{array}$ \\
\hline
\end{tabular}




\begin{tabular}{|c|c|c|}
\hline \multicolumn{3}{|l|}{ Perception of family financial status ${ }^{\mathrm{a}}$} \\
\hline $\begin{array}{l}\text { Poorer } \\
\text { Like others } \\
\text { Richer }\end{array}$ & $\begin{array}{c}847 \\
8410 \\
2474\end{array}$ & $\begin{array}{r}7.49 \\
71.58 \\
20.92\end{array}$ \\
\hline \multicolumn{3}{|l|}{$\begin{array}{l}30 \text { minutes' exercises in the last } 7 \\
\text { days }^{\mathrm{a}}\end{array}$} \\
\hline $\begin{array}{l}\text { None } \\
1 \text { to } 2 \text { days } \\
3 \text { to } 5 \text { days } \\
6 \text { to } 7 \text { days }\end{array}$ & $\begin{array}{l}5354 \\
3190 \\
1520 \\
1868\end{array}$ & $\begin{array}{l}44.28 \\
27.04 \\
13.13 \\
15.55\end{array}$ \\
\hline Engaged in physical activity at schoola & 4362 & 37.25 \\
\hline $\begin{array}{l}\text { Depression }^{\mathbf{a}} \\
\text { Never } \\
\text { Sometimes } \\
\text { Always }\end{array}$ & $\begin{array}{l}5375 \\
4816 \\
1707 \\
\end{array}$ & $\begin{array}{c}45.65 \\
40.1 \\
14.25 \\
\end{array}$ \\
\hline Chronic Illness & 995 & 8.39 \\
\hline $\begin{array}{l}\text { Watching TV } \text { - (per day) } \\
\text { None } \\
=<2 \text { hours } \\
>\text { 2hours }\end{array}$ & $\begin{array}{l}547 \\
6296 \\
5092 \\
\end{array}$ & $\begin{array}{r}4.46 \\
52.96 \\
42.58 \\
\end{array}$ \\
\hline $\begin{array}{l}\text { Using Internet (non-related to } \\
\text { schoolwork) }^{\mathrm{a}} \text { (per day) } \\
\text { None } \\
=<2 \text { hours } \\
>2 \text { hours }\end{array}$ & $\begin{array}{l}2309 \\
5961 \\
3621 \\
\end{array}$ & $\begin{array}{l}19.29 \\
50.62 \\
30.09 \\
\end{array}$ \\
\hline $\begin{array}{l}\text { Playing video games }^{\mathrm{a}} \text { - (per day) } \\
\text { None } \\
=<2 \text { hours } \\
>2 \text { hours }\end{array}$ & $\begin{array}{l}5368 \\
5028 \\
1599 \\
\end{array}$ & $\begin{array}{r}44.3 \\
42.33 \\
13.37 \\
\end{array}$ \\
\hline $\begin{array}{l}\text { Smoking "Cigarette or Shisha"a - } \\
\text { (ever use) }\end{array}$ & 2365 & 19.68 \\
\hline $\begin{array}{l}\text { Legal substance }^{\text {a }} \\
\text { "Sniffing home solvent products or } \\
\text { misusing Medications" - (last } 30 \text { days } \\
\text { use) }\end{array}$ & 2748 & 23.02 \\
\hline $\begin{array}{l}\text { Illegal Substance } \\
\text { "Alcohol, marijuana, or illicit drugs" - } \\
\text { (ever use) }\end{array}$ & 385 & 3.14 \\
\hline
\end{tabular}




\subsection{Substance Use}

Based on the results, $19.6 \%$ of students had experienced smoking at least once in their lifetime, $3.1 \%$ had ever tried illegal drugs, and 23\% used legal substance at least once in the last month. There were significant differences in the use per gender. Male students were more likely to smoke $\left(\chi^{2}=67.63, \mathrm{df}=\right.$ 203, $P=0.000)$ and use illegal substances $\left(\chi^{2}=56.33, \mathrm{df}=203, P=0.000\right)$, while female students were more likely to use legal substances $\left(\chi^{2}=14.21, \mathrm{df}=203, P=0.000\right)$ (Table 2$)$.

Table 2: Media exposure, using tobacco, legal, and illegal substances by gender

\begin{tabular}{|c|c|c|c|}
\hline \multirow[t]{2}{*}{ Measures } & \multicolumn{3}{|c|}{ Gender $\%$} \\
\hline & Males $(n=6290)$ & Female $(n=5831)$ & $P$-value \\
\hline Smoking "Cigarette or Shisha" - (ever use) & $26.12 \%$ & $12.46 \%$ & $<0.001^{\mathrm{a}}$ \\
\hline $\begin{array}{l}\text { Legal Substance use "Sniffing home solvent } \\
\text { products or Medications" - (last } 30 \text { days } \\
\text { use) }\end{array}$ & $18.52 \%$ & $28.07 \%$ & $<0.001^{\mathrm{a}}$ \\
\hline $\begin{array}{l}\text { Illegal Substance use "Marijuana, alcohol or } \\
\text { illicit drugs" - (ever use) }\end{array}$ & $3.95 \%$ & $2.22 \%$ & $<0.001^{\text {a }}$ \\
\hline \multicolumn{4}{|l|}{ Watching TV - (per day) } \\
\hline $\begin{array}{l}\text { None } \\
=<2 \text { hours } \\
>2 \text { hours }\end{array}$ & $\begin{array}{c}4.02 \% \\
55.38 \% \\
40.59 \% \\
\end{array}$ & $\begin{array}{c}4.95 \% \\
50.25 \% \\
44.8 \% \\
\end{array}$ & $0.001^{\mathrm{a}}$ \\
\hline \multicolumn{4}{|l|}{$\begin{array}{l}\text { Using Internet (non-related to schoolwork) } \\
\text { - (per day) }\end{array}$} \\
\hline $\begin{array}{l}\text { None } \\
=<2 \text { hours } \\
>2 \text { hours }\end{array}$ & $\begin{array}{l}21.37 \% \\
52.68 \% \\
25.95 \%\end{array}$ & $\begin{array}{c}16.97 \% \\
48.33 \% \\
34.7 \% \\
\end{array}$ & $<0.001^{\mathrm{a}}$ \\
\hline \multicolumn{4}{|l|}{ Playing video games - (per day) } \\
\hline $\begin{array}{l}\text { None } \\
=<2 \text { hours } \\
>2 \text { hours }\end{array}$ & $\begin{array}{l}31.81 \% \\
48.65 \% \\
19.54 \%\end{array}$ & $\begin{array}{c}58.35 \% \\
35.22 \% \\
6.43 \%\end{array}$ & $<0.001^{\text {a }}$ \\
\hline aChi-2 test & & & \\
\hline
\end{tabular}

\subsection{Media Exposure Effects}

The prevalence of the various types of media exposure is reported in Table 1. Logistic regression was first conducted for the total sample for ever-use of smoking, illegal substances and 30-day use of legal 
substances, to examine which of the media exposure types might be associated with use. Results showed that viewing $>2$-hours of television were significantly associated with tobacco, legal and illegal substances use $(P<0.01, P<0.01$ and $P<0.05$ respectively). There were $35 \%, 18 \%$ and $38 \%$ (presented in table 3 ) increased likelihoods of using tobacco, legal and illegal substances for students who watch $>2$-hours of television compared with students who watch $\leq 2$-hours. Likewise, students who used the Internet for $>2$ hours were significantly more likely to smoke or use legal or illegal substances than those who used the Internet for $\leq 2$-hours ( $P<0.01, P<0.01$ and $P<0.01$ respectively). Furthermore, playing video games for $>2$-hours was also associated with a significant increase in odds of legal and illegal substances use compared with those who play for $\leq 2$-hours ( $P<0.01$ and $P<0.05$ respectively). A similar effect was seen for students who play video games $\leq 2$-hours compared with students who never play video games ( $P<$ 0.05 and $P<0.05$ respectively).

Thereafter, two separate multivariate logistic regressions were conducted for males and females. For males, results showed that heavy and light Internet users were significantly more likely to smoke tobacco when compared with non-Internet users $(P<0.01$ and $P<0.05$ respectively). For females, only heavy Internet users were significantly more likely to smoke tobacco compared to peers who have never used the Internet $(P<0.05)$. In addition, females who play video games for more than 2 -hours were more likely to use legal and illegal substances than did their counterparts who have never played video games $(P<$ $0.01, P<0.01$ respectively). A similar effect was seen for females with light use of video games ( $\leq 2$-hours) compared with females who have never played video games $(P<0.05$ and $P<0.05$ respectively) (Table $3)$. 
Table 3: Logistic regression analysis of tobacco, legal and illegal substances with media exposure $(\mathrm{N}=12,121)$

\begin{tabular}{|c|c|c|c|c|c|c|}
\hline & & $\mathrm{ng}^{\mathrm{b}, \mathrm{d}}$ & Leg & tance $c$,d & Illeg & tance $b, d$ \\
\hline & OR & $95 \% \mathrm{Cl}$ & OR & $95 \% \mathrm{Cl}$ & OR & $95 \% \mathrm{Cl}$ \\
\hline Total Sample & & & & & & \\
\hline TV & & & & & & \\
\hline$>2$-hours vs never & 1.40 & $0.99-1.99$ & 1.16 & $0.85-1.58$ & 0.93 & $0.50-1.72$ \\
\hline$=<2$-hours vs never & 1.04 & $0.73-1.46$ & 0.98 & $0.71-1.35$ & 0.67 & $0.37-1.24$ \\
\hline$>2$-hours vs $=<2$-hours & 1.35 & $1.17-1.55^{\mathrm{a}}$ & 1.18 & $1.05-1.31^{\mathrm{a}}$ & 1.38 & $1.02-1.86^{\mathrm{a}}$ \\
\hline Internet & & & & & & \\
\hline$>2$-hours vs never & 1.63 & $1.30-2.04^{\mathrm{a}}$ & 1.26 & $1.07-1.47^{\mathrm{a}}$ & 1.36 & $0.91-2.04$ \\
\hline$=<2$-hours vs never & 1.20 & $0.98-1.46$ & 0.99 & $0.84-1.17$ & 0.87 & $0.59-1.26$ \\
\hline$>2$-hours vs $=<2$-hours & 1.35 & $1.15-1.59^{\mathrm{a}}$ & 1.26 & $1.11-1.44^{\mathrm{a}}$ & 1.56 & $1.13-2.16^{a}$ \\
\hline Video games & & & & & & \\
\hline$>2$-hours vs never & 1.31 & $1.04-1.65^{a}$ & 1.60 & $1.29-1.98^{\mathrm{a}}$ & 2.15 & $1.38-3.37^{a}$ \\
\hline$=<2$-hours vs never & 1.11 & $0.96-1.28$ & 1.17 & $1.03-1.33^{a}$ & 1.43 & $1.01-2.00^{\mathrm{a}}$ \\
\hline$>2$-hours vs $=<2$-hours & 1.17 & $0.95-1.45$ & 1.36 & $1.11-1.66^{a}$ & 1.50 & $1.04-2.17^{\mathrm{a}}$ \\
\hline Males Only & & & & & & \\
\hline TV & & & & & & \\
\hline$>2$-hours vs never & 1.24 & $0.83-1.85$ & 0.90 & $0.57-1.44$ & 0.71 & $0.36-1.40$ \\
\hline$=<2$-hours vs never & 0.91 & $0.61-1.34$ & 0.85 & $0.53-1.38$ & 0.58 & $0.28-1.18$ \\
\hline$>2$-hours vs $=<2$-hours & 1.36 & $1.15-1.62^{\mathrm{a}}$ & 1.05 & $0.89-1.25$ & 1.23 & $0.84-1.80$ \\
\hline Internet & & & & & & \\
\hline$>2$-hours vs never & 1.75 & $1.31-2.35^{\mathrm{a}}$ & 1.23 & $0.99-1.53$ & 1.17 & $0.71-1.93$ \\
\hline$=<2$-hours vs never & 1.33 & $1.04-1.70^{\mathrm{a}}$ & 1.03 & $0.84-1.25$ & 0.74 & $0.49-1.14$ \\
\hline$>2$-hours vs $=<2$-hours & 1.31 & $1.07-1.61^{\mathrm{a}}$ & 1.19 & $0.96-1.48$ & 1.56 & $1.00-2.42^{\mathrm{a}}$ \\
\hline Video games & & & & & & \\
\hline$>2$-hours vs never & 1.08 & $0.84-1.40$ & 1.47 & $1.15-1.88^{\mathrm{a}}$ & 1.90 & $1.14-3.17^{\mathrm{a}}$ \\
\hline$=<2$-hours vs never & 1.06 & $0.88-1.27$ & 1.05 & $0.87-1.26$ & 1.30 & $0.84-1.99$ \\
\hline$>2$-hours vs $=<2$-hours & 1.02 & $0.81-1.28$ & 1.40 & $1.11-1.75^{a}$ & 1.46 & $0.99-2.14$ \\
\hline Females Only & & & & & & \\
\hline TV & & & & & & \\
\hline$>$ 2-hours vs never & 1.58 & $0.82-3.01$ & 1.45 & $0.97-2.18$ & 1.68 & $0.53-5.35$ \\
\hline$=<2$-hours vs never & 1.26 & $0.64-2.49$ & 1.15 & $0.76-1.74$ & 0.94 & $0.32-2.73$ \\
\hline$>2$-hours vs $=<2$-hours & 1.24 & $0.97-1.59$ & 1.26 & $1.09-1.44^{\mathrm{a}}$ & 1.78 & $0.98-3.21$ \\
\hline Internet & & & & & & \\
\hline$>2$-hours vs never & 1.51 & $1.05-2.18^{a}$ & 1.23 & $0.96-1.56$ & 1.70 & $0.80-3.62$ \\
\hline$=<2$-hours vs never & 1.06 & $0.76-1.48$ & 0.94 & $0.72-1.23$ & 1.20 & $0.59-2.45$ \\
\hline$>2$-hours vs $=<2$-hours & 1.42 & $1.06-1.90^{\mathrm{a}}$ & 1.29 & $1.09-1.54^{\mathrm{a}}$ & 1.41 & $0.90-2.22$ \\
\hline Video games & & & & & & \\
\hline$>2$-hours vs never & 2.38 & $1.60-3.55^{a}$ & 1.75 & $1.19-2.56^{a}$ & 4.09 & $1.67-10.04^{\mathrm{a}}$ \\
\hline$=<2$-hours vs never & 1.10 & $0.90-1.35$ & 1.23 & $1.03-1.47^{a}$ & 1.99 & $1.16-3.41^{\mathrm{a}}$ \\
\hline$>2$-hours vs $=<2$-hours & 2.15 & $1.46-3.19^{a}$ & 1.42 & $0.96-2.09$ & 2.05 & $0.82-5.10$ \\
\hline $\begin{array}{l}{ }^{a} \text { OR/Cl significant } p<0.05 \\
\text { b Ever-use. } \\
{ }^{\text {c }} \text { During the past } 30 \text { days. } \\
\text { d Analysis adjusted for the } \\
\text { income, perceived family's } f\end{array}$ & . & region, & . &  & ca & monthly \\
\hline
\end{tabular}

\section{Discussion}

In this cross-sectional analysis, we found that the odds of using tobacco, legal and illegal substances were higher for students who were watching television, surfing the Internet or playing video games for more than the earlier AAP recommendations of two hours of screen time per day compared with their peers 
who complied with the limits. These findings were consistent with the results of previous studies (Fischer et al., 2011; Tucker et al., 2013) and provide future direction for research about media and health behaviors.

In spite of the growing literature on media, studies into the effect of media use on adolescents' substance use behaviors are almost nonexistent in the Kingdom. To the best of our knowledge, this study is the first to examine the association between three types of media; television, the Internet and video games, with smoking and the use of legal and illegal substances among adolescents in the KSA. Therefore, a major contribution of this study is providing evidence for an independent association between various types of media and tobacco, legal and illegal substances use among adolescents.

The study revealed that after controlling for multiple demographic and risk factors, there is a strong multivariate association between heavy use of the Internet with smoking and the use of legal and illegal substances. Other studies from Greece (Fisoun et al., 2012) and China (Gong et al., 2009) showed similar results. With limited entertainment and extracurricular activities, young Saudis are increasingly relying on media and technology for entertainment. In the latest report published by the Saudi Communication and Information Technology Committee in 2015, the majority of more than 21 million users of the Internet in the KSA spend at least 120 minutes daily on social media websites only (KSACITC, 2015). This widespread adoption of the Internet by Saudi adolescents is mainly linked to the digital media's ability to offer wide-ranging materials. Today, the Internet provides a new platform for advertisement with the potential to reach millions of adolescents around the world and the Kingdom. Furthermore, the Internet allows adolescents to buy drugs easily; a previous study by Columbia University found that over $85 \%$ of online pharmacies do not require a prescription or proof of age (USNCASA, 2006).

In addition, we found that there is a strong association between television viewing for $>2$-hours and the use of tobacco and other legal and illegal substances. Similar results were found in an American study between movies and alcohol, and between music and marijuana (Primack et al., 2009). It is possible that television which contains references to tobacco, solvents and illegal drugs such as alcohol and marijuana through music videos, television series and films, are more likely to make this type of activity seems to be cool and fun. According to the policy statement published in 2010 by Pediatrics, the official journal of the AAP, media usually tends to popularize and glamorize substance abuse and encourage younger viewers to engage in risky behaviors (Strasburger, 2010). 
Although tobacco products are not advertised directly on local television in the KSA, passive promotion still occurs in movie scenes and television programs in local and international channels. In 2015, the National Tobacco Control Committee in KSA issued an anti-smoking law prohibiting promotion of tobacco and its derivatives by any means of advertising in any official media (KSAMOH, 2015) . However, the rise of cable television has made advertising more liberal and harder to monitor and control. With this new media environment, Saudis found a window of entertainment that is imbued by Western social and cultural values, that competes with traditional social structures and religion. According to Professor Miller, foreign television productions accounted for $50 \%$ of total programming in KSA (Miller, 2003). As a result of that, Saudi adolescents often watch different cultures and lifestyles from their own, and receive mixed messages about various topics, which might be considered to be socially acceptable in other parts of the world, yet are taboo in local culture. In this sense, media influences adolescents by producing characters that adolescents get attracted to and perceived to be peers and who they long to be. Such foreign examples and their media activities provide templates for youths' behaviors (Escabar-Chaves et al, 2005).

Recent studies continued to focus on television in spite of all the new forms of media, largely because adolescents are heavy users of television and they spend the most time with this medium. Moreover, there are no cinemas in the Kingdom. Without movie theaters; the popularity of television, whether it is cable TV, Netflix, or Apple TV is still growing as Saudis perceive television to be the main source of entertainment and information. Based on our sample, more than $95 \%$ of students watch television daily; almost half of them (42.5\%) watch it for $>2$-hours, compared to $30 \%$ using the Internet, and only $13.3 \%$ playing video games for more than two hours. This finding is consistent with previous literature on the number of hours' adolescents spend watching television in the KSA. A study by King Abdulaziz Medical City (2013) showed that $40 \%$ of adolescents aged between nine and 14 years watch television for more than three hours a day during weekends (Al-Ghamdi, 2013).

Similar to other studies, we found a link between excessive video gaming ( $>2$-hours) and substance use (Denniston et al., 2011; Ream et al., 2011). Armstrong et al. examined video games in a sample of 4,691 elementary school students and found that drinking alcohol and sniffing solvents were significantly higher for those playing $\geq 3$ hours compared with those who played for $\leq 2$ hours only (Armstrong et al., 2010). However, other studies failed to find a relation between duration of playing video games and certain substances (Walther et al., 2012). Interestingly, the current study found that the light use of video games ( $\leq 2$-hours) was also significantly associated with legal and illegal substances. There are several potential 
explanations for this finding; one possibility is that substance use is either more prevalent or more glamorously portrayed in video games. Secondly, it may be that those who use illegal substances like to play video games. Greenberg et. al. showed that participants who reported being addicted to substance such as alcohol, are most vulnerable to be dependent on another activity such as video games (Greenberg et al., 1999). Thirdly, adolescents are more likely to play video games at home, whether in their bedrooms, playrooms, or molhak (a common outdoor room, located in the outdoor premises of many homes in the KSA; usually built for sons/daughters to give them privacy to entertain their friends), hence having more unsupervised time though at home. Based on an American study on elementary school students, it was found that students spend $24 \%$ of their time at home alone, mostly unsupervised (Morrongiello et al., 2011).

\subsection{Gender differences}

The analyses by gender found that media exposure associated with substance use was different for males and females. For males, light and heavy exposure to the Internet was linked with smoking, which may be because males typically prefer to use the Internet to play online games, where they might be encouraged to smoke while playing with their friends or online peers (Huang et al., 2014). Although not statistically significant, we found that male students who reported limited television use ( $\leq 2$ hours) were less likely to use legal and illegal substances compared with those who never watch television. Maybe adolescents, who never watch television, tend to be more sociable and active than those who watch television. Therefore, they might be more likely to engage in risky behaviors around peers than alone. Previous research has suggested that peer presence increases risk-taking behaviors in adolescents (Smith et al., 2014). This increase in adolescents' risk taking behavior has been attributed to the brain's reward circuitry, which makes adolescent more sensitive to the rewards of peer relationships (Albert \& Steinberg, 2011). This association merits further study.

For females, the study found that light and heavy exposures to video games were significantly associated with the use of legal and illegal substances. It might be that a male-dominated activity like video games have either an image of masculinity, or such culture with a negative influence on the health behaviors seems more appealing to adolescent females who use substances (Desai et al., 2010).

The gender difference in tobacco and substance use observed in our study may be attributed to cultural differences and social behaviors associated with a traditional patriarchal society. Although tobacco and substance use, in general, are more stigmatized in KSA, female experience more social disapproval of 
tobacco or substance use. Consequently, consistent with other Middle Eastern research (Sweileh et al., 2014), the prevalence of illegal drugs use may have been underestimated in our study. Alcohol, marijuana, and illicit drugs are not legally, religiously or socially accepted in the KSA; therefore, though the survey was confidential and anonymous, we cannot deny that some students may have under reported any substance use even if it was on a single occasion.

While there are a lot of concerns regarding illegal substances, the greatest danger comes from using legal products like, glue, paints, nail polish remover and over the counter medicines. More than $28 \%$ of the female sample, compared to $18.52 \%$ of the male sample reported that they used legal substances at least once in the last month. These numbers should be a warning sign as more powerful and harmful substances are introduced on to the market. The U.S. Substance Abuse and Mental Health Services Administration Report in 2009 found that more than 17\% of adolescents who use drugs started by sniffing common household products (USDHHS, 2009). This difference in prevalence may be due to the nature of the position of females in the social structure of Saudi culture, including the fact that females are highly protected and sheltered, hence limiting their mobility on their own. Household products are cheap and easily accessible to females who may not have the same access to illegal substances or tobacco products as males.

\subsection{Limitations}

The limitations in this study must be acknowledged. The data in this study used a cross-sectional selfreported survey, which are subject to recall bias and are less sensitive measures of exposure than other techniques, such as longitudinal studies (USNRC, 1985). With cross-sectional designs, it is difficult to determine whether the outcome followed exposure in time or exposure resulted from the outcome. In addition, we only measured student perception at one time point, and captured exposure to media in one questionnaire item, limiting exploration of the differential effects of each media type. More importantly, we did not directly measure exposure to tobacco/substance use depictions. Rather, we relied only on measures of overall exposure, i.e., we addressed the quantitative exposure to media, however, did not examine the quality of the content of exposure, which may be even more important. The problem with such measures is that students viewing equal amounts of television, Internet or video games may be differentially exposed to tobacco/substances depictions depending on their preferences and attention levels. However, the consistency of our findings with the existing literature demonstrates the utility of self-reported measures (DiFranza et al., 2006; Primack et al., 2009). Despite these limitations, the study has several strengths, including the large sample, use of well-validated measures of media exposure, 
tobacco/substances use and other demographic characteristics and social influences. The present study controlled for covariates that were missing from other studies, such as depression, chronic illness, daily exercises and relationship with father/mother, adding confidence to the independence of the associations.

\subsection{Implications}

These findings have numerous implications for theory and practice. First, the study is a step towards the development of a theoretical framework for understanding the relationship of media exposure with tobacco and substance use behaviors among adolescents living in the KSA. Further work in media use is necessary to focus our future interventions efforts on the most relevant media type and content related to risky behaviors to reduce its impact on population health. Second, such findings can be used by child, adolescent, and public health advocates to reduce portrayals of substances and promote positive health behaviors. Third, this study indirectly reflects the importance of media literacy, a subject which needs to be integrated within school curriculums and in conversations at home. Fourth, our findings are important for beginning to inform future media-related policy initiatives.

\section{Conclusion}

Despite the conservative nature of the Saudi society, this study showed a significant association between different types of media and adolescents' tobacco and substance use behaviors. Though media exposure without a doubt comes with numerous potential benefits and opportunities for growth and learning, there are certain drawbacks that must be kept in mind. This suggests increased attention to the growing role media might play in shaping adolescents health behaviors in the KSA. 


\section{Abbreviations}

APP: American Academy of Pediatrics

$\mathrm{Cl}$ : Confidence Interval

IRB: Institutional Review Board

KSA: Kingdom of Saudi Arabia

OR: Odds Ratio

SAR: Saudi Arabian Riyal

USD: United State Dollar 


\section{References}

Abdalla, A., Saeed, A., Abdulrahman, B., Al-Kaabba, A., Al-Hamdan, N., Alzalabani, A., 2012. Effect of tobacco advertisements on smoking habits among adolescents in Saudi Arabia. Med J Cairo Univ 80, 111-119.

AlBuhairan, F.S., 2016. Jeeluna ${ }^{\circledR}$ Study: National assessment of the health needs of adolescents in Saudi Arabia. King Abdullah International Medical Research Center .

AlBuhairan, F.S., Tamim, H., Al Dubayee, M., AlDhukair, S., Al Shehri, S., Tamimi, W., El Bcheraoui, C., Magzoub, M.E., De Vries, N., Al Alwan, I., 2015. Time for an adolescent health surveillance system in Saudi Arabia: findings from “Jeeluna." J. Adolesc. Heal. 57, 263-269.

Albert D., Steinberg L. (2011). Peer influences on adolescent risk behavior. In Bardo M. T., Fishbein D. H., Milich R. (Eds.), Inhibitory control and drug abuse prevention: From research to translation (pp. 211228). New York, NY: Springer

Al-Ghamdi, S.H., 2013. The association between watching television and obesity in children of school age in Saudi Arabia. J. Fam. Community Med. 20, 83.

Al-Musa, H.M., Al-Montashri, S.D.S., 2016. Substance abuse among male secondary school students in Abha City, Saudi Arabia: prevalence and associated factors. Biomed. Res. 27.

Armstrong, K.E., Bush, H.M., Jones, J., 2010. Television and video game viewing and its association with substance use by Kentucky elementary school students, 2006. Public Health Rep. 125, 433-440.

Bassiony, M.M., 2009. Smoking in Saudi Arabia. Saudi Med. J. 30, 876-881.

Brown J.D., Halpern C.T., L’Engle K.L., 2005. Mass media as a sexual super peer for early maturing girls. J. Adolesc. Heal. 36:420-427

Brunborg G.S., Andreas J.B., Kvaavik E., 2017. Social media use and episodic heavy drinking among adolescents. Psychol Rep 120:475-490.

Calado M., Lameiras M., Sepulveda A.R., Rodriguez Y., Carrera M.V., 2011. The association between exposure to mass media and body dissatisfaction among Spanish adolescents. Womens Health Iss 21:390-399

Dahal, S., Maharjan, S., Subedi, R.K., Maharjan, J., 2015. Role of media in provoking cigarette smoking 
among adolescents in urban Nepal. Health (Irvine. Calif). 7, 98.

Denniston M.M., Swahn, M.H., Hertz, M.F., \& Romero, L.M., 2011. Associations between electronic media use and involvement in violence, alcohol and drug use among United States high school students. West. J. Emerg. Med. 12.

Desai, R.A., Krishnan-Sarin, S., Cavallo, D., Potenza, M.N., 2010. Video-gaming among high school students: health correlates, gender differences, and problematic gaming. Pediatrics 126, e1414-e1424.

DiFranza, J.R., Wellman, R.J., Sargent, J.D., Weitzman, M., Hipple, B.J., Winickoff, J.P., 2006. Tobacco promotion and the initiation of tobacco use: assessing the evidence for causality. Pediatrics 117, e1237-e1248.

Escobar-Chaves, L.S., Tortolero, S. R., Markham, C.M., Low B.J., Eitel P., \& Thicksun, P., 2005. Impact of the media on adolescent sexual attitudes and behaviors. Pediatrics, 116, 303-326.

Ferguson C. J., 2007. The good, the bad, and the ugly: a meta-analytic review of positive and negative effects of violent video games. Psychiatr. Q. 78, 309-316.

Fischer, P., Greitemeyer, T., Kastenmüller, A., Vogrincic, C., Sauer, A., 2011. The effects of risk-glorifying media exposure on risk-positive cognitions, emotions, and behaviors: a meta-analytic review. Psychol. Bull. 137, 367.

Fisoun, V., Floros, G., Siomos, K., Geroukalis, D., Navridis, K., 2012. Internet addiction as an important predictor in early detection of adolescent drug use experience-implications for research and practice. J. Addict. Med. 6, 77-84.

Gong J., Chwn X., Zeng J., Li F., Zhou D., Wang Z., 2009. Adolescent addictive internet use and drug abuse in Wuhan, China. Addict. Res. Theory 17, 291-305.

Greenberg J.L., Lewis S.E., Dodd D.K., 1999. Overlapping addictions and self-esteem among collegmen and women. Addict. Behav. 24, 565-571.

Groesz L.M., Levine M.P., Murnen S.K., 2002. The effect of experimental presentation of thin media images on body satisfaction: A meta-analytic review. Int J Eat Disord.31, 1-16.

Hanewinkel, R., Sargent, J.D., 2009. Longitudinal study of exposure to entertainment media and alcohol use among German adolescents. Pediatrics 123, 989-995. 
Huang G.C., Unger J.B., Soto D., Fujimoto K., Pentz M.A., Jordan-Marsh M., Valente T.W., 2014. Peer influences: the impact of online and offline friendship networks on adolescent smoking and alcohol use. J Adolesc Heal. 54, 508-14. doi:10.1016/j.jadohealth.2013.07.001

Islam, S.M.S., Johnson, C.A., 2007. Western media's influence on Egyptian adolescents' smoking behavior: The mediating role of positive beliefs about smoking. Nicotine Tob. Res. 9, 57-64.

Kilase M., Elsiddig, B., Ahmed, M., 2013. Prevalence and factors of smoking among the Saudi youth in the northern border region: The role of the tobacco control program in the region. Int. J. Manag. Res. Dev. $3,8$.

Kilbourne, J., 2011. Beauty...and the Beast of Advertising. Center of Media Literacy.

$\begin{array}{lllll}\text { K.S.A.C.I.T.C., } & 2015 . & \text { Annual } & \text { Report } & \text { 1436H H }\end{array}$ http://www.citc.gov.sa/en/MediaCenter/Annualreport/Pages/default.aspx $\quad$ In: $\quad$ K.S.A. Communications and Information Technology Commission

K.S.A.G.A.S.T.A.T., 2017. Population by Single Age, Nationality and Gender. http://www.stats.gov.sa/en/43, (accessed 2.25.17). In K.S.A. General Authority for Statistics; Population and Housing Census

K.S.A.G.A.S.T.A.T., 2004. Saudi Arabia's Census of 2004. http://www.stats.gov.sa/ar/13, (accessed 2.25.17). In K.S.A. General Authority for Statistics; Population and Housing Census

K.S.A.M.O.H., 2017. Canceled an anti-smoking campaign. In K.S.A Ministry of Health.

K.S.A.M.O.H., 2015. Anti-smoking System. http://www.tcpmoh.gov.sa/Ar/National-Committee/Antismoking-System, (accessed 1.25.17). In K.S.A Ministry of Health;National Tobacco Control Committee.

McCool, J., Freeman, B., Tanielu, H., 2014. Perceived social and media influences on tobacco use among Samoan youth. BMC Public Health 14, 1100.

Miller, T. (Ed.). 2003. Television: Critical concepts in media and cultural studies. London: Routledge.

Morrongiello, B.A., Kane, A., Zdzieborski, D., 2011. "I think he is in his room playing a video game": Parental supervision of young elementary-school children at home. J. Pediatr. Psychol. 36, 708-717.

Primack, B.A., Kraemer, K.L., Fine, M.J., Dalton, M.A., 2009. Media exposure and marijuana and alcohol use among adolescents. Subst. Use Misuse 44, 722-739. 
Ream G.L., Elliott, L. C., \& Dunlap, E., 2011. Playing video games while using or feeling the effects of substances: associations with substance use problems. Int. J. Environ. Res. public Heal. 8, 3979-3998.

Shibuya, A., Sakamoto, A., Ihori, N., \& Yukawa, S., 2008. The effects of the presence and context of video game violence on children: A longitudinal study in Japan. Simulation and Gaming, 39(4), 528-539. doi:10.1177/1046878107306670.

Smith A.R., Chein J., Steinberg, L., 2014. Peers increase adolescent risk taking even when the probabilities of negative outcomes are known. Dev. Psychol. doi:10.1037/a0035696

Strasburger, V., Hogan, M., 2013. American Academy of Pediatrics. Council on Communications and Media. Policy statement: children, adolescents and the media. Pediatrics. https://www.aap.org/enus/advocacy-and-policy/aap-health-initiatives/pages/media-and-children.aspx (accessed 2.25.17).

Strasburger V.C, 1995. Adolescents and the Media: Medical and Psychological Impact. Newbury Park, CA.

Strasburger V.C., 2010. American Academy of Pediatrics. Council on Communications and Media. Policy statement: children, adolescents, substance abuse, and the media. Pediatrics. 2010;126(4):791-799.

Sweileh, W.M., Sa'ed, H.Z., Al-Jabi, S.W., Sawalha, A.F., 2014. Substance use disorders in Arab countries: research activity and bibliometric analysis. Subst. Abuse Treat. Prev. Policy 9, 33.

Tucker, J.S., Miles, J.N. V, D’Amico, E.J., 2013. Cross-lagged associations between substance use-related media exposure and alcohol use during middle school. J. Adolesc. Heal. 53, 460-464.

U.S.D.H.H.S., 2009. Results from the 2009 National Survey on Drug Use and Health: Summary of National Findings. 2009. In: U.S. Department of Health and Human Services; Substance Abuse and Mental Health Services; Administration Center for Behavioral Health Statistics and Quality.

U.S.N.C.A.S.A., 2006. "You've got drugs: Prescription drug pushers on the Internet. In: U.S. The National Center on Addiction and Substance Abuse at Columbia University.

U.S.N.R.C.,1985. Epidemiology and air pollution. National Academies. (Vol. 15).In U.S. National Research Council.

Van den Bulck \& Beullens, K., J., 2005. Television and music video exposure and adolescent alcohol use while going out. Alcohol Alcohol. 40, 249-253.

Villani, S., 2001. Impact of media on children and adolescents: a 10-year review of the research. J. Am. 
Acad. Child Adolesc. Psychiatry 40, 392-401.

Walther B., Morgenstern, M., \& Hanewinkel, R., B., 2012. Co-occurrence of addictive behaviours: personality factors related to substance use, gambling and computer gaming. Eur. Addict. Res. 18, 167-174.

Wang, D., Wang, Y., Wang, Y., Li, R., Zhou, C., 2014. Impact of physical exercise on substance use disorders: a meta-analysis. PLoS One 9, e110728. 


\section{Chapter 8 \\ Sleep deprivation: prevalence and associated factors among adolescents in Saudi Arabia}

This chapter has been published with the following citation:

Nasim, M., Saade, M., and AlBuhairan, F. Sleep deprivation: prevalence and associated factors among adolescents in Saudi Arabia. Sleep Medicine 2019;53:165-171. DOI:

https://doi.org/10.1016/i.sleep.2018.08.031 


\section{Abstract}

Study Objectives: A limited number of studies have examined sleep deprivation; (SD), among adolescents in Saudi Arabia. This study estimates SD prevalence and associated factors within a nationally representative sample of adolescents in Saudi Arabia.

Methods: A secondary data analysis of Jeeluna ${ }^{\circledR}$, a national cross-sectional school-based survey, was undertaken. Jeeluna ${ }^{\circledR}$ assessed health risk behaviors and health status among adolescents (10-19 years) in schools across Saudi Arabia. Based on self-reports of daily average sleep duration, binary logistic regression was used to investigate potential association among SD, socio-demographics, and various health behavior factors.

Results: Data from 12,121 adolescents (male 51\%, female 49\%) was analysed. Early- and middle-stage adolescents constituted the majority (81\%) of the sample. SD (sleep $<7$ hours/day) was reported by $46 \%$ on weekdays and $33 \%$ on weekends. Three quarters of all adolescents reported feeling unrefreshed on awakening. The adjusted odds ratio (A-OR) for SD was higher for adolescents of older age (18-19 years) (OR1.18, Cl 1.05 -1.32), female gender (OR1.23, $\mathrm{Cl} 1.14$ - 1.34), lower perceived socioeconomic status (OR1.51, Cl 1.28 - 1.78), and those eating <3 main meals per day (OR1.17; Cl 1.09 - 1.27). In contrast, AORs were lower among adolescents reporting television and computer screen exposure $\geq 2$ hours per day (OR 0.81, Cl 0.75 - 0.88; OR 0.83, Cl 0.77 - 0.91), and those taking daytime naps ( $\geq 3$ days) per week (OR 0.87, Cl 0.81-0.94).

Conclusions: Sleep deprivation is highly prevalent among adolescents in Saudi Arabia with reported prevalence being higher on weekdays versus weekends. The study identifies multiple associated factors that can inform preventative strategies and programs to support adolescent sleep and wellbeing.

Keywords: adolescent, sleep deprivation, short sleep duration, epidemiological survey, behaviors, Saudi Arabia 


\section{Introduction}

Sleep deprivation (SD) is a growing problem among adolescents. In fact, sleep deprivation among adolescents has been called a silent global concern on an "epidemic scale" [1, 2]. There are numerous studies highlighting the serious physical, psychological and social impact of SD on the health and wellbeing of adolescents. SD among adolescents has been associated with increased risk of being overweight/obese [3], future risk of excessive weight gain [4, 5] and cardiometabolic risk [6-8]. The relationship between SD and mental health disturbances among adolescents is also well documented, with SD negatively affecting cognitive state, mood and emotional stability $[9,10]$. SD is associated with increased risk of developing depression, anxiety, suicidal ideation and self-harm [11-13]. Furthermore, sleep deprived adolescents exhibit poor concentration, decision-making skills as well as symptoms of excessive daytime sleepiness (EDS) $[9,11]$. Adolescents with SD are more likely to be involved in unintentional accidents and injuries, (particularly motor vehicle crashes) [14] and other health risk behaviors [15-18] compared to those with adequate sleep. Poor academic performance [18-21] and school absenteeism [22] are also commonly reported in this group.

Previous studies have reported multiple biological, demographic, and environmental factors to be associated with SD in adolescents. These include stage of adolescence (age) [23], gender [24], socioeconomic status [24], environmental demands on time (academic responsibilities and maintaining peer friendship) [25], technology use [26], and lifestyle factors (caffeinated beverage consumption [27, 28], cigarette smoking, khat [28], and alcohol use). All the aforementioned factors have been linked to delayed sleeping times in adolescents. Furthermore, early school start times have also been implicated as a major cause of sleep insufficiency in adolescents [29].

A steady decline in self-reported sleep times has been observed among adolescents. In the United States, the proportion of students regularly getting $\geq 7$ hours of night time sleep fell from $72 \%$ in 1991 to $63 \%$ in 2012 [24]. Similarly in Europe, the Healthy Lifestyle in Europe by Nutrition in Adolescence HELENA study reported that $33 \%$ of adolescents sleep $<8$ hours per day [8]. To our knowledge, there are few studies reporting SD among adolescents from the Middle East [30-33]. This is supported by the lack of studies from Middle Eastern countries included in a systematic review addressing features of inadequate sleep in adolescents [4]. In the Kingdom of Saudi Arabia, two school-based cross-sectional studies have reported average sleep duration among adolescents to be between 7 and 7.2 hours daily [32, 34]. One study of 2863 individuals reported that $31 \%$ of school students were sleeping $<7$ hours, whereas $50 \%$ were sleeping $<8$ hours per day [32]. These studies, however, were not nationally representative samples and looked at 
sleep duration among specific age groups of adolescents. No other study has reported SD prevalence in a sample of participants that covers the whole age spectrum (10-19 years) of adolescence in the country.

This study aims to estimate the prevalence of SD among a nationally representative sample of adolescents in Saudi Arabia and to identify associated factors. Such findings may be used to highlight the issue of SD among adolescents in the country and guide future educational/behavioral/policy changes that can improve sleep sufficiency in this important subgroup of the population.

\section{Methods}

\subsection{Background of the Jeeluna ${ }^{\circledR}$ study: study design and data collection}

The "Jeeluna ${ }^{\circledR}$ " study [35] was the first nationally representative, epidemiological school-based crosssectional observational health survey conducted in 2011/2012 across all 13 regions of Saudi Arabia. Jeeluna ${ }^{\circledR}$ is the Arabic term for "our generation". Prior to this study, nationally representative adolescent health indicators were unavailable in the country. The objective of Jeeluna ${ }^{\circledR}$ study was to assess the health risk behaviors and health status of adolescents in Saudi Arabia. Schools in Saudi Arabia are gender segregated, and education falls under the responsibility of the Ministry of Education. Intermediate schools include grades 7-9, and secondary schools include grades 10-12. Upon successful completion of grade 12, students are eligible to pursue further education at the university/college level.

\subsection{Jeeluna ${ }^{\circledR}$ study design}

Jeeluna is a national study of students attending intermediate and secondary public and private schools in Saudi Arabia. Subjects were selected using multistage, stratified, cluster random sampling. The final data included 282 schools, with a school response rate of $97.5 \%$ and a student response rate of $32 \%$. Ethical approval for the Jeeluna ${ }^{\circledR}$ study was granted by the Institutional Review Board (IRB) at King Abdullah International Medical Research Center and Saudi Arabian Ministry of Education.

\subsection{Jeeluna ${ }^{\circledR}$ study data collection}

Standardized, structured training of 52 teams of data collectors occurred in all 13 regions of Saudi Arabia. A total of 34 training workshops took place, conducted by the principal investigator or another trainer 
who had received "train the trainer" training. Each team consisted of two data collectors and two phlebotomists/nurses. Collection involved a three-step process: (1) administering a self-report questionnaire; (2) taking anthropometric measurements; and (3) performing blood sampling. Steps 1 and 2 were conducted by data collectors and step 3 by nurses/phlebotomists. Data collectors also ensured only students with signed consent and assent forms were included in the study and were available to answer any student questions on the study.

\subsubsection{Jeeluna ${ }^{\circledR}$ survey}

The survey was compiled by adopting items focused on adolescent health behaviors from the Youth Risk Behavior Survey (YRBS) and the Global Based Student Health Survey [36, 37] . In addition, questions that assessed psychosocial history (home and education) were guided by clinical tools. The final tool was reviewed and refined by experts and piloted in a sample of adolescents. In total, 103 questions were asked that covered 11 domains; family (9), education (5), dietary behaviors (15), activity (physical and sedentary) (12), safety (8), bullying and violence (7), tobacco and substance use (22), health (4), health services (7), and health knowledge (10).

\subsection{Secondary Survey: Data variables selected for this study}

To fulfill our study objectives, relevant data variables related to socio-demographics, health risk behaviors, and sleep were extracted from the "Jeeluna" study dataset and analyzed.

Sleep duration was assessed by participants' answering the following two self-reported questions; How many hours do you usually sleep on each weekday? How many hours do you usually sleep on each weekend day? Response options for both questions were $<5,6,7,8,9$, and $\geq 10$ (hours). Weekly frequency of taking a daytime nap was based on asking the participant the number of days per week in which they took an afternoon nap? Response options ranged from $0,1,2,3,4,5,6$ days with the last option being daily.

In addition to sleep, other variables of interest included the following: gender, age group based on stages of adolescence (early: 10-14yrs; middle: 15-17yrs; late: 18-19yrs); body mass index (BMI) percentiles (determined from BMI for age growth charts); self-reported socioeconomic status (SES); academic performance; television screen time per day (hours); Internet use per day (hours); video game playing per day (hours); daily soda and energy drink consumption; number of meals per day; engagement in physical activity (number of days per week for at least 30 minutes each day); and cigarette and tobacco use in the past month. 


\subsection{Defining sleep deprivation}

Currently, there is no universally accepted definition for SD. Published studies use different cut-off values for determining SD. Another complicating factor is that different guidelines use different age brackets for defining the various stages of adolescence. Furthermore, the age brackets differ with regard to the number of hours of sleep that are recommended. These factors make it complicated to find a single unit measure to define SD across all three stages of adolescence (early, middle and late). Other studies have used $<7$ hours and $<8$ hours to describe SD in adolescents [32,38]. For this study, the operational definition of our outcome variable, SD, has been based on the National Sleep Foundation (NSF) sleep duration guidelines [39]. NSF guidelines were informed by a comprehensive systematic review of all published literature looking at sleep duration and health, as well as sleep expert recommendations [39].

According to the guidelines, adolescents in the (6-13) and (14-17) year age groups are not recommended to sleep $<7$ hours per day [39]. As these two age groups cover the majority of adolescents in our study sample (81\%), we adopted less than 7 hours sleep to define SD. This criterion of $<7$ hours would also be appropriate for late stage adolescents ( $\geq 18$ years of age) for whom guidelines recommend sleeping a minimum of 7- 9 hours per day [38].

\subsection{Data Analysis}

Descriptive statistics of sample sociodemographic, health behavior, and sleep characteristics were reported in terms of frequency The complex sampling design as described earlier was accounted for in the weighting of the data. Data was weighted to account for the probability of selection of students within each school, and the probability of selection of schools within each district. Weighting the data ensured that it was nationally representative of the adolescent student population. Detailed methodology pertaining to the original study has previously been published [35].

Descriptive univariate analysis was carried out to quantify the adolescent's socio-demographic, health behavior and sleep profiles. Results were reported in terms of frequency, weighted frequency, percent and standard error (SE) of percent. Bivariate analysis (Pearson's chi square test) was undertaken as an intermediate step to generate the binary logistic regression model. Only potential covariates that were significant on bivariate analysis ( $p$ value $<0.05$ ) were entered into the binary logistic regression model in order to identify factors associated with SD among adolescents. Results were reported in terms of odds ratio, standard error, $95 \%$ confidence interval, and $\mathrm{p}$-value of the final parsimonious logistic model. 
Significance was declared at alpha less than 0.05. Statistical analysis was done using SAS Version 9.4 (SAS Institute, Cary, NC).

\section{Results}

\subsection{Sample characteristics:}

Table 1 shows the socio-demographic and health behavior characteristics of participants. A total of 12,121 adolescents between 10 and 19 years participated in the study (mean age was 15.7 years). The sample was fairly evenly distributed between the two genders. Middle stage adolescents, aged 15-17 years, made up the majority of the sample (53\%), followed by early stage (10-14 years) adolescents (28\%). A considerable percentage of adolescents were either overweight/obese (30\%) or underweight (15\%). Most adolescents perceived their socioeconomic status to be similar to their peers $(72 \%)$.

In general, dietary habits were reported to be poor; $89 \%$ of participants reported daily soft drink consumption and $40 \%$ reported daily energy drink consumption. Close to half the sample $(43 \%)$ reported not eating three main meals per day. Furthermore, large proportions of adolescents reported daily engagement in sedentary activities (watching $\geq 2$ hours of television [43\%], computer time [31\%], video game playing [13\%]). Reported physical activity levels among adolescents were poor, with the majority (71\%) exercising <3 days per week. Table 1 provides details. 
Table 1: Sample Characteristics

\begin{tabular}{|c|c|c|c|c|c|c|c|}
\hline Sociodemographics & & & & Health behaviors & & & \\
\hline & Frequency & $(\%)^{a}$ & SE (\%) & & Frequency & $(\%)^{a}$ & $\begin{array}{l}\text { SE } \\
(\%)\end{array}$ \\
\hline Stage of Adolescence ${ }^{b}$ & & & & Physical Exercise Per Week & & & \\
\hline Early [10-14 yrs] & 3,254 & 27.96 & 1.4 & $<3$ days & 8,544 & 71.16 & 0.6 \\
\hline Middle [15-17 yrs] & 6,461 & 53.05 & 1.11 & $\geq 3$ days & 3,388 & 28.84 & 0.6 \\
\hline Late [18-19 yrs] & 2,406 & 18.99 & 1.1 & Total & 11,932 & 100 & \\
\hline Total & 12,121 & 100 & & TV Screen Time & & & \\
\hline & & & & $<2$ hours & 6,843 & 57.32 & 0.6 \\
\hline Gender & & & & $\geq 2$ Hours & 5,092 & 42.68 & 0.6 \\
\hline Male & 6,290 & 51.17 & 1.47 & Total & 11,935 & 100 & \\
\hline Female & 5,831 & 48.83 & 1.47 & Video Game Time & & & \\
\hline Total & 12,121 & 100 & & $<2$ hours & 10,396 & 86.66 & 0.43 \\
\hline & & & & $\geq 2$ Hours & 1,599 & 13.34 & 0.43 \\
\hline Body Mass Index & & & & Total & 11,995 & 100 & \\
\hline $\begin{array}{l}\text { Underweight }<5 \text { th } \\
\text { Centile }\end{array}$ & 1,812 & 14.57 & 0.44 & $\begin{array}{l}\text { Computer (Internet) Screen } \\
\text { Time }\end{array}$ & & & \\
\hline $\begin{array}{l}\text { Healthy weight 5- } \\
<85 \text { th Centile }\end{array}$ & 6,612 & 55.26 & 0.52 & $<2$ hours & 8,270 & 69.4 & 0.68 \\
\hline $\begin{array}{l}\text { Overweight } \geq 85 \text { th } \\
\text { Centile }-<95 \text { th Centile }\end{array}$ & 1,712 & 14.11 & 0.32 & $\geq 2$ Hours & 3,621 & 30.6 & 0.68 \\
\hline Obese $\geq 95$ th Centile & 1,912 & 16.06 & 0.48 & Total & 11,891 & 100 & \\
\hline Total & 12,048 & 100 & & Daily Soda Consumption & & & \\
\hline & & & & No & 1,350 & 11.45 & 0.38 \\
\hline Academic Performance & & & & Yes & 10,670 & 88.55 & 0.38 \\
\hline Poor & 222 & 1.68 & 0.16 & Total & 12,020 & 100 & \\
\hline Average & 330 & 2.75 & 0.19 & $\begin{array}{l}\text { Daily energy drink } \\
\text { consumption }\end{array}$ & & & \\
\hline Above Average & 11,180 & 93.85 & 0.31 & No & 7,230 & 60.49 & 0.68 \\
\hline Don't Know & 202 & 1.71 & 0.13 & Yes & 4,782 & 39.51 & 0.68 \\
\hline Total & 11,934 & 100 & & Total & 12,012 & 100 & \\
\hline & & & & No. Main Meals Per Day & & & \\
\hline Self-reported SES & & & & $<3$ meals & 5,241 & 43.45 & 0.63 \\
\hline Poorer than others & 847 & 7.25 & 0.27 & $\geq 3$ meals & 6,749 & 56.55 & 0.63 \\
\hline Similar to others & 8,410 & 71.68 & 0.53 & Total & 11,990 & 100 & \\
\hline Better than others & 2,474 & 21.07 & 0.51 & $\begin{array}{l}\text { Smoking Cigarettes (in last } \\
30 \text { days) }\end{array}$ & & & \\
\hline & & & & No & 11,138 & 93.44 & 0.35 \\
\hline Total & 11,731 & 100 & & Yes & 811 & 6.56 & 0.35 \\
\hline & & & & Total & 11,949 & 100 & \\
\hline
\end{tabular}

A total of12,121 adolescents aged 10-19 years were included in the analysis, however all totals do not summate to 12,121 due to missing responses from some participants. SE (\%): Standard error of percent

a Adjusted for complex sampling design.

${ }^{\mathrm{b}}$ Stages of adolescence based on age group categorization from healthy children.org (American Academy of Pediatrics). 


\subsection{Sleep characteristics of sample}

The prevalence of adolescents reporting SD during the week was high overall. Nearly half (46\%) of the sample reported SD during weekdays in contrast to a third (33\%) during weekends. The majority of adolescents (74\%) rarely or never felt refreshed in the morning after waking from sleep. Furthermore, frequent daytime napping was highly prevalent, with nearly $60 \%$ of participants taking daytime naps three or more times per week (Table 2).

Table 2: Sleep characteristics of sample

\begin{tabular}{|c|c|c|c|c|c|c|c|c|}
\hline & \multicolumn{8}{|c|}{ Stage of Adolescence [Age group in years] } \\
\hline & \multicolumn{2}{|c|}{ Early [10-14] } & \multicolumn{2}{|c|}{ Middle [15-17] } & \multicolumn{2}{|c|}{ Late [18-19] } & \multicolumn{2}{|c|}{ Total } \\
\hline & $\mathrm{n}$ & $\%$ & $\mathrm{n}$ & $\%$ & $\mathrm{n}$ & $\%$ & $\mathrm{n}$ & $\%$ \\
\hline \multicolumn{9}{|l|}{$\begin{array}{l}\text { Sleep Duration } \\
\text { Weekdays }\end{array}$} \\
\hline$<7$ Hours & 1,725 & 26.74 & 3,527 & 54.68 & 1198 & 18.57 & 5,418 & $46.65^{*}$ \\
\hline$\geq 7$ Hours & 1,449 & 26.74 & 2,816 & 51.97 & 1,153 & 21.28 & 6,450 & 54.35 \\
\hline \multicolumn{9}{|l|}{$\begin{array}{l}\text { Sleep Duration } \\
\text { Weekends }\end{array}$} \\
\hline$<7$ Hours & 1,049 & 26.36 & 2,052 & 51.56 & 879 & 22.09 & 3,980 & $33,47^{* *}$ \\
\hline$\geq 7$ Hours & 2,140 & 27.05 & 4,297 & 54.32 & 1,473 & 18.62 & 7,910 & 66.53 \\
\hline \multicolumn{9}{|l|}{$\begin{array}{l}\text { Afternoon Napping } \\
\text { Per week }\end{array}$} \\
\hline$<3$ naps & 1,556 & 32.7 & 2,464 & 51.78 & 739 & 15.53 & 4,759 & 39.98 \\
\hline$\geq 3$ naps & 1,633 & 22.86 & 3,896 & 54.53 & 1,616 & 22.62 & 7,145 & 60.02 \\
\hline \multicolumn{9}{|l|}{$\begin{array}{l}\text { Feeling Refreshed } \\
\text { in the Morning }\end{array}$} \\
\hline Never, rarely & 2,366 & 26.28 & 4,841 & 53.78 & 1,795 & 19.94 & 9,002 & 75.69 \\
\hline Sometimes, often, always & 823 & 28.46 & 1,513 & 52.32 & 556 & 19.23 & 2,892 & 24.31 \\
\hline
\end{tabular}

* denotes prevalence of SD reported in the sample on weekdays

${ }^{* *}$ denotes prevalence of SD reported in the sample on weekends

\subsection{Factors associated with sleep deprivation}

Pearson Chi square bivariate analysis showed the following factors were significantly associated with sleep deprivation: stage of adolescence $(p=0.0006)$, gender $(p<.0001)$, socioeconomic status $(p<.0001)$, academic performance $(p<.0001)$, meal servings per day $(p<.0001)$, screen time (television and computer 
use) ( $p$ <.0001), playing video games $(p=0.0006)$, physical activity $(p=0.0014)$ and daytime napping ( $p$ $<.0001)$.

Table 3 presents the findings of adjusted binary logistic regression analysis, females [OR 1.23; $\mathrm{Cl}$ (1.14 1.34)] and older (18-19 years old) adolescents, [OR 1.19; 95\% Cl (1.05-1.32)] were more likely to report SD. Adolescents who considered themselves to be "poorer than others" in socioeconomic status [OR 1.51; $\mathrm{Cl}(1.28$ - 1.78)] and adolescents who reported eating fewer than three meals per day [OR 1.17; $\mathrm{Cl}$ (1.09 1.27)] were also more likely to report SD (Table 3).

In contrast, adolescents reporting screen exposure to television and computers (Internet) for $\geq 2$ hours per day [OR 0.81, $\mathrm{Cl}(0.75-0.88)]$, [OR 0.83, $\mathrm{Cl}(0.77-0.91)$ ], were less likely to report SD. Likewise, adolescents who frequently napped $\geq 3$ days per week [OR $0.87, \mathrm{Cl}(0.81-0.94)]$ had a decreased likelihood of reporting SD (Table 3). 
Table 3: Factors associated with SD: Results of the binary logistic regression model $(\mathbf{N}=\mathbf{1 2}, \mathbf{1 2 1})$

\begin{tabular}{|c|c|c|c|c|}
\hline Parameter & A-OR & SE & $95 \% \mathrm{Cl}$ & P-value \\
\hline \multicolumn{5}{|l|}{ Gender } \\
\hline Male & 1 & & & \\
\hline Female & $1.23^{*}$ & 0.05 & $1.14-1.34$ & 0 \\
\hline \multicolumn{5}{|l|}{$\begin{array}{l}\text { Stages of Adolescence } \\
\text { [Age Group] }\end{array}$} \\
\hline Early [10-14 yrs] & 1 & & & \\
\hline Middle [15-17 yrs] & 0.96 & 0.04 & $0.89-1.06$ & 0.369 \\
\hline Late [18-19 yrs] & $1.18^{*}$ & 0.07 & $1.05-1.32$ & 0.005 \\
\hline \multicolumn{5}{|l|}{ Body Mass Index } \\
\hline Underweight & 0.89 & 0.06 & $0.77-1.02$ & 0.104 \\
\hline \multicolumn{5}{|l|}{$<5$ th Centile } \\
\hline Healthy weight & 0.95 & 0.05 & $0.85-1.06$ & 0.34 \\
\hline \multicolumn{5}{|l|}{$5-<85$ th Centile } \\
\hline Overweight & 1 & & & \\
\hline \multicolumn{5}{|l|}{$\geq 85$ th $-<95$ th Centile } \\
\hline Obese $\geq 95$ th Centile & 0.93 & & $0.81-1.07$ & 0.309 \\
\hline \multicolumn{5}{|l|}{ Self Reported SES } \\
\hline Better than others & 1 & & & \\
\hline Like Others & $1.12^{*}$ & 0.05 & $1.02-1.23$ & 0.021 \\
\hline Poorer than others & $1.51^{*}$ & 0.13 & $1.28-1.78$ & 0 \\
\hline \multicolumn{5}{|l|}{$\begin{array}{l}\text { Self-reported academic } \\
\text { performance }\end{array}$} \\
\hline Average & 1.47 & 0.28 & $1.02-2.13$ & 0.04 \\
\hline Above Average & 0.99 & 0.15 & $0.74-1.33$ & 0.95 \\
\hline Don't Know & 1.46 & 0.32 & $0.96-2.23$ & 0.077 \\
\hline \multicolumn{5}{|l|}{ TV Screen Time } \\
\hline$<2$ hours & 1 & & & \\
\hline$\geq 2$ Hours & $0.81 *$ & 0.03 & $0.75-0.88$ & 0 \\
\hline \multirow{2}{*}{\multicolumn{5}{|c|}{$\begin{array}{l}\text { Computer (Internet) } \\
\text { Screen Time }\end{array}$}} \\
\hline & & & & \\
\hline$<2$ hours & 1 & & & \\
\hline$\geq 2$ Hours & $0.83^{*}$ & 0.04 & $0.77-0.91$ & 0 \\
\hline \multirow{2}{*}{\multicolumn{5}{|c|}{$\begin{array}{l}\text { Video Game } \\
\text { Screen time }\end{array}$}} \\
\hline & & & & \\
\hline$<2$ hours & 1 & & & \\
\hline$\geq 2$ Hours & 0.96 & 0.06 & $0.85-1.08$ & 0.451 \\
\hline \multicolumn{5}{|l|}{ No. of Main Meals/day } \\
\hline$\geq 3$ meals & 1 & & & \\
\hline$<3$ meals & $1.17^{*}$ & 0.05 & $1.09-1.27$ & 0 \\
\hline \multicolumn{5}{|l|}{$\begin{array}{l}\text { Daily Energy Drink } \\
\text { Consumption }\end{array}$} \\
\hline Yes & 1 & & & \\
\hline No & 1.01 & 0.04 & $0.93-1.01$ & 0.755 \\
\hline \multicolumn{5}{|l|}{$\begin{array}{l}\text { Cigarette Smoking in the } \\
\text { past month }\end{array}$} \\
\hline No & 1 & & & \\
\hline
\end{tabular}




\begin{tabular}{|c|c|c|c|c|}
\hline Yes & 1.05 & 0.08 & $0.89-1.22$ & 0.574 \\
\hline \multicolumn{5}{|c|}{$\begin{array}{l}\text { Freq of physical exercise } \\
\text { (30mins) per week }\end{array}$} \\
\hline$<3$ days & 1 & & & \\
\hline$\geq 3$ days & 0.92 & 0.04 & $0.85-1.01$ & 0.091 \\
\hline \multicolumn{5}{|c|}{$\begin{array}{l}\text { Afternoon Nap } \\
\text { Frequency/week }\end{array}$} \\
\hline$<3$ naps & 1 & & & \\
\hline$\geq 3$ naps & $0.87^{*}$ & 0.04 & $0.81-0.94$ & 0.001 \\
\hline
\end{tabular}

\section{Discussion}

This is the first study to report the prevalence of SD for a nationally representative sample of adolescents in Saudi Arabia. In fact, the present study's weekday estimated prevalence of SD is the highest reported figure to date, with close to half the sample (46\%) sleeping hours that are non-recommended by the National Sleep Foundation. Furthermore, this study is the first to assess SD across all stages of adolescence (early, middle and late) in Saudi Arabia.

The high prevalence of SD among adolescents in our study mirrors a global trend of SD affecting high proportions of the adolescent population in many countries, such as the US [24], Europe, [8] China, [38] Japan, [40] and Kuwait.[41]. In addition, it extends and corroborates previous work in Saudi Arabia undertaken by Hazzaa et al who reported the prevalence of SD (sleeping <7 hours) among adolescents to be $31 \%$ in 2009-2010 [32,33]. It is interesting to note that high SD prevalences have also been reported among children and adults in Saudi Arabia. A recent study of 2,025 Saudi adults reported that 33.8\% were sleeping $<7$ hours [42]. Given the high prevalence of SD among Saudi society, it is plausible that the sleep behavior of adolescents is being influenced by the sleep habits and patterns of their parents [43]. Sleeping less than 7 hours may have a greater impact on adolescents compared to adults since adolescents biologically have an increased sleep need (i.e require more sleep hours per day) compared to adults. Indeed, the National Sleep Foundation sleep duration recommendations of 2015 state that sleeping 6 hours for adults 18-64 years, "may be appropriate" The same sleep duration in adolescents, however, is not recommended.

A number of factors could explain the high prevalence of SD among adolescents seen in the country. It is well documented that puberty in adolescents shifts biological circadian rhythms delaying release of the sleep inducing hormone melatonin with levels peaking later at night (11pm-8am) [44] and resulting in 
delayed sleep onset [45-48]. Puberty therefore biologically predisposes adolescents to encounter difficulties in initiating sleep early and waking up early. In addition to biology, a number of environmental factors may be contributing to the SD observed among adolescents in our study. For example, sleeping late may be a cultural and behaviorally acceptable normal habit for the general Saudi population. Many social activities tend to occur during the late hours of the night; retail shops and restaurants stay open quite late throughout the week with most shopping malls closing their doors at $11 \mathrm{pm}$. It is therefore not unusual to see young children and adolescents out in public places late at night. One study observing sleeping habits in 1,035 Saudi adolescents in Jeddah reported average school night sleeping time on weekdays to be 23.55 hours, with over a third sleeping after midnight [34]. Sleep deprivation therefore may be an outcome of evening orientation and later chronotype in our sample. A study among a sample of adolescents (Vollmer et al.) reported that circadian rhythms can be shifted to "eveningness" or eveningtype orientation by factors that prolong daylight into evening and night hours, such as artificial nocturnal light, electronic media use, and other factors [47]. Furthermore, climatic zones can also influence chronotype, with adolescents living in the subtropics having later chronotypes. Saudi Arabia is a country with subtropical climate; however, to objectively assess the relationship between chronotype and sleep deprivation among our sample, further in-depth studies are needed that collect data on adolescent sleep timings. Late sleep times in households may arise where parents are unaware of the importance of getting enough sleep; the differences in sleep need among adults, children and adolescents in terms of required daily sleep hours; and fundamentally the consequences that sleep deprivation can have on their own health and that of their adolescents. A study addressing problems and challenges regarding sleep medicine in Saudi Arabia reported that most of the Saudi public were unaware of the adverse physical, psychological and social effects of sleep deprivation [48]. As such, parents themselves may be less strict in insisting their children and adolescents go to sleep at set times. In fact, parental knowledge regarding child sleep, child sleep needs, and sleep hygiene practices are known to be associated with "indices of healthy sleep". Parents with more knowledge on child sleep report earlier bedtimes on weekdays and weekends [49]. School start times in Saudi Arabia may be another disrupting factor. On weekdays, children and adolescents in Saudi Arabia have exceptionally early wake times because the majority of schools begin at 07:00. Multiple studies have shown that early school start times are linked to SD, and that by delaying school start times, weeknight sleep duration in adolescents is increased [49]. To improve adolescent sleep duration at night, the American Academy of Pediatrics issued a policy statement in 2014 recommending that "middle and high schools should aim for school start times no earlier than 8.30 am" [50]. In fact, our study did show much higher prevalence of SD among adolescents during weekdays (46\%) (note a time 
when schools are open) compared to weekends (33\%), suggesting that early school start times could be an influencing factor for the SD reported by Saudi adolescents in our sample.

Female gender, older age group of adolescents, those who perceived themselves to be poorer than others, and those who ate fewer main meals per day were identified as having increased likelihood of SD among our sample. Population based studies in the United States reinforce our findings that female adolescents report sleeping fewer hours than their male counterparts. Girls tend to undergo pubertal changes earlier than boys, which may account for the difference seen in SD. The association between increasing adolescent age and SD has been established in previous studies [51]. Older adolescents are more independent and autonomous than younger adolescents; as such they are less likely to have parents monitoring their sleep times [52]. They may also be more likely than younger adolescents to have access to personal electronic devices (smartphones the nocturnal use of which has been associated with SD) and to be more likely to socialize online. The association of lower SES increasing likelihood of adolescents reporting SD has been published in a few studies. It has been postulated that families of low SES have lower awareness of sleep hygiene practices and that their homes may be less organized and more noisy [53]. Saudi households also tend to be large in size, with the average family size ranging between 5.5 to 6.4 persons per household [54]. Coupled with low SES, it is conceivable that adolescents from poorer households may not have access to their own room and may have to share rooms and beds with siblings [55]. Bedroom sharing is known to impede the ability to sleep adequately and is associated with later nocturnal sleep times, later wake times, and SD [56].

Our study showed daytime napping and prolonged screen time exposure (to television and Internet) was negatively associated with SD. Daytime napping is common among school and university students in the country $[57,58]$; for instance, one study reported that $41 \%$ of elementary students take daytime naps. This was also the case in our study, in which a significant number of adolescents reported taking daytime naps. Although daytime napping is thought to delay sleep time and to contribute to shorter nocturnal sleep duration [59] in adolescents, it has also been found to work as a mechanism to compensate for sleep deficits during weekdays and weekends $[58,60]$. Further studies are needed to better explain the napping behavior among adolescents in Saudi Arabia and to understand the temporal relationship between daytime napping behavior and SD in this population.

As for prolonged screen time exposure (television or Internet use unrelated to schoolwork), our results showed that adolescents were less likely to have SD when compared to those with less screen time exposure. This finding contradicts the published literature on this topic [26]. However, our results are in 
line with another study that looked at lifestyle correlates of SD among adolescents within Saudi Arabia. The study by Al-Hazzaa found that adolescents watching $>5$ hours had 1.505 odds of sleeping 8 hours or more [33]. It appears that in the context of Saudi Arabia, there is a level of repeatability to our findings, it is not clear why prolonged screen exposure would increase sleep duration among adolescents in the country, and further in-depth studies are needed.

The limitations of our study include its cross-sectional design, which make it impossible to determine the temporal relationship between our variables of interest and SD or to make any inferences on SD causality. Furthermore, the question assessing sleep duration was self-reported; responses are subjective and therefore prone to measurement and recall bias which can affect the validity and accuracy of reported sleep durations. The question itself "How many hours do you sleep" relied upon students remembering when they go to bed and when they wake up and giving an average estimate of their sleep hours. Again, the value would be subject to both recall and measurement bias. Asking exact sleep times and wake times from the participants would have been a more accurate method of calculating their sleep durations. Objective measures such as actigraphy or polysomnography would be the preferred method to accurately assess sleep times. Finally, lack of a universal definition for defining SD means that different studies use different cut-off numbers of hours to define the outcome, making comparisons between studies difficult.

\section{Conclusions}

Sleep deprivation among adolescents in Saudi Arabia is a significant public health concern. Almost onehalf of all adolescents in the study suffered from SD during weekdays, and nearly three-quarters reported not feeling refreshed in morning. Frequent daytime napping during the week was also observed. We found that a number of biological, demographic, lifestyle, and environmental factors were significantly associated with SD among Saudi adolescents. Given the health, academic, and societal impact of SD, there is an urgent need for preventive strategies. Delaying school start times would be a good first step. Promoting adolescent and public awareness of the importance of adequate sleep and consequences of sleep deprivation, in addition to recommending sleep hygiene behaviors, would also help address the problem. 


\section{References}

1. Ruthann Richter, S.M.N.C. Among teens, sleep deprivation an epidemic. 8th Oct 2015; Available from: https://med.stanford.edu/news/all-news/2015/10/among-teens-sleep-deprivation-anepidemic.html.

2. Hagenauer, M.H., et al., Adolescent Changes in the Homeostatic and Circadian Regulation of Sleep. Developmental Neuroscience, 2009. 31(4): p. 276-284.

3. Sivertsen, B., et al., Sleep and body mass index in adolescence: results from a large populationbased study of Norwegian adolescents aged 16 to 19 years. BMC Pediatrics, 2014. 14: p. 204-204.

4. Shochat, T., M. Cohen-Zion, and O. Tzischinsky, Functional consequences of inadequate sleep in adolescents: A systematic review. Sleep Medicine Reviews, 2014. 18(1): p. 75-87.

5. Thind, H., et al., Does Short Sleep Lead to Obesity Among Children and Adolescents?: Current Understanding and Implications. American Journal of Lifestyle Medicine, 2014.

6. Quist, J.S., et al., Sleep and cardiometabolic risk in children and adolescents. Sleep Med Rev, 2015. 29: p. 76-100.

7. Knutson, K.L., Sleep duration and cardiometabolic risk: a review of the epidemiologic evidence. Best Pract Res Clin Endocrinol Metab, 2010. 24(5): p. 731-43.

8. Rey-Lopez, J.P., et al., Sleep time and cardiovascular risk factors in adolescents: the HELENA (Healthy Lifestyle in Europe by Nutrition in Adolescence) study. Sleep Med, 2014. 15(1): p. 104-10.

9. Lo, J.C., et al., Cognitive Performance, Sleepiness, and Mood in Partially Sleep Deprived Adolescents: The Need for Sleep Study. Sleep, 2015.

10. Short, M.A. and M. Louca, Sleep deprivation leads to mood deficits in healthy adolescents. Sleep Med, 2015. 16(8): p. 987-93.

11. Gangwisch, J.E., et al., Earlier parental set bedtimes as a protective factor against depression and suicidal ideation. Sleep, 2010. 33(1): p. 97-106.

12. Hysing, M., et al., Sleep problems and self-harm in adolescence. Br J Psychiatry, 2015. 207(4): p. 306-12.

13. Clarke, G. and A.G. Harvey, The Complex Role of Sleep in Adolescent Depression. Child and adolescent psychiatric clinics of North America, 2012. 21(2): p. 385-400.

14. Martiniuk, A.L., et al., Sleep-deprived young drivers and the risk for crash: the DRIVE prospective cohort study. JAMA Pediatr, 2013. 167(7): p. 647-55. 
15. Wong, M.M., G.C. Robertson, and R.B. Dyson, Prospective relationship between poor sleep and substance-related problems in a national sample of adolescents. Alcohol Clin Exp Res, 2015. 39(2): p. 355-62.

16. Terry-McElrath, Y.M., et al., Sleep and Substance Use among US Adolescents, 1991-2014. Am J Health Behav, 2016. 40(1): p. 77-91.

17. Pasch, K.E., et al., Longitudinal bi-directional relationships between sleep and youth substance use. J Youth Adolesc, 2012. 41(9): p. 1184-96.

18. Stea, T.H., T. Knutsen, and M.K. Torstveit, Association between short time in bed, health-risk behaviors and poor academic achievement among Norwegian adolescents. Sleep Med, 2014. 15(6): p. 666-71.

19. Hysing, M., et al., Sleep and academic performance in later adolescence: results from a large population-based study. J Sleep Res, 2016.

20. Tonetti, L., V. Natale, and C. Randler, Association between circadian preference and academic achievement: A systematic review and meta-analysis. Chronobiol Int, 2015. 32(6): p. 792-801.

21. Curcio, G., M. Ferrara, and L. De Gennaro, Sleep loss, learning capacity and academic performance. Sleep Medicine Reviews, 2006. 10(5): p. 323-337.

22. Hysing, M., et al., Sleep and school attendance in adolescence: results from a large populationbased study. Scand J Public Health, 2015. 43(1): p. 2-9.

23. Felden, É.P.G., et al., Factors associated with short sleep duration in adolescents. Revista Paulista de Pediatria (English Edition).

24. Keyes, K.M., et al., The great sleep recession: changes in sleep duration among US adolescents, 1991-2012. Pediatrics, 2015. 135(3): p. 460-8.

25. Moore, M. and L.J. Meltzer, The sleepy adolescent: causes and consequences of sleepiness in teens. Paediatr Respir Rev, 2008. 9(2): p. 114-20; quiz 120-1.

26. Hale, L. and S. Guan, Screen time and sleep among school-aged children and adolescents: A systematic literature review. Sleep Medicine Reviews, 2015. 21: p. 50-58.

27. Sanchez, S.E., et al., Sleep Quality, Sleep Patterns and Consumption of Energy Drinks and Other Caffeinated Beverages among Peruvian College Students. Health (Irvine Calif), 2013. 5(8b): p. 2635.

28. Lemma, S., et al., The Epidemiology of Sleep Quality, Sleep Patterns, Consumption of Caffeinated Beverages, and Khat Use among Ethiopian College Students. Sleep Disord, 2012. 2012: p. 583510. 
29. Wheaton, A.G., D.P. Chapman, and J.B. Croft, School Start Times, Sleep, Behavioral, Health, and Academic Outcomes: A Review of the Literature. J Sch Health, 2016. 86(5): p. 363-81.

30. Bawazeer, N.M., et al., Sleep duration and quality associated with obesity among Arab children. Obesity (Silver Spring), 2009. 17(12): p. 2251-3.

31. Kilani, H., et al., Lifestyle Habits: Diet, physical activity and sleep duration among Omani adolescents. Sultan Qaboos Univ Med J, 2013. 13(4): p. 510-9.

32. Al-Hazzaa, H.M., et al., Prevalence of short sleep duration and its association with obesity among adolescents 15- to 19-year olds: A cross-sectional study from three major cities in Saudi Arabia. Ann Thorac Med, 2012. 7(3): p. 133-9.

33. Al-Hazzaa, H.M., et al., Lifestyle correlates of self-reported sleep duration among Saudi adolescents: a multicentre school-based cross-sectional study. Child Care Health Dev, 2014. 40(4): p. 533-42.

34. Merdad, R.A., et al., Sleep habits in adolescents of Saudi Arabia; distinct patterns and extreme sleep schedules. Sleep Med, 2014. 15(11): p. 1370-8.

35. AlBuhairan, F.S., et al., Time for an Adolescent Health Surveillance System in Saudi Arabia: Findings From "Jeeluna". J Adolesc Health, 2015. 57(3): p. 263-9.

36. World Health Organisation. Global school-based student health survey (GSHS). Noncommunicable diseases and their risk factors 2018 03/01/2018]; Available from: http://www.who.int/ncds/surveillance/gshs/en/.

37. Centers for Disease Control and Prevention. YRBSS in Brief. Adolescent and School Health 2016 [cited 2018 03/01]; Available from: https://www.cdc.gov/healthyyouth/data/yrbs/index.htm.

38. Chen, T., et al., Sleep duration in Chinese adolescents: biological, environmental, and behavioral predictors. Sleep Med, 2014. 15(11): p. 1345-53.

39. Hirshkowitz, M., et al., National Sleep Foundation's updated sleep duration recommendations: final report. Sleep Health, 2015. 1(4): p. 233-243.

40. Ohida, T., et al., An epidemiologic study of self-reported sleep problems among Japanese adolescents. Sleep, 2004. 27(5): p. 978-85.

41. Al-Haifi, A.A., et al., Relative Contribution of Obesity, Sedentary Behaviors and Dietary Habits to Sleep Duration Among Kuwaiti Adolescents. Global Journal of Health Science, 2016. 8(1): p. 107117.

42. Ahmed, A.E., et al., Prevalence of sleep duration among Saudi adults. Saudi Medical Journal, 2017. 38(3): p. 276-283. 
43. Fuligni, A.J., et al., Daily Concordance between Parent and Adolescent Sleep Habits. The Journal of adolescent health : official publication of the Society for Adolescent Medicine, 2015. 56(2): p. 244250.

44. Center, N.A.a.Y.a.H.I. Sleep deprivation in adolescents and young adults. 2014; Available from: http://nahic.ucsf.edu/wp-content/uploads/2014/08/sleep-brief-final.

45. Carskadon, M.A., C. Vieira, and C. Acebo, Association between puberty and delayed phase preference. Sleep, 1993. 16(3): p. 258-62.

46. Carskadon, M.A., Sleep in Adolescents: The Perfect Storm. Pediatric Clinics of North America, 2011. 58(3): p. 637-647.

47. Vollmer, C., Michael, U., Randler, C. Outdoor light at night (LAN) is correlated with eveningness in adolescents. Chronobiol Int, 2012. 4: p. 502-508.

48. BaHammam, A.S., Sleep medicine in Saudi Arabia: Current problems and future challenges. Annals of Thoracic Medicine, 2011. 6(1): p. 3-10.

49. McDowall, P.S., D.E. Elder, and A.J. Campbell, Relationship between parent knowledge of child sleep, and child sleep practices and problems: A pilot study in a children's hospital cohort. J Paediatr Child Health, 2017. 53(8): p. 788-793.

50. Adolesent sleep working group, c.o.a., council on school health, American Academy of Pediatrics Policy statement, School Start Times for Adolescents. Pediatrics, 2014. 134(3): p. 642.

51. Felden, É.P.G., et al., Factors associated with short sleep duration in adolescents. Revista Paulista de Pediatria (English Edition), 2016. 34(1): p. 64-70.

52. Randler, C. and S. Bilger, Associations among sleep, chronotype, parental monitoring, and pubertal development among German adolescents. J Psychol, 2009. 143(5): p. 509-20.

53. Felden, É.P.G., et al., Sleep in adolescents of different socioeconomic status: a systematic review. Revista Paulista de Pediatria, 2015. 33(4): p. 467-473.

54. Abdul Salam, A., et al., Population distribution and household conditions in Saudi Arabia: reflections from the 2010 Census. SpringerPlus, 2014. 3: p. 530.

55. Li, S., et al., Factors associated with bed and room sharing in Chinese school-aged children. Child Care Health Dev, 2009. 35(2): p. 171-7.

56. Li, S., et al., Bed-and room-sharing in Chinese school-aged children: prevalence and association with sleep behaviors. Sleep Med, 2008. 9(5): p. 555-63.

57. Thorleifsdottir, B., et al., Sleep and sleep habits from childhood to young adulthood over a 10-year period. J Psychosom Res, 2002. 53(1): p. 529-37. 
58. Gradisar, M., et al., Adolescent napping behavior: Comparisons of school week versus weekend sleep patterns. Sleep and Biological Rhythms, 2008. 6(3): p. 183-186.

59. Jakubowski, K.P., et al., Temporal Relationships Between Napping and Nocturnal Sleep in Healthy Adolescents. Behav Sleep Med, 2017. 15(4): p. 257-269.

60. Malone, S.K., et al., Characteristics associated with Sleep Duration, Chronotype, and Social jet lag in Adolescents. The Journal of school nursing : the official publication of the National Association of School Nurses, 2016. 32(2): p. 120-131. 
Chapter 9

Discussion 
Chapter 9 
This is the first study to address health and the health needs of adolescents in Saudi Arabia at a national level. Though there have been studies addressing specific health related items or issues among some groups and cohorts of adolescents, these studies are scarce, do not address overall health, and are limited to certain subpopulations or geographical areas of the country. Health, as defined by the World Heath Organization in 1948 is the "state of complete physical, mental and social well-being and not merely the absence of disease or infirmity" (1), and given the changing needs of populations and the reality of increasing chronic disease, has been adapted further to include the ability to adapt and self-manage in the face of social, physical, and emotional challenges (2). Local literature and evidence on adolescent health is scarce and when available typically focuses on specific disease conditions in subpopulations of adolescents. For the first time, with Jeeluna, data reflecting the comprehensive definition of health is addressed, and data representative of adolescents at the national level in Saudi Arabia is available.

The great majority of adolescents are disease-free. I intentionally refrain from stating they are 'healthy', because lack of illness/disease does not necessarily equate to health. Adolescence, however, is a time of exploration, experimentation, and establishing behaviors that often continue into adulthood and contribute to health risk, i.e., health risk behaviors. It is for this reason that this study has a great deal of focus on different adolescent behaviors. It is known that approximately $70 \%$ of premature adult death is due to behaviors that are initiated in adolescence (and which can be prevented) (3). Therefore, recognizing what behaviors our adolescents engage in and intervening earlier to prevent them, has a triple dividend on the long term (4). Simply stated, preventing many of the behaviors that initiate in adolescence will contribute to overall adult health on the long term. In other words, not only will investing in adolescent health benefit adolescents themselves, but it will also positively impact future health trajectories across the life-course and support a healthier start for subsequent generations (4).

In order to be able to make recommendations and take action to address adolescents' health in Saudi Arabia, it is first essential to have a baseline understanding of the status quo. Prior to conducting Jeeluna, there was no existing baseline information or evidence to resort to. In fact, that was the very reason that led me to conceiving the study. Upon completing my fellowship in adolescent medicine in Toronto, Canada, I returned back to my home country of Saudi Arabia, where I was the first physician specialized in adolescent medicine. My immediate aim was to start practicing within my area of specialization and be able to serve this often-forgotten population. I had learned early in my training that it was important to conduct a needs assessment prior to setting up a new service, so that I would be able to address the particular needs of the population I was serving. Being challenged by many about the need for such a 
service to be established further exaggerated the need for having the evidence to support my claims. It was not long after I began my literature search, that I realized that the topic I was searching for was almost negligible. The great bulk of the literature on adolescents and their health came from the West; this is not what I was looking for. I required local, or at least regional, evidence to be able to support my claims of the need for setting up adolescent health services and programs. This was because of the fact that many around me associated adolescent health and behaviors with culture, and that 'adolescence was something of the West'. There was a lack of understanding that adolescence is a stage in life where multiple areas of growth and development occur. The only way to truly find out how adolescence was presenting in Saudi Arabia and what the health needs of our young people were was to carry out a research study in order to generate the evidence. It is only with such evidence that decisions towards policy development and program planning and delivery can take place in an evidence-informed manner.

\section{Identified health needs and health risk behaviors}

Chapter 3 begins with providing an overall picture of the status of health and the existing health risk behaviors among adolescents in Saudi Arabia. This chapter sets the stage for subsequent chapters that delve into further exploration of specific problematic items that were identified in Chapter 3. Since the methodology applied to the overall study, as described in Chapter 2, was done at the population level and subsequent weighting of the data took place thereafter, the results found are applicable and can be generalized at the national level.

Not surprisingly, adolescents in Saudi Arabia were found to engage in behaviors that put their health at risk. Most prominently, adolescents were found to have poor dietary habits, inadequate physical activity, lacked traffic safety and were exposed to bullying and physical violence. A considerable proportion of the adolescent population was overweight or obese. Similarly, there was a considerable number of adolescents who reported symptoms suggestive of underlying depression or anxiety. Strikingly, though it is known that there are gender differences when it comes to mental health problems in adolescents, with it being more prevalent among females, this disparity was even greater in our population. Though tobacco and alcohol/substance use exist, the rates were less than that reported from other parts of the world.

Another item that was addressed in Chapter 3 was access to health services. This presented as a challenge to $24 \%$ of adolescents, with the quality of care also being an area of concern. Being a determinant of health, access to care is essential when addressing health status of a population. It is important for 
promoting and maintaining health and the quality of life and preventing and managing disease. Achieving health equity is also impacted by access to care (5).

Early on in the study, it was concluded that establishing a surveillance system to periodically (re)assess the status of health of adolescents is needed. This first round of Jeeluna identified the problems and magnitude of each problem; as with any population health issue, subsequent rounds of assessment are required to identify trends post introduction of the needed interventions, policies, or otherwise. It is only through such a system, that at the country level, we will be able have a comprehensive picture and approach to systematically address the changing needs of our young people.

\section{Weight Status: the double burden of malnutrition}

Overweight and obesity have become increasingly prevalent globally (6). Approximately half of the adolescent population in Saudi Arabia was found to be overweight/obese. It is not surprising considering the existent unhealthy eating behaviors found and the insufficient/lack of physical activity. Increased weight is known to be a risk factor for NCDs on the long term which greatly contribute to the burden of disease in Saudi Arabia and many other countries. It is foreseeable that much attention is given to overweight/obesity. The other extreme of malnutrition is often associated with childhood wasting and stunting in the younger years. Childhood wasting is expected to remain above the World Health Organization's global target of $<5 \%$ in many countries of the world (6). Adolescent malnutrition in the form of underweight is often neglected and may go unnoticed with underlying pathological conditions, such as eating disorders. Because body image is increasingly important during adolescence, it may be the time when young people begin to experience fad diets and other weight-loss measures. It may also be the time of onset of eating disorders. Fifteen percent of adolescents in Saudi Arabia were found to be underweight in Jeeluna, which is considerably lower than the prevalence of overweight/obesity; however, a good proportion of underweight adolescents believed that they required further weight loss. This is a red flag that may reflect underlying distorted body image. There is insufficient awareness and education around the topic of underweight in adolescents in Saudi Arabia, and for this reason, I highlight it here so that it be further addressed before it becomes a problem of larger magnitude. 


\section{Mental health: protective and risk factors}

Chapters 5 and 6 address mental health. Mental health problems have been found to be increasingly prevalent among adolescents over the past few decades (7). There is increasing attention to the fact that almost half of the burden of disease among adolescents and youth is attributed to mental health disorders (8), particularly depression and anxiety. As mentioned earlier, the gender disparity in mental health conditions is wider in the region (9).

Being such a prevalent condition, understanding the underlying predictors, in order to be able to address or prevent to the extent possible, is important. Females were found to be almost two times more likely than males to have underlying symptoms of depression or anxiety. Though gender, as well as other genetic traits, cannot be prevented, this alerts us to the importance of providing additional or different support measures to young female adolescents. Important protective factors, such as good relationships with parents cannot be overemphasized, as this is an area that can largely be promoted through adequate education and awareness of parents through parenting skills and effective communication for parents and their children alike. Similarly, physical activity, as a protective factor, is also important not only for mental health but for physical health as well.

With bullying and physical violence being prevalent among adolescents in Saudi Arabia, it was important to explore this area further. The short and long-term consequences of exposure to bullying and violence are known for both victims and perpetrators. Historically, bullying at schools in Saudi Arabia, had often gone unnoticed or undermined. This may be due to the lack of awareness and understanding of the phenomenon, as some believed that it was part of normal childhood play and teasing one another (10). We therefore thought it would be meaningful to explore the relationship of such with factors that would be considered of relative importance and would get the needed attention. Demonstrating evidence of a strong association between these experiences and increased odds of mental health problems and lower academic performance highlighted the problem of bullying and violence. Since then, there has in fact, been increasing efforts in the country and in schools in particular with the prevention of bullying and increasing the awareness of this among students, parents, and school professionals.

\section{Media and substance use}

There has been increasing concerns over the past several years about the role media may be playing in shaping young peoples' behaviors. Though some may not realize it, 'role modeling' may take place 
through what is observed in the media. As a country, Saudi Arabia has one of the highest rates of social media usage. It ranks as the $13^{\text {th }}$ country, with the use clearly above the global average (11). Though traditional media was censored for many years, in the past decade, there has been increasing exposure and access to the global media through the Internet, social media, and cable television. Though quality of content viewed in media is very important, quantifying the extent of exposure is an equally important first step.

Tobacco and substance use has been a topic of taboo and is more often addressed in the adult population. Addressing it in the adolescent population, both among early and late adolescents, as well as adolescents of both genders, is an area that has been shied away from. Therefore, obtaining the baseline information, though recognizing that underreporting may have been the case, of the prevalence of substance use among adolescents in Saudi Arabia is certainly an important start.

With Jeeluna, identifying the magnitude of both of these issues, i.e., media exposure and substance use, are significant objectives met. Taking this to the next step and addressing the relationship between the two sheds even further insight and highlights the importance of education programs directed at substance use prevention, including education on digital/media use, as well as systems' approach to policies directed to the media industry and Ministry of Culture.

\section{Sleep deprivation}

Sleep deprivation has been found to have serious physical and psychosocial impacts on adolescents and their health. Being largely a nocturnal society, with individuals often staying up late into the night and taking daytime afternoon naps, it is not surprising that adolescents in Saudi Arabia are similarly sleeping late and being sleep deprived. Early school start times has not been a supportive factor and certainly only aggravates the problem of sleep deprivation.

The reason sleep was specifically selected for further exploration in Chapter 8 , is because it is a topic often not explored with adolescents, it is something every single adolescent will carry out on a daily basis, it is practical to make some changes to sleeping schedules, and the literature has largely described the physical and psychosocial impacts of sleep deprivation, which are preventable. Chapter 8 also highlights the importance of not just educating adolescents, but also their parents who are setting examples for their children and are also getting an understanding of the importance of sleep and sleep hygiene. 


\section{Conclusion}

In conclusion and to my knowledge, this study, Jeeluna, has been the largest population-based study on adolescents not only in Saudi Arabia, but also in the Middle East region. Much of the data collected, particularly that on behaviors, was based on self-report, which comes with its own limitations. Some of this data was based on quantitative reflections with no or limited qualitative information. Furthermore, other data was based on objective measurements carried out by the research team which was utilized to provide an accurate magnitude of defined conditions, such as weight status. The data was collected directly from adolescents themselves, with no parental/guardian input; this has its advantages, though having some information from caregivers will be of benefit as well. Despite acknowledging these methodological limitations, Jeeluna has without a doubt clearly demonstrated that adolescents in Saudi Arabia largely have unmet needs when it comes to their health and they are engaging in behaviors that puts their health at risk. Future research is to take these limitations into consideration and build on them for further enhancing data collection. The evolving health needs of adolescents and their daily lives is to be continuously taken into consideration and addressed in future studies and measured indices, so as to be timely and relevant.

This study has laid the foundation for evidence-informed decision making for policy and program development and resource allocation. Having data available at the macro and micro levels, allows for prioritization to take place per regional needs, as opposed to a 'one-size fits all' approach. Importantly, a cross-sectoral approach is required to be able to address the comprehensive nature of health and its complexities that warrant 'health in all policies'. This is further addressed in the last chapter on Impact of this research. I envision this having been the first round of a series of rounds of study that will collectively result in a surveillance system that will provide the medium to identify trends and assessment over time. Only by doing so, will we be able to keep up with the dynamic nature of young people and the developing changes that go on in their everyday lives. 


\section{References}

1. Preamble to the Constitution of $\mathrm{WHO}$ as adopted by the International Health Conference, New York, 19 June - 22 July 1946; signed on 22 July 1946 by the representatives of 61 States.

2. Huber, M., Knottnerus, J. A., Green, L., Horst, H. v d., Jadad, A. R., Kromhout, D., et al. How should we define health? BMJ 2011; 343 :d4163 doi:10.1136/bmj.d4163

3. The second decade. Improving adolescent health and development. WHO, 1998.

4. Patton, G.C., Sawyer, S.M., Santelli, J.S., et al. Our future: a Lancet commission on adolescent health and wellbeing. Lancet. 2016;387(10036):2423-2478. doi:10.1016/S0140-6736(16)00579-1

5. Access to Health Services. Office of Disease Prevention and Health Promotion (ODPHP), 2019. Available at: https://www.healthypeople.gov/2020/topics-objectives/topic/Access-to-HealthServices [Accessed 22 Nov 2019)

6. LBD Double Burden of Malnutrition Collaborators. Mapping local patterns of childhood overweight and wasting in low- and middle-income countries between 2000 and 2017. Nat Med. 2020 May;26(5):750-759. doi: 10.1038/s41591-020-0807-6

7. Collishaw S, Maughan B, Natarajan L, Pickles A. Trends in adolescent emotional problems in England: a comparison of two national cohorts twenty years apart. J Child Psychol Psychiatry. 2010;51:885-94.

8. Gore FM, Bloem PJ, Patton GC, Ferguson J, Joseph V, Coffey C, et al. Global burden of disease in young people aged 10-24 years: a systematic analysis. Lancet. 2011;377:2093-102.

9. Obermeyer, C. M., Bott, S., Sassine, A.J. Arab Adolescents: Health, Gender, and Social Context, Journal of Adolescent Health, 2015;57(3): 252-262.

10. AlBuhairan, F., Al Eissa, M., Alkufeidy, N., Almuneef, M. Bullying in early adolescence: An exploratory study in Saudi Arabia. International Journal of Pediatrics and Adolescent Medicine 2016. 3.10.1016/j.ijpam.2016.01.002.

11. Time per day spent using the Internet. Globalwebindex, 2019. 
Summary 
Chapter 10 
Adolescents aged $10-19$ years make up $16 \%$ or 1.2 billion of the world's population today. Though they comprise a significant proportion of the world's population, their needs are often unaddressed (1). Adolescence is a critical transitional period from childhood to adulthood, which presents with many opportunities. The global community has fortunately realized this window of opportunity and relatively more attention to adolescents and their needs has been given in the past decade. This is reflected in global agendas, including the Sustainable Development Goals. The significance of investing in this young population has economic and social benefits with a significant return on investment.

Saudi Arabia is the largest country in the Arabian Peninsula with a population of 34 million (2). It has a young population with $46.3 \%$ below 30 years; $14 \%$ of the population are adolescents aged $10-19$ years (3). Saudi Arabia has a high literacy rate which has increased among adults from $70 \%$ in 1992 to $95 \%$ in 2017, and among youth 15-24 years, it increased from 88\% in 1992 to 99\% in 2017 (4). Universal health coverage is provided to all, though there remains much room for prevention and health promotion. Much of the preventive efforts have focused on childhood immunizations, which have been successful with achieving high target rates and decreasing communicable disease.

Despite the large proportion of adolescents in Saudi Arabia, they have been quite neglected when it comes to addressing their needs, particularly their health care needs. Historically, health care has catered for children or adults, with the cut-off being 12 years (increased to 14 years in recent years). This means that at the magical age of 12 years, an individual is cared for by a healthcare provider trained to address adult health care needs. Younger adolescents are cared for by providers trained to address childhood needs; this does not include adolescent health needs, but primarily covers earlier childhood needs. The leaves adolescents to be cared for by individuals who are not in tune with the particular needs of adolescents and so a significant gap exists. This is coupled with the fact that existing national datasets dichotomize the population into $<15$ years and $\geq 15$ years, addressing only child or adult related issues respectively.

Jeeluna study was therefore conceived in order to fill these gaps. It has generated the evidence to inform the development of the required services/programs and policies necessary to address the health needs of adolescents in Saudi Arabia. It is a population, school-based study conducted throughout all 13 regions of the country. To my knowledge, this is the largest epidemiological study conducted on adolescents in the region. It has included over 12,500 adolescent participants and health has been addressed in its various domains, including physical, mental, and social/behavioral aspects, so as to have a comprehensive understanding of the status quo. 
This thesis is based on scholarly publications from the Jeeluna study. Each publication focuses on a specific aspect of adolescent health, whether it be an issue relating to a physical, mental, or social aspect of health, yet at the same time, each reflects the strong interrelationship between these domains of health as well as the social determinants of health.

The health status and behaviors that our adolescents engage in are aligned with the burden of disease we see among adults in Saudi Arabia. This highlights the importance of having a life course lens to health and investing in adolescent health in order to prevent many of these behaviors and conditions that may persist into adulthood and further shoulder the burden of disease in the future. In recent years, Saudi Arabia has taken significant strategic steps towards transformation, both economically and as a society. The ambitious Vision 2030 for the country focuses on achieving a thriving economy and a vibrant society, with multiple key objectives, including having fulfilling and healthy lives for its citizens and residents. Efforts for this paradigm shift, including a focus on value-based care, prevention, and health promotion are areas being highlighted at the national transformation level. Though Jeeluna was conceived back in 2007 , long before the conception of Vision 2030, it is of great opportunity and of reassurance that the recommendations that have stemmed out of each of the chapters/publications are aligned with various objectives of the Vision 2030. The Health Sector Transformation Program, which is one of the Vision Realization Programs, includes membership from the different government sectors (5), which supports the importance of the cross-sectoral approach to health, as well as the importance of health in all policies.

Further work beyond this thesis has been conducted in which key health indicators have been mapped using geographical information systems so that regional level data is also available, in order to reflect the needs of a particular region and be able to prioritize addressing regional adolescent health needs. This knowledge has been shared with the various government stakeholders, such as the Ministry of Health, Ministry of Education, and Ministry of Economy and Planning.

Jeeluna provides the baseline status of health among adolescents in Saudi Arabia. It is recommended that a national surveillance system be established so that trends in adolescents' health be identified over time, as implementation of the needed services, policies, and required capacity building in adolescent health take place. 


\section{References}

1. Adolescents

Overview.

UNICEF.

Available

at:

https://data.unicef.org/topic/adolescents/overview/\#: :text=Adolescents\%20\%E2\%80\%93\%20defin ed\%20by\%20the\%20United,the\%20Rights\%20of\%20the\%20Child. [Accessed on 17 May 2021]

2. General Authority for Statistics Kingdom of Saudi Arabia. Available at: https://www.stats.gov.sa/en [Accessed on 17 May 2021]

3. Population Pyramid. Available at: https://www.populationpyramid.net/saudi-arabia/2020/ [Accessed on 17 May 2021]

4. Saudi Arabia Education and Literacy. UNESCO Institute for Statistics. Available at: http://uis.unesco.org/en/country/sa [Accessed on 17 May 2021]

5. Health Sector Transformation Program. Vision Realization Programs. Available at: https://www.vision2030.gov.sa/v2030/vrps/hstp/ [Accessed on 12 June 2021]. 
Impact paragraph 
Chapter 11 
Though adolescents comprise a significant proportion of Saudi Arabia's population, insufficient attention has been given to their health needs. Furthermore, data reflective of their health needs is scarce, reflects certain adolescent subpopulations, and addresses limited aspects of their health. For the first time, Jeeluna study has generated the evidence to reflect the comprehensive status of health among a nationally representative sample of adolescents across the country. In fact, Jeeluna has put forward to the country an expanded database of adolescent health parameters and indices with a total of over 1.5 million variables available. Though many analyses and sub-analyses have taken place, there continues to be room for further and ongoing analyses.

The impact of Jeeluna can largely focus on two areas: 1) implications for research and 2) implications for policy and practice.

\section{1) Implications for research}

The limitations of Jeeluna's research methodology have already been addressed throughout the previous chapters. Many articles have been published contributing to the scholarly and scientific literature. Data from Jeeluna has been utilized in global research collaborations to support the learning and understanding of global adolescent health issues through pooled data analyses (1). In an effort to support data access to other researchers, I advocated for open access data for several years. This materialized to some extent by having an institutional online platform that was developed and which provides information about Jeeluna, data visualizations, and a means for requesting data for research purposes (2). Having data publicly accessible has obvious multiple benefits; this has been taken to the next step with a national research data and repository platform which have realized the importance of Jeeluna data and requested that it be publicly available on this national platform. Lastly, the National Institute of Health Research in Saudi Arabia has identified its priority research tracks for the next 5 years; adolescent health research has been identified as one of these priorities (as part of a combined track for women, newborn, child, adolescent health, and rare genetic diseases) using evidence from Jeeluna to support identifying this as an area of national priority and further identifying priority research topics and questions within adolescent health research for Saudi Arabia. This is the first time in the history of Saudi Arabia that adolescent health is placed on the national research agenda.

2) Implications for policy and practice 
Commonly being free of disease, there is often a misconception that adolescents are healthy. Programs or health services for adolescents may therefore be considered an additional and unnecessary cost to an organization or system. Focusing on adolescents and their health must be perceived as an investment, rather than a cost. Investing in young people's health has been shown to have a triple dividend on adolescents and young people, future adulthood through the lifecourse, and intergenerational trajectories (3). Based on the evidence generated through Jeeluna, recommendations have been made to multiple stakeholders, including the Ministry of Health, Ministry of Education, Ministry of Economy and Planning, and the Shoura Council. This supports having a cross-sectoral approach to health policies and programs. With the country's Vision 2030, national transformation programs, including the Health Sector Transformation Program, which includes membership from all sectors, have been initiated; this is a true testament to the crosssectoral nature of implementation at the country level (4). Schools are essential places for identifying and addressing adolescent health issues, as well as educating adolescents about various health related matters. Policies have been implemented for school food canteens, as well as physical education, in an effort to combat obesity.

By viewing health through a life-course approach, the importance of continuity of care cannot be overemphasized. An area identified as a gap in health care in Saudi Arabia is the age limits of child/adult health care. Children and adolescents at the age of 14 years are transferred to adult care, where providers are not necessarily trained to care for adolescents and youth and their health needs. Adolescents, particularly those with chronic disease, unfortunately 'fall through the cracks' at this age. Recommendations for increasing the age limits of child health care to at least 18 years of age, in addition to having transition programs, have been made. Implementation of such has taken place at individual institutions where I have had a direct impact in; however, this requires policy and implementation at a national system's level for widespread implementation and sustainability. With this, comes the need for capacity building among all stakeholders. This has also been identified as a gap (5) and some efforts have been made for building capacity. Again, in order to have the buy-in from stakeholders, funding opportunities are important and are more likely to take place when national policies are developed and implemented with a top-down approach. 
Impact paragraph

The implications of Jeeluna are multiple; however, in order to objectively assess them, a national adolescent health surveillance system is required so that the impact of efforts and changing dynamics of the society may be regularly measured and monitored (6). 


\section{References}

1. NCD Risk Factor Collaboration (NCD-RisC). Worldwide trends in children's and adolescents' body mass index, underweight, overweight and obesity, in comparison with adults, from 1975 to 2016: a pooled analysis of 2,416 population-based measurement studies with 128.9 million participants. The Lancet 2017; 390(10113):2627-2642. doi: 10.1016/S0140-6736(17)32129-3

2. JEELUNA. Adolescent Health Research Program. King Abdullah International Medical Research Center. Available at: https://kaimrc.med.sa/?page id=5036

3. Patton, G.C., Sawyer, S.M., Santelli, J.S., et al. Our future: a Lancet commission on adolescent health and wellbeing. Lancet. 2016;387(10036):2423-2478. doi:10.1016/S0140-6736(16)00579-1

4. Health Sector Transformation Program. Vision Realization Programs. Available at: https://www.vision2030.gov.sa/v2030/vrps/hstp/ [Accessed on 12 June 2021].

5. AlBuhairan, F. \& Olsson, T. Advancing adolescent health and health services in Saudi Arabia: Exploring healthcare providers' training, interest and perceptions of the healthcare needs of young people. Adv Med Educ Pract 2014;5: 281-287. DOI http://dx.doi.org/10.2147/AMEP.S66272

6. AlBuhairan, F., Tamim, H., Al Dubayee, M., AlDhukair, S., Al Shehri, S., Tamimi, W., El Bcheraoui, C., Magzoub, M., de Vries, N., Al Alwan, I. Time for an Adolescent Health Surveillance System in Saudi Arabia: Findings from "Jeeluna". J Adol Health 2015; 57(3):263-269. doi: 10.1016/j.jadohealth.2015.06.009 
About the author 
Chapter 12 
Fadia AlBuhairan is a pediatrician, subspecialized in adolescent medicine from Saudi Arabia. It was during her medical school years that she noticed that adolescents were inadequately addressed and were considered to be 'younger adults'. This potential neglect of young people ignited her curiosity and led her to discover and take deep interest in the field of adolescent health and medicine. After obtaining her medical degree from King Saud University in Riyadh, she joined the pediatrics postgraduate residency training program at the Ministry of National Guard-Health Affairs (MNGHA) in Riyadh, obtained Board certification in Pediatrics, and subsequently pursued a clinical Fellowship in Adolescent Medicine from the University of Toronto and SickKids Hospital in Toronto, Canada. She also obtained her Master's in Public Health (MPH) from the Bloomberg School of Public Health at Johns Hopkins University in the United States.

Upon completing her clinical Fellowship in 2007, Fadia returned home to Saudi Arabia and established the first specialized adolescent health and adolescent gynecology clinics in the Arab World at the Ministry of National Guard Hospital in Riyadh. Being under the governance of the Department of Pediatrics, whose age limits for child care was 12 years, Fadia managed to convince the administration to increase the limits of adolescent medicine practice to 18 years and obtained the necessary hospital medical privileges to do so. She intended to conduct a local adolescent needs assessment, which soon grew into a proposal for a national assessment. With that, 'Jeeluna' was conceived with the aim of identifying the needs of adolescents countrywide in Saudi Arabia. To date, and as far as she knows, Jeeluna is the largest epidemiological study on adolescents in the Middle East North Africa (MENA) region. By applying the holistic view of health, Jeeluna generated the evidence to inform policy, practice, and programming for adolescents' physical, mental, emotional, and social health and wellbeing.

Fadia's active research efforts led her to establish and lead the Adolescent Health Research Program at the King Abdullah International Medical Research Center (KAIMRC), MNGHA. She was also appointed as the Head of the Center of Excellence of the National Family Safety Program, where national evidence was generated to address the issues of child maltreatment and prevention, and subsequently Head of Population Health Research at KAIMRC. She recently led the national research agenda on women, newborn, child, adolescent health and rare diseases theme for the Saudi National Institute of Health (SNIH). 
After many years at the MNGHA, Fadia moved to the private sector where she joined AlDara Hospital and Medical Center (AHMC), a greenfield hospital, and inaugurated the medical services in her capacity as Chief Medical Officer, as well as the Chairwoman of the Department of Pediatrics and Adolescent Medicine. To no surprise, she set the age limits of pediatrics practice at 18 years so as to be able to address child and adolescent health needs in a developmentally appropriate and sensitive manner. She was behind integrating population health approaches into clinical practice at AHMC.

Fadia is currently an Advisor at the Health Sector Transformation Program in Saudi Arabia, which aims at reform of the health sector in order to support improving overall population health in the country, in alignment with the national Vision 2030. She is a member of the World Health Organization's (WHO) Strategic and Technical Advisory Group of Experts (STAGE) on maternal, newborn, child, and adolescent health and nutrition, advising the WHO on related matters. She is Adjunct Professor at Alfaisal University in Riyadh, and previously was Adjunct Associate Professor at the Johns Hopkins Bloomberg School of Public Health in the United States, as well as the King Saud bin Abdulaziz University for Health Sciences in Saudi Arabia. She is much involved in civil society and NGOs and is currently the Vice President and founding member of the Arab Coalition for Adolescent Health and Medicine (regional), Board member of the Child Care Association (Saudi Arabia), and previous Vice President of the Saudi Society for Adolescent Health.

Fadia leverages her clinical, population health, and scholarly expertise and leadership in strategically planning and informing the necessary public health policies, programs, and clinical services required to address health holistically at systems' levels and through an intersectoral and life-course lens to health. She is the recipient of the 2020 Society for Adolescent Health and Medicine (SAHM) Regional Chapter Award. 



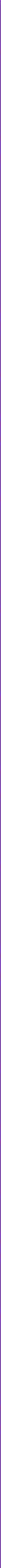

